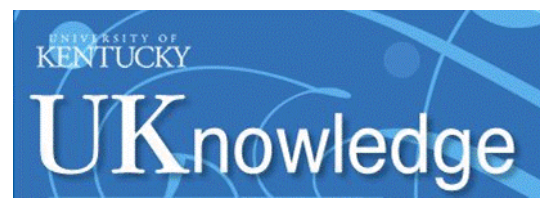

University of Kentucky

UKnowledge

Theses and Dissertations--Mechanical

Engineering

2019

\title{
DEVELOPMENT OF A MUFFLER INSERTION LOSS FLOW RIG
}

Jonathan Chen

University of Kentucky, jonchen814@gmail.com

Author ORCID Identifier:

(iD) https://orcid.org/0000-0001-5610-0068

Digital Object Identifier: https://doi.org/10.13023/etd.2019.099

Right click to open a feedback form in a new tab to let us know how this document benefits you.

\section{Recommended Citation}

Chen, Jonathan, "DEVELOPMENT OF A MUFFLER INSERTION LOSS FLOW RIG" (2019). Theses and Dissertations--Mechanical Engineering. 131.

https://uknowledge.uky.edu/me_etds/131

This Master's Thesis is brought to you for free and open access by the Mechanical Engineering at UKnowledge. It has been accepted for inclusion in Theses and Dissertations--Mechanical Engineering by an authorized administrator of UKnowledge. For more information, please contact UKnowledge@lsv.uky.edu. 


\section{STUDENT AGREEMENT:}

I represent that my thesis or dissertation and abstract are my original work. Proper attribution has been given to all outside sources. I understand that I am solely responsible for obtaining any needed copyright permissions. I have obtained needed written permission statement(s) from the owner(s) of each third-party copyrighted matter to be included in my work, allowing electronic distribution (if such use is not permitted by the fair use doctrine) which will be submitted to UKnowledge as Additional File.

I hereby grant to The University of Kentucky and its agents the irrevocable, non-exclusive, and royalty-free license to archive and make accessible my work in whole or in part in all forms of media, now or hereafter known. I agree that the document mentioned above may be made available immediately for worldwide access unless an embargo applies.

I retain all other ownership rights to the copyright of my work. I also retain the right to use in future works (such as articles or books) all or part of my work. I understand that I am free to register the copyright to my work.

\section{REVIEW, APPROVAL AND ACCEPTANCE}

The document mentioned above has been reviewed and accepted by the student's advisor, on behalf of the advisory committee, and by the Director of Graduate Studies (DGS), on behalf of the program; we verify that this is the final, approved version of the student's thesis including all changes required by the advisory committee. The undersigned agree to abide by the statements above.

Jonathan Chen, Student

Dr. David W. Herrin, Major Professor

Dr. Alexandre Martin, Director of Graduate Studies 


\title{
DEVELOPMENT OF A MUFFLER INSERTION LOSS FLOW RIG
}

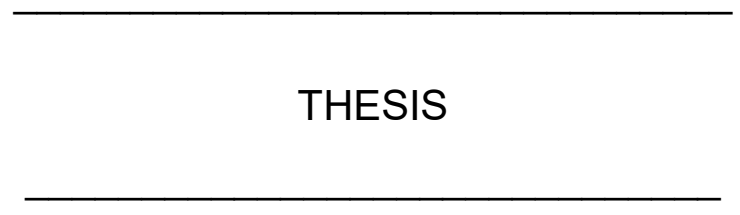

A thesis submitted in partial fulfillment of the requirements for the degree of Master of Science in Mechanical Engineering in the College of Engineering at the University of Kentucky

\author{
By \\ Jonathan Chen \\ Lexington, Kentucky \\ Director: Dr. David W. Herrin, Professor of Mechanical Engineering \\ Lexington, Kentucky \\ 2019
}

Copyright @ Jonathan Chen 2019 


\section{ABSTRACT OF THESIS \\ DEVELOPMENT OF A MUFFLER INSERTION LOSS FLOW RIG}

Mufflers and silencers are commonly used to attenuate noise sources such as internal combustion engines and HVAC systems. Typically, these environments contain mean flow that can affect the acoustic properties of the muffler components and may produce flow generated noise. To characterize the muffler performance, common metrics such as insertion and transmission loss and noise reduction are used in industry. Though transmission loss without flow is often measured and is a relatively simple bench top experiment and useful for model validation purposes, mean flow can significantly affect the muffler performance. There are a few existing and commercial transmission loss rigs that incorporate flow into the measurement procedure. These rigs are useful for model verification including flow but do not predict how the muffler will perform in the system since the source, termination, and pipe lengths significantly impact performance. In this research, the development of an insertion loss test rig is detailed. This testing strategy has the advantage of being simpler, quantifying the self-generated noise due to flow, and taking into account the effect of tailpipe length and a realistic termination. However, the test does not include the actual source and is not as useful for model validation. An electric blower produces the flow and a silencer quiets the flow. Loudspeakers are positioned just downstream of the flow silencer and they are used as the sound source. The low frequency source is a subwoofer installed in a cylindrical enclosure that includes a conical transition from speaker to pipe. Special care is taken to reduce any flow generated noise. Qualification of the system is detailed by comparing the measured transmission loss, noise reduction, and insertion loss to one-dimensional plane wave models. The results demonstrate that the developed rig should be useful as a muffler evaluation tool after a prototype has been constructed. The rig can also be used for transmission loss and noise reduction determination which will prove beneficial for laboratory testing.

KEYWORDS: Insertion Loss, Transmission Loss, Noise Reduction, Flow-Induced Noise, Plane Wave Theory, Source Properties

Jonathan Chen

Student's Signature

$17^{\text {th }}$ April, 2019 


\section{DEVELOPMENT OF A MUFFLER INSERTION LOSS FLOW RIG}

\section{By}

Jonathan Chen

\begin{tabular}{c} 
Dr. David W. Herrin \\
\hline Director of Thesis \\
Dr. Alexandre Martin \\
\hline Director of Graduate Studies
\end{tabular}

$17^{\text {th }}$ April, 2019

Date 


\section{ACKNOWLEDGMENTS}

I want to express my sincerest gratitude to my mentor, Dr. Herrin. I am grateful for his guidance in becoming a better-rounded engineer and for introducing me to the $\mathrm{NVH}$ world. He has provided me with tremendous opportunities as a graduate student and has supported me professionally and personally. Lastly, I have enjoyed our wide-ranging conversations on various topics over the years. They were always amusing and enriching.

I want to thank my other professors, Dr. Wu, and Dr. Baker, who has taught and assisted me in my graduate studies and served on my committee. I would also like to recognize Dr. Henninger; he has been an indispensable source of technical advice and encouragement throughout my undergraduate and graduate career. Special thanks to Hank Howell as he has been an invaluable mentor for this project.

It has been a pleasure to work with my friends, colleagues, and professionals in the Vibro-Acoustics Consortium. In particular, my experiences with professionals at Blachford Inc. and Thermo King were vital in my personal growth. Special thanks to Floyd Taylor, Andy Kerr, and Herb Mefford, who supported and helped me construct this fixture.

However, the people who deserve my largest gratitude is my family. It is hard to sum in words my appreciation. My parents, Fu Kuei and Lili for giving continued guidance and support in my life. My siblings, Jennifer and Jerry, whom I could not live without. Finally, my late grandmother, Mei Ling who helped raise me. Without their support, my venture into higher education would have been impossible. They are the most important people in my life and have made me who I am today. I love them dearly. 


\section{TABLE OF CONTENTS}

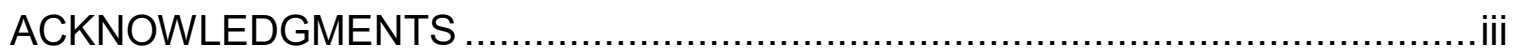

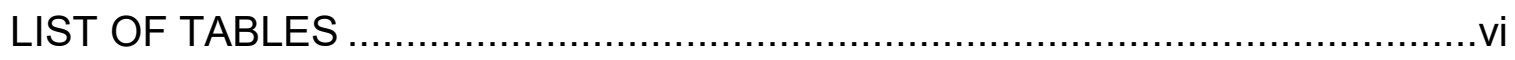

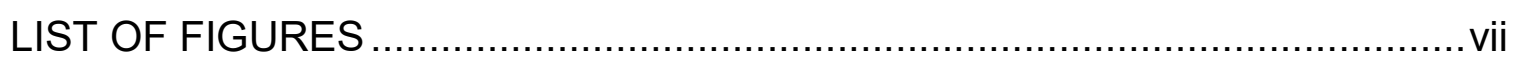

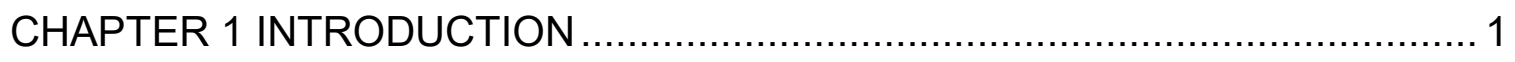

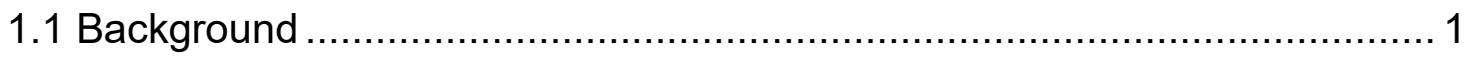

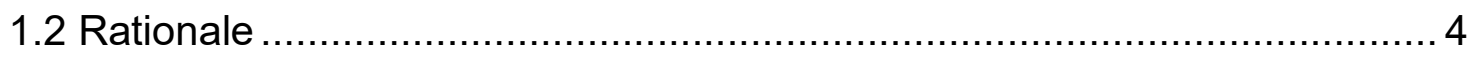

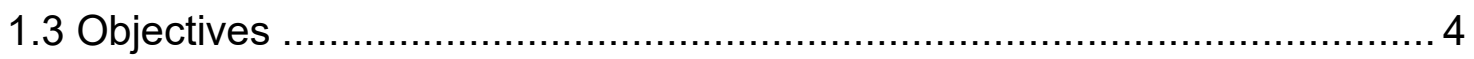

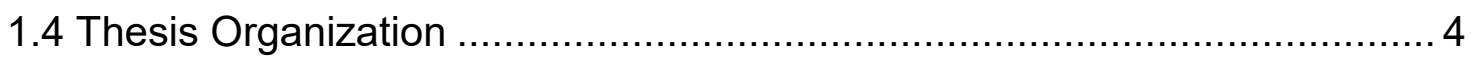

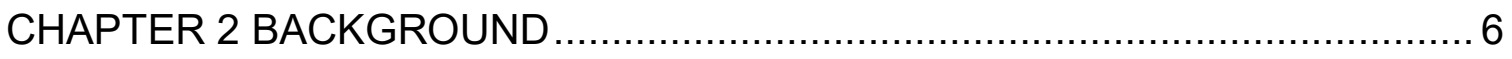

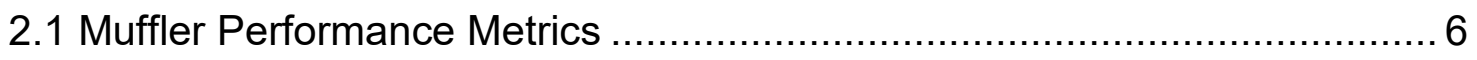

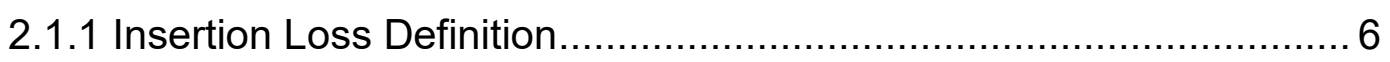

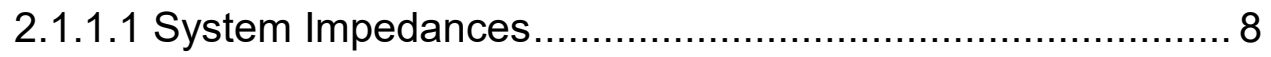

2.1.2 Transmission Loss Sans Flow Definition ................................... 12

2.1.3 Noise Reduction Definition...................................................... 17

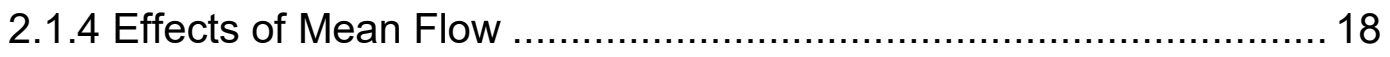

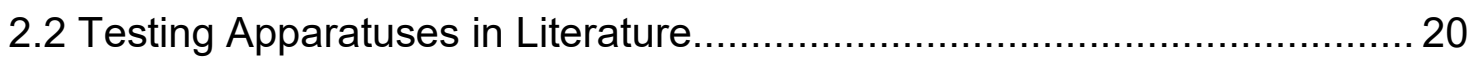

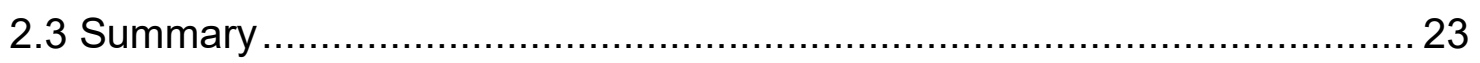

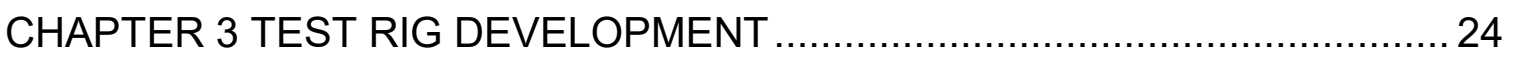

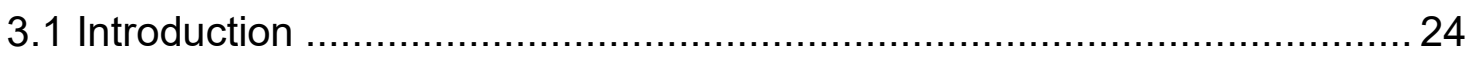

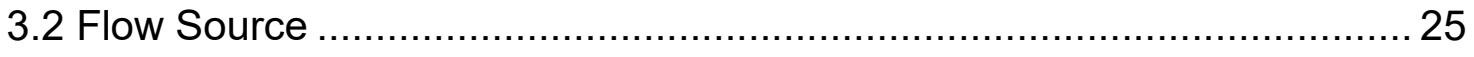

3.2.1 Flow Rate Determination ..................................................... 25

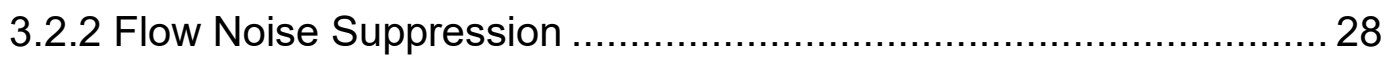

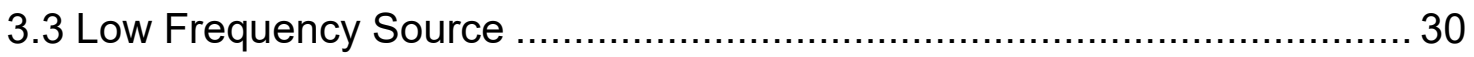




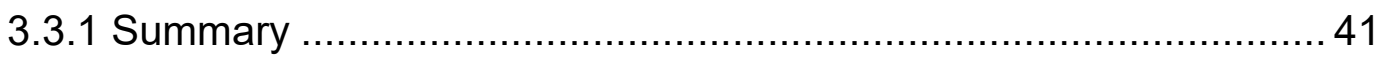

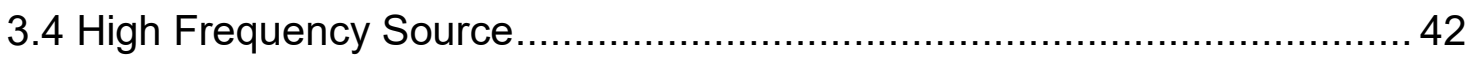

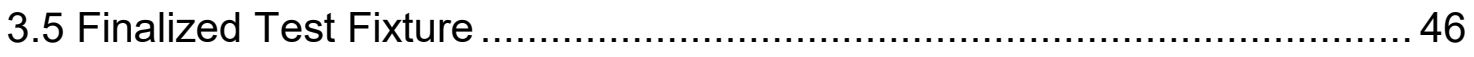

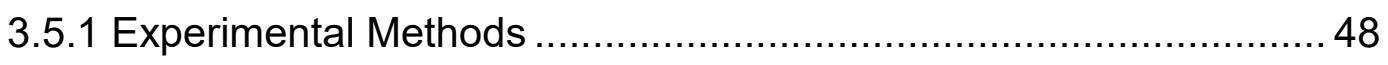

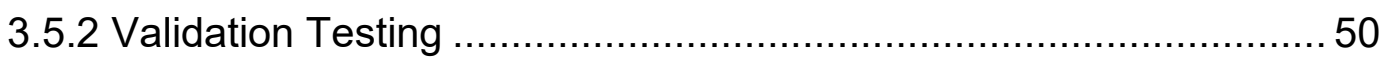

CHAPTER 4 TEST RIG QUALIFICATION .................................................. 53

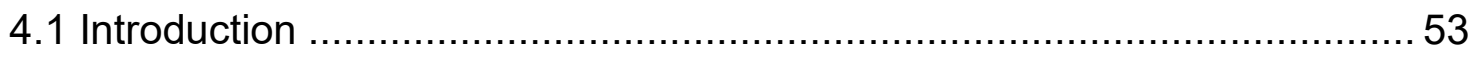

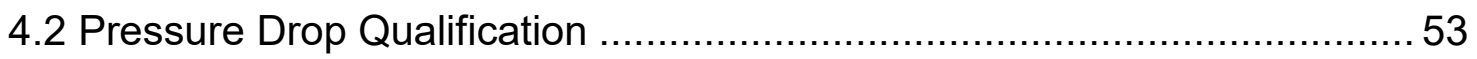

4.3 Open Pipe Termination - Transmission Loss Qualification (Sans Flow) .... 55

4.4 Traditional Transmission Loss Qualification (Sans Flow) .......................5 57

4.5 Noise Reduction Qualification (Sans Flow) …...................................58

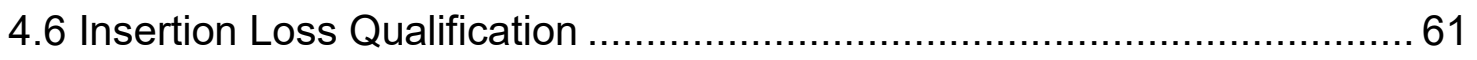

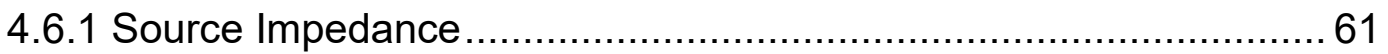

4.6.2 Termination Impedance with Flow ............................................. 64

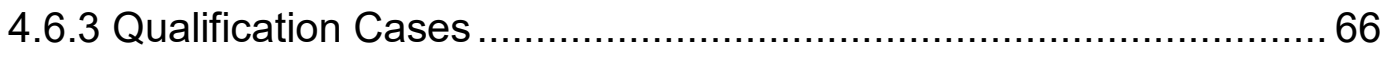

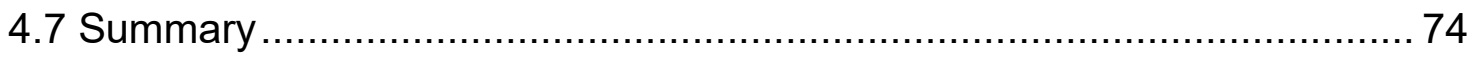

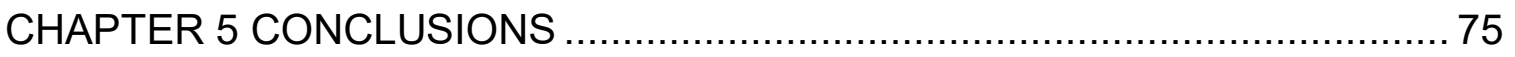

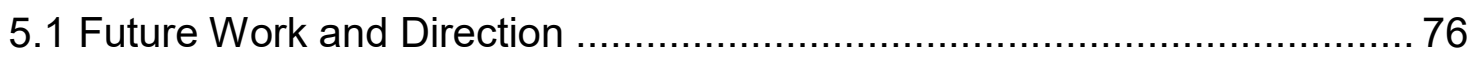

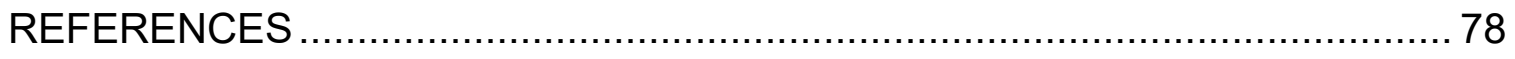

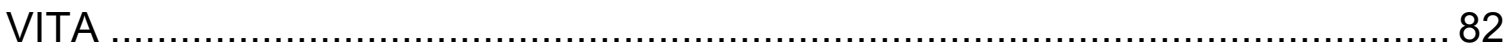




\section{LIST OF TABLES}

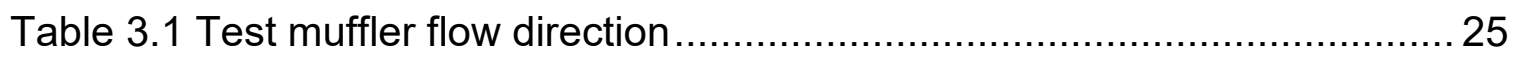

Table 3.2 Acoustic components in the cabinet ………................................. 33

Table 3.3 Covers used for flow-induced noise mitigation ................................ 38

Table 3.4 Test rig cutoff frequency ……................................................ 48

Table 3.5 Equipment used for validation testing ........................................ 51

Table 3.6 Low frequency limit defined as when acoustic sources exceed flow

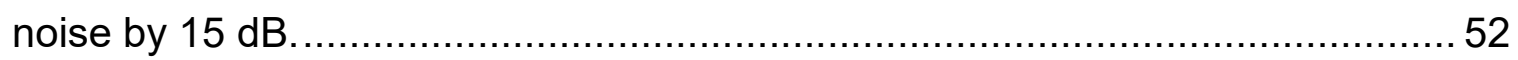




\section{LIST OF FIGURES}

Figure 2.1 Insertion loss measurement technique ....................................... 7

Figure 2.2 Insertion loss derivation using the transfer matrix approach................ 8

Figure 2.3 Particle velocity schematic for the source and termination impedance 8

Figure 2.4 Two-microphone method to measure system properties................... 9

Figure 2.5 Plane wave decomposition schematic [11]................................ 11

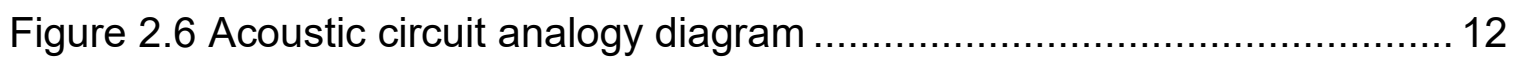

Figure 2.7 Transmission loss definition sans flow [16] ................................. 13

Figure 2.8 Transmission loss measurement with the three-point method.......... 13

Figure 2.9 Transmission loss measurement with the two-load method .............. 15

Figure 2.10 Transmission loss measurement with the two-source method ........ 17

Figure 2.11 Noise reduction measurement setup ......................................... 17

Figure 2.12 Plane waves inside a duct without flow ...................................... 19

Figure 2.13 Plane waves inside a duct with flow ........................................ 19

Figure 2.14 General schematic of a two-source transmission loss flow rig [1, 2] 20

Figure 2.15 Impulse technique transmission loss flow rig at the Carlyle

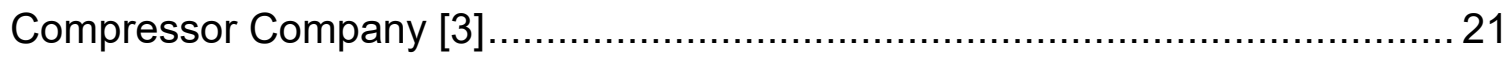

Figure 2.16 Wave decomposition and impulse technique transmission loss flow

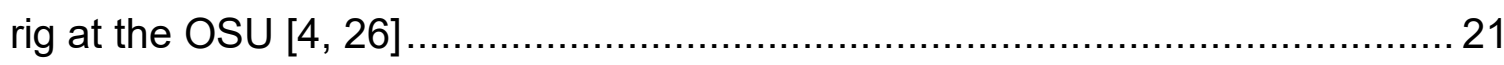

Figure 2.17 Industry schematic of an insertion loss flow rig ........................... 22

Figure 2.18 Industry setup using a three-point transmission loss flow rig........... 22

Figure 2.19 Alternative setup using of two-load transmission loss flow rig ......... 22

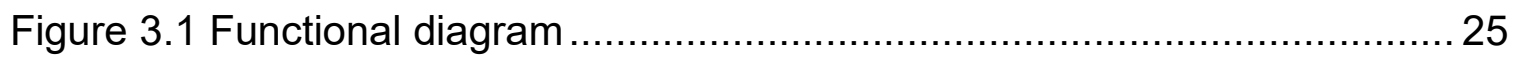

Figure 3.2 Fully developed turbulent flow pattern [31] ................................ 27 


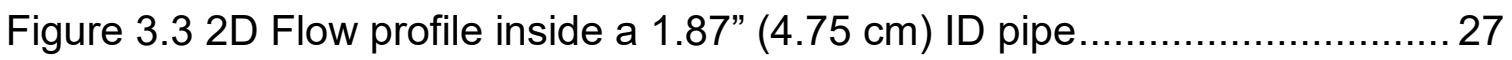

Figure 3.4 Experimental setup for flow noise intensity scan at end of the pipe .. 28

Figure 3.5 Flow noise before outlet silencer implementation ........................... 29

Figure 3.6 Outlet silencer transmission loss .............................................. 30

Figure 3.7 Flow noise after outlet silencer application .................................... 30

Figure 3.8 Low frequency source final design ........................................... 31

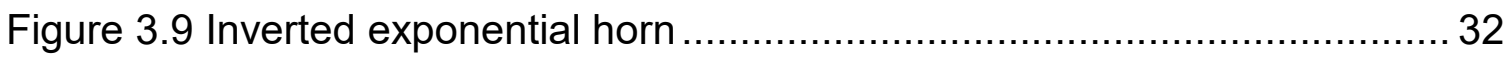

Figure 3.10 1D plane wave model of the low frequency source cabinet.............33

Figure 3.11 FEM and SIDLAB models for cabinet transmission loss without flow

Figure 3.12 Final low frequency response with a swept sine excitation.............. 34

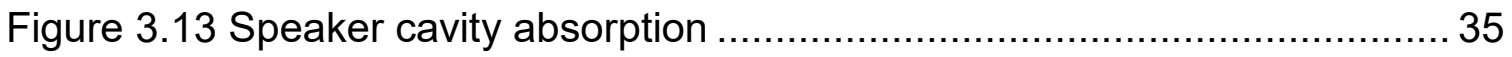

Figure 3.14 Sound absorption coefficient of the layered absorber..................... 35

Figure 3.15 Experimental setup for perforate studies ..................................... 36

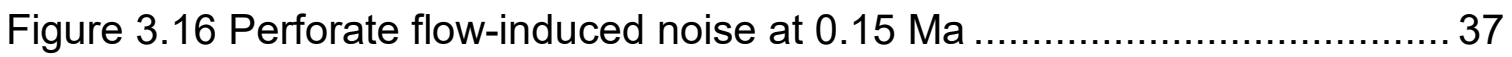

Figure 3.17 Flow noise suppression using a paper cover at $0.15 \mathrm{Ma}$................ 38

Figure 3.18 Acoustic insertion loss of a few cover materials ........................... 39

Figure 3.19 Flow noise suppression using a porous fabric at $0.15 \mathrm{Ma} \ldots \ldots \ldots \ldots . . . .39$

Figure 3.20 Acoustic insertion loss of a fabric cover..................................... 40

Figure 3.21 One-third octave band comparison of flow noise between the existing flow source and an addition of a low frequency source cabinet......................... 41

Figure 3.22 Pipe tee frequency response .................................................. 43

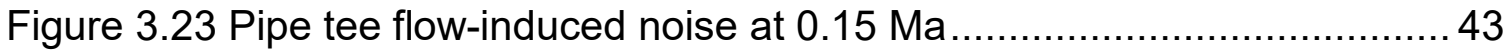

Figure 3.24 Perforated cover applied to the side branch with $0.15 \mathrm{Ma}$ flow ....... 43 
Figure 3.25 Acoustic insertion loss of various covers .................................. 44

Figure 3.26 Final high frequency source attachment................................... 44

Figure 3.27 One-third octave band comparison of flow noise between the existing flow source and an addition of a high frequency source .................................. 45

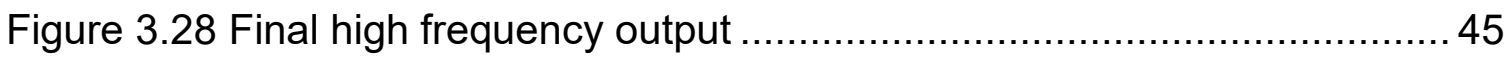

Figure 3.29 Completed insertion loss flow rig CAD …................................. 46

Figure 3.30 Picture of the completed test fixture …....................................... 46

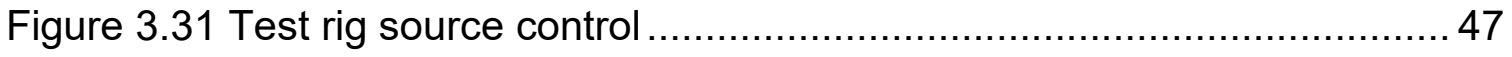

Figure 3.32 Intensity scan used to measure test rig output ............................ 48

Figure 3.33 Microphone hemisphere to measure test rig output.......................50

Figure 3.34 Sound pressure level inside the duct........................................51

Figure 3.35 Sound power levels of acoustic excitations against flow noise ........52

Figure 4.1 Test fixture qualification process ……...................................... 53

Figure 4.2 Reduced area qualification case …............................................ 54

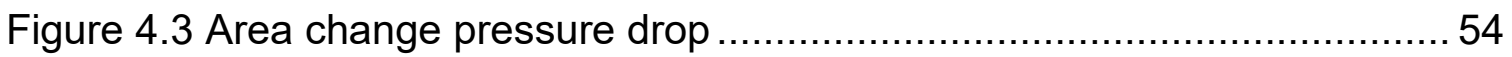

Figure 4.4 Open expansion chamber test case ……................................... 55

Figure 4.5 Open expansion chamber pressure drop …................................... 55

Figure 4.6 Transmission loss measurement of an open termination ................ 57

Figure 4.7 Open termination transmission loss......................................... 57

Figure 4.8 Transmission loss expansion chamber test case …...................... 58

Figure 4.9 Open expansion chamber transmission loss ................................. 58

Figure 4.10 Two-microphone method to measure load impedance at location 259

Figure 4.11 Measured load impedance at microphone 2 …........................... 59

Figure 4.12 Muffler noise reduction test cases ............................................ 60 
Figure 4.13 Open expansion chamber noise reduction .................................. 60

Figure $4.14\{45.3 \%\}$ Expansion chamber noise reduction .............................. 60

Figure $4.15\{3.3 \%\}$ Perforated expansion chamber noise reduction.................. 61

Figure 4.16 Sound wave behavior inside a duct of a generic source................ 62

Figure 4.17 Source impedance measurement setup .................................... 63

Figure 4.18 Test rig normalized source impedance ....................................... 63

Figure 4.19 Test rig sound absorption based on the source impedance ............63

Figure 4.20 Test rig termination impedance with flow.................................... 65

Figure 4.21 Expansion chamber termination impedance with flow ................... 65

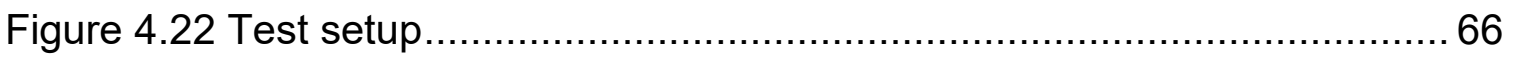

Figure 4.23 Expansion chamber muffler cases........................................... 66

Figure 4.24 Acoustic insertion loss for an open expansion chamber ................. 67

Figure 4.25 Insertion loss for an expansion chamber with $0.1 \mathrm{Ma}$ flow ............. 67

Figure $4.26\{3.3 \%\}$ Expansion chamber insertion loss ................................ 68

Figure $4.27\{3.3 \%\}$ Expansion chamber insertion loss with 0.1 Ma mean flow... 68

Figure $4.28\{3.3 \%\}$ Expansion chamber insertion loss with 0.15 Ma mean flow. 69

Figure $4.29\{3.3 \%\}$ Expansion chamber insertion loss with 0.2 Ma mean flow... 69

Figure $4.30\{2 \%\}$ Expansion chamber insertion loss ................................... 70

Figure $4.31\{2 \%\}$ Expansion chamber insertion loss with 0.1 Ma mean flow ...... 70 Figure $4.32\{2 \%\}$ Expansion chamber insertion loss with 0.15 Ma mean flow.... 71 Figure $4.33\{2 \%\}$ Expansion chamber with 0.2 Ma mean flow........................ 71

Figure $4.34\{45.3 \%\}$ Expansion chamber insertion loss ................................ 72

Figure $4.35\{45.3 \%\}$ Expansion chamber insertion loss with 0.1 Ma mean flow. 72 Figure $4.36\{45.3 \%\}$ Expansion chamber insertion loss with 0.15 Ma mean flow73 
Figure $4.37\{45.3 \%\}$ Expansion chamber insertion loss with 0.2 Ma mean flow. 73

Figure 4.38 Test rig with no flow and tailpipe radiated sound with 0.15 and 0.2

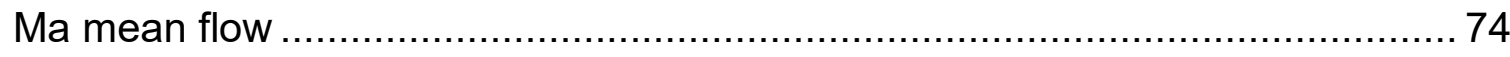




\section{CHAPTER 1 INTRODUCTION}

\subsection{Background}

Excessive environmental noise has a negative impact on living things including humans. Significant levels of noise are produced by transportation, construction, power generation, and climate control equipment; this noise must be dealt with in order to reduce environmental noise. Inside these complex systems, the primary causes are rotating equipment which includes engines, motors, gears, fans, pumps, and compressors. Noise is produced by combustion, flow, impact, and other mechanisms, and must be abated unless reduced significantly at the source. Sound travels along three paths: air, structure, or fluid-borne. These paths are typically coupled together and treating the most dominant path is the most beneficial to reduce levels.

Several techniques exist to reduce each path's contribution to the overall sound pressure level. For structure-borne noise, isolators can be inserted into paths to reduce excitation into the support structure and damping can be used to reduce radiation at resonances. Fluid-borne noise can be treated through various methods such as flexible ducting and avoidance of sharp edges. Airborne paths can be treated through various techniques such as sound absorptive materials and barrier applications. The most significant cause of airborne noise is likely combustion. Sound will propagate through both the intake and exhaust piping, and mufflers or silencers are normally used to attenuate that sound.

Mufflers are typically applied in environments where airborne noise can be constricted to a duct and significant flow is normally present. Mufflers can be characterized as either dissipative, reactive, or both. A dissipative or absorptive muffler works similar to acoustic materials where sound is being converted to heat as a result of friction. In reactive mufflers, sound is canceled or reflected back towards the source. Typical reactive elements include expansion chambers, Helmholtz resonators, and quarter wave tubes. These elements are often combined in interesting ways. For example, expansion chambers are lined with 
sound absorption. Quarter wave tubes are often incorporated in expansion chambers as extended inlets or outlets.

The first step to designing a muffler is to know the operating conditions and desired attenuation. The operating conditions determine the frequencies where the muffler must be effective. Once the performance targets are established, a combination of simulation tools and measurements can be performed to assess performance prior to production. Transmission loss is typically chosen as the initial parameter since it does not change from system to system. Generally, muffler design begins with plane wave analysis followed by finite and boundary element analyses. In these models, flow is often "ignored" to allow for validation against measurement. However, predictions of flow generated noise in muffling elements is difficult because time steps must be very small which results in very long solution times. Moreover, results are highly sensitive to the settings for the CFD analysis including turbulence modeling.

Though simulation is invaluable in the design process, time is limited. Engineers routinely design mufflers using plane wave simulation or 1D CFD. Virtual prototyping is sometimes performed using finite or boundary element analysis. At this juncture, a physical prototype is commonly manufactured, and the betterequipped labs will measure transmission loss with flow to validate the models followed by installation on the actual product. If possible, source impedance for the source should be measured along with the source strength. With a validated model and measured source impedance and source strength, reasonably accurate predictions can be made of the insertion loss and sound pressure level at the termination.

Though the aforementioned procedure may be preferred, very few labs have the resources or time to take all of these steps. Instead, a muffler is designed and prototyped after some basic analysis. Deterministic analysis may be performed but normally only for a couple of design iterations. Transmission loss measurements without flow may be performed but that is unlikely at many 
companies. Measurements with flow are rarely made due to the complexity, models are not validated, and source impedance is seldom measured. The muffler is then installed on the actual engine and modifications are made if the muffler does not meet expectations.

The objective of the research in this thesis is to develop a muffler insertion loss flow rig. Insertion loss is the emphasis, though the rig could be modified for transmission loss because measurements are easier. An insertion loss measurement is of greatest interest since it should approximate performance on the actual product. In addition, the flow generated noise inside the muffler can be assessed.

Several different muffler flow rigs have been developed in both academia and industry. The researchers at KTH [1] developed a muffler transmission loss flow rig. Elnady [2] developed and commercialized a similar rig based on the KTH rig. Both the KTH and Elnady rigs use the two-source method. Researchers at Ohio State University $[3,4]$ developed a transmission loss rig and used the acoustic impulse response and wave decomposition to determine the transmission loss. Hank Howell and Joseph Sullivan developed a rig to measure transmission and insertion loss. This rig is used privately and there are no publications. The rig detailed in this thesis is based on their design.

Notice that the aforementioned rigs are mostly designed for the measurement of transmission loss. For the most part, insertion loss has not been measured even though it is the performance metric of greatest interest in industry. Moreover, flow generated noise can be directly measured. It is recommended that the rig is used for bench tests prior to installation on the actual engine which often is not available to the muffler designers.

Rig development and qualification are difficult. Hence, this thesis provides all the important details about the rig construction. All parts are noted and the strategies for achieving broadband acoustic excitation and quiet flow are detailed. It is hoped that these details will aid future researchers in their efforts. 


\subsection{Rationale}

Hence, an insertion loss rig has been developed that can be adapted for testing transmission loss. Measurements may be made without or with flow. The reasons for the emphasis on insertion loss are as follows.

1. As noted by Bies et al. [5], insertion loss is more representative of the actual performance of the muffler installed and is often the preferred metric. Transmission loss is more valuable for model validation.

2. Insertion loss is more easily measured. Sound power measurements can be made with microphones outside the flow.

\subsection{Objectives}

The objectives of this research are as follows.

1. Measure muffler insertion loss in the presence of mean flow and require the following:

a. Generate a "quiet" mean flow with a Mach number of 0.05 to 0.15 . The flow rate should be easily varied.

b. Produce low and high frequency broadband noise that is independent of the flow and much larger than the flow noise source. Sources are expected to be at least $30 \mathrm{~dB}$ above the flow noise levels.

2. Measure other acoustic metrics without flow such as transmission loss and noise reduction.

3. Qualify the test rig to measure:

a. Insertion loss with and without flow

b. Transmission loss without flow

C. Noise reduction without flow

4. Determine the muffler back pressure with increasing flow speeds.

\subsection{Thesis Organization}

Chapter 1 presents the rationale, objectives, and motivation of this research. 
Chapter 2 offers background and theory implemented in the design of the testing apparatus as well as industry and academic benchmarks.

Chapter 3 details the research and development of the flow and acoustic sources. Chapter 4 details the measurement campaign to qualify the rig for accurate determination of acoustic attenuation (insertion loss, transmission loss, and noise reduction).

Chapter $\mathbf{5}$ concludes the research while offering plans and recommendations for improvements to the test rig. 


\section{CHAPTER 2 BACKGROUND}

\subsection{Muffler Performance Metrics}

Common metrics to describe muffler performance are insertion and transmission loss, and noise reduction. These metrics characterize different aspects of a muffler's performance. Insertion loss compares the sound pressure level with the muffler installed to the baseline no muffler case. Transmission loss is a function of the muffler alone and can be considered as the performance of the muffler with infinite length pipes on both sides. Noise reduction is just the difference in sound pressure level between the upstream and downstream sides of the muffler. Transmission loss is easily determined via analysis and can be measured using impedance tubes. Insertion loss and noise reduction are normally measured after the muffler is installed. Insertion loss is preferred, but noise reduction is used when it is impractical to measure a baseline case with no muffler installed.

In the early design stages, engineers develop a muffler model using plane wave simulation. These analyses are sometimes supplemented with more precise finite or boundary element simulations. The metric selected is almost always transmission loss because source properties are rarely known. Zhang and Herrin [6] recommended over designing by approximately $10 \mathrm{~dB}$. Once it looks as though the muffler is likely to meet performance requirements, a prototype is developed and installed in the system. Insertion loss is now the metric most commonly used. These two metrics are only equivalent if both the source and termination are anechoic. The sections which follow define both metrics and the measurement techniques for each.

\subsubsection{Insertion Loss Definition}

Measurement of insertion loss is straightforward and is characterized as the difference between the sound power level of a straight open pipe and a muffler. It depends on the muffler itself but also on the source and termination impedances as well as the pipe lengths on each side of the muffler. Of special note, insertion loss depends on the source and is hence different for each type of engine. Thus, 
this metric is commonly used as a final evaluation parameter through experimentation. It can be expressed as

$$
I L=S W L_{0}-S W L_{1}
$$

where $S W L_{0}$ is the sound power level in $\mathrm{dB}$ for a straight pipe and $S W L_{1}$ is the $\mathrm{dB}$ level with the muffler installed.
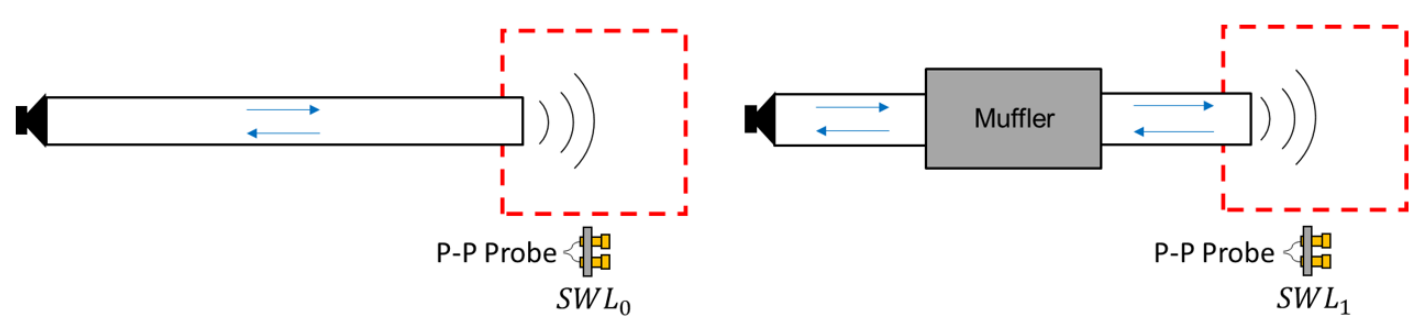

Figure 2.1 Insertion loss measurement technique

If the sound power difference is measured, there are several techaniques including measuring sound power by a sound intensity scan as shown in Figure 2.1, measuring the power radiated into a reverberation room, or approximating the sound power by measuring sound pressure level at several positions in the field. In the latter case, it is preferable if an anechoic chamber is used. If sound pressure level difference is measured, sound pressure is normally measured near the termination exterior to or just inside the duct.

Insertion loss can be predicted by using the transfer matrices for a straight pipe and muffler with the same inlet/outlet diameter. Depending on the industry, the straight pipe reference length is either equal to the total length of the system with the muffler installed (i.e., combined length of piping and muffler) [7] or the length of the piping up to the muffler entrance [8]. Selection of this reference length will impact the measurement and seems to be selected for measurement ease depending on the industry. The insertion loss can be expressed as

$$
I L(d B)=20 \log _{10}\left|\frac{T_{11} Z_{T}+T_{12}+T_{21} Z_{S} Z_{T}+T_{22} Z_{S}}{D_{11} Z_{T}+D_{12}+D_{21} Z_{S} Z_{T}+D_{22} Z_{S}}\right|
$$


where $[D]$ is the straight pipe transfer matrix, $[T]$ is the system with a muffler installed transfer matrix, $Z_{T}$ is the termination or radiation impedance, and $Z_{S}$ is the source impedance [5]. This expression will be used for the qualification of the rig in Chapter 4.

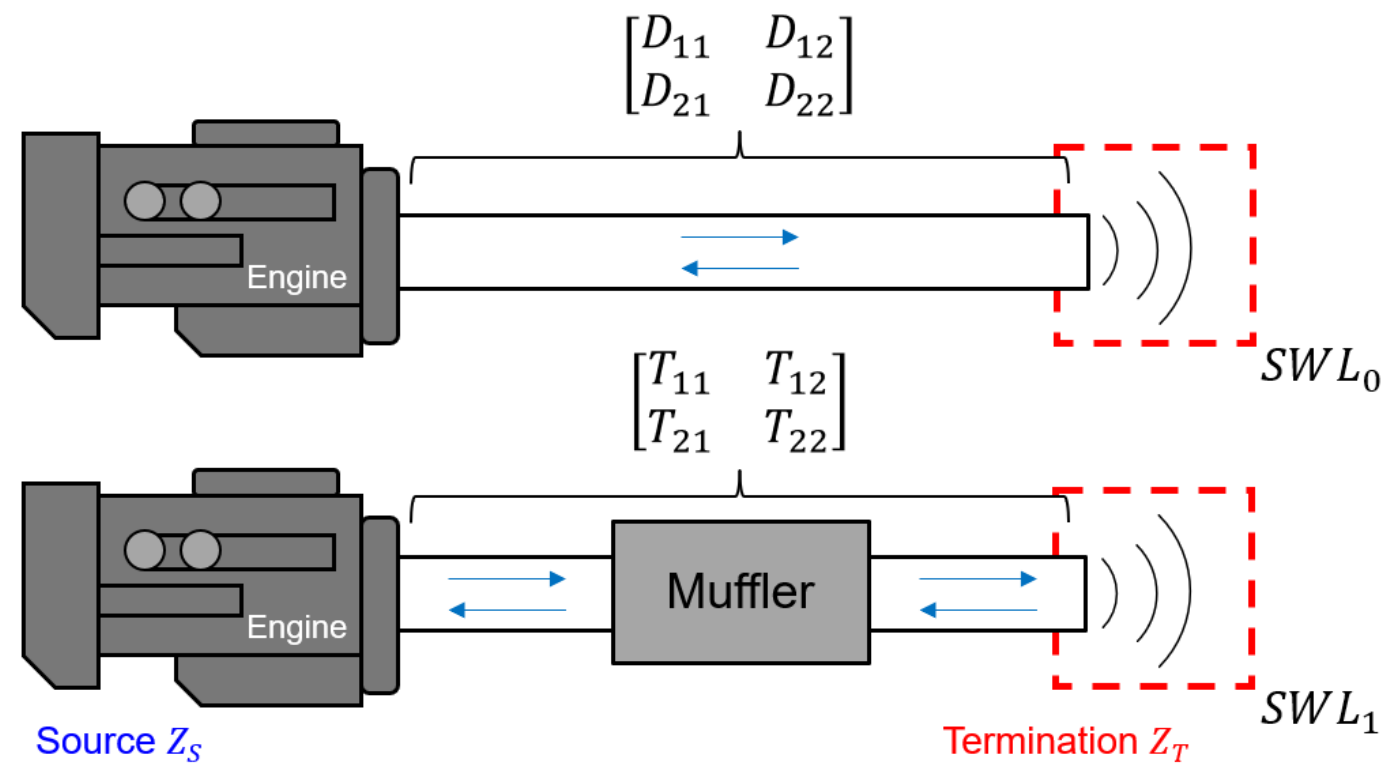

Figure 2.2 Insertion loss derivation using the transfer matrix approach

\subsubsection{System Impedances}

This section defines and discusses termination and source impedance. Source and termination impedance are shown in Figure 2.3.

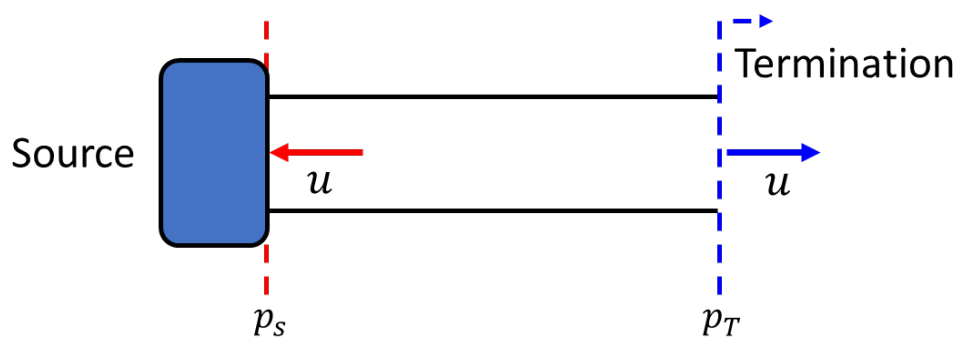

Figure 2.3 Particle velocity schematic for the source and termination impedance A source and load impedance are both defined as the ratio of sound pressure to volume velocity which is expressed as

$$
z=\frac{p}{S u}
$$


where $p$ is the sound pressure, $u$ is the particle velocity and $S$ is the cross-sectional area. The difference between a source and load impedance is that the direction of particle velocity is towards the source in the former case and away from the source in the latter as shown in Figure 2.3. A termination impedance is a special case of load impedance where the location selected is at the end of the pipe. The impedance can be measured using direct or indirect approaches. A direct approach is almost always used for a load impedance whereas direct and indirect approaches are used to measure source impedance.

Source or load impedance is measured directly by using a source that is more powerful than any sources that are downstream. Downstream is defined in this context as the direction from the source to the position where impedance is measured. Normally this external source should be orders of magnitude stronger in amplitude than any sources downstream. This is almost always the case when load impedance is measured. In the case of source impedance, this is far more difficult since engines are powerful acoustic sources and the lower order harmonics are very high in amplitude. The measurement procedure for determining impedance is described in ASTM E1050 [9] and is summarized in the discussion which follows.

The measurement setup is shown in Figure 2.4. Two microphones are placed upstream of the impedance measurement location. Standing waves will be present in the tube and the measurement goal is to decompose the waves into the incident and reflected waves.

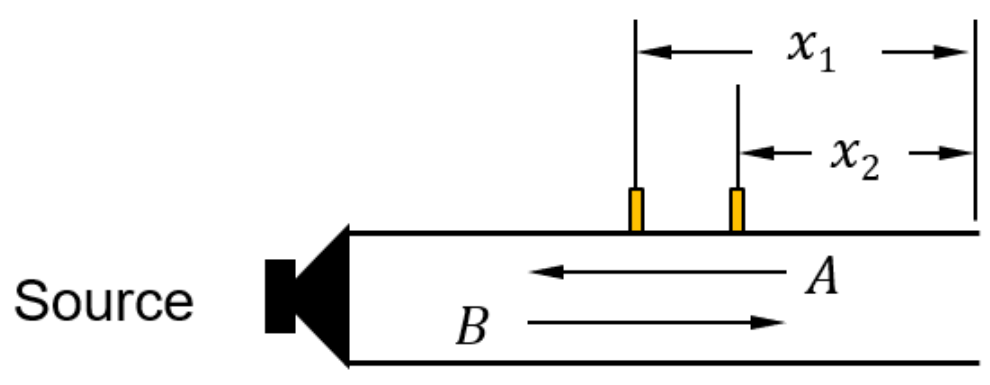

Figure 2.4 Two-microphone method to measure system properties 
Utilizing two microphones, a transfer function expression can be derived between location 1 and 2 . The transfer function is the ratio of the complex acoustic pressures at positions $1\left(x_{1}\right)$ and $2\left(x_{2}\right)$ and is expressed as,

$$
H_{12}=\frac{p\left(x_{2}\right)}{p\left(x_{1}\right)}=\frac{A e^{-j k x_{2}}+B e^{j k x_{2}}}{A e^{-j k x_{1}}+B e^{j k x_{1}}}
$$

Where $A$ and $B$ are the complex amplitudes of the incident and reflected waves respectively. A complex reflection coefficient can be expressed as,

$$
R=B / A
$$

Notice that $R$ is a function of the transfer function and positions $x_{1}$ and $x_{2}$. The source or load impedance can then be expressed in terms of the reflection coefficient as,

$$
\mathrm{z}=\frac{1+R}{1-R} \rho c
$$

Indirect methods require different acoustic load impedances. The system must be modified so that two unknowns, source impedance, and source strength, may be determined. In the two-load methodology presented by Boden and Åbom [10], the incident sound wave $(A)$ from the source is decomposed into two parts: 1) an outgoing component from the source $\left(P_{s^{+}}\right)$and 2$)$ the reflected component $(B$. $R_{S}$ ). Thus, the incident sound wave is defined as,

$$
A=P_{S+}+B \cdot R_{S}
$$

where $R_{S}$ is the reflection coefficient of the source. These quantities are obtained by using two microphones and plane wave decomposition. 


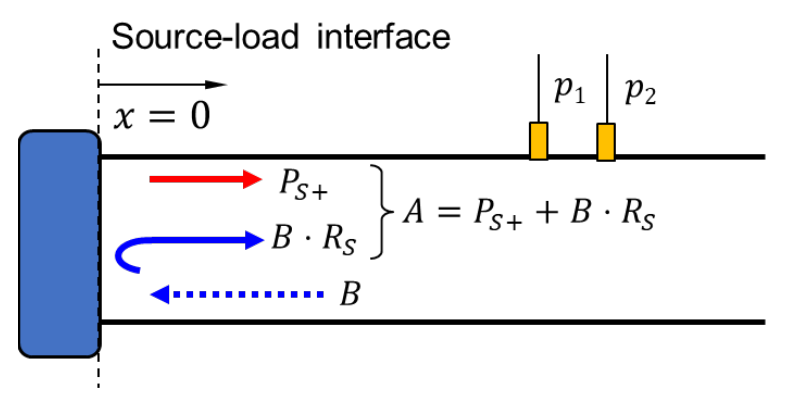

Figure 2.5 Plane wave decomposition schematic [11]

By applying two different acoustic loads (1 and 2), a system of two equations and two unknowns can be developed and expressed as,

$$
\left[\begin{array}{ll}
1 & B^{(1)} \\
1 & B^{(2)}
\end{array}\right]\left\{\begin{array}{c}
P_{S+} \\
R_{S}
\end{array}\right\}=\left\{\begin{array}{l}
A^{(1)} \\
B^{(2)}
\end{array}\right\}
$$

$P_{S+}$ and $R_{S}$ can be solved for. Zhang et al. [12] used this approach. Source impedance can then be determined via [11]

$$
z_{s}=\frac{1+R_{s}}{1-R_{S}}
$$

Note that the source reflection coefficient $R_{S}$ may be complex.

In older work, Boden and Åbom [10] used a different processing scheme to determine the source impedance $\left(z_{s}\right)$, but the approach is similar to the wave decomposition. Alternatively, acoustic ducts can be defined by a circuit analogy where the source is modeled as a voltage source with a resistor in series as shown in Figure 2.6. It follows that,

$$
\frac{p_{S}}{z_{S}+z_{L}}=\frac{p_{L}}{z_{L}}
$$

where $p_{S}$ is source strength, $p_{L}$ is the acoustic load pressure, $z_{S}$ is the source impedance and $z_{L}$ is the load impedance $[12,13,14]$. 


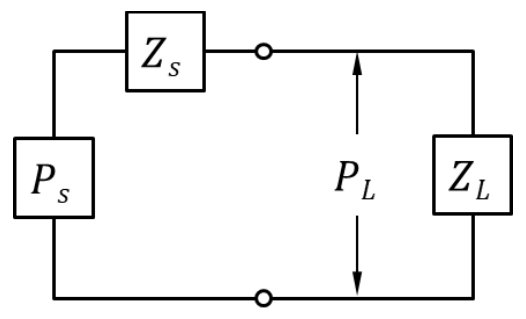

Figure 2.6 Acoustic circuit analogy diagram

Load pressures can be measured with the direct approach discussed earlier or can be simulated using plane wave theory. A system of two equations and two unknowns can be formed using Equation (2-9) as a basis and then the source impedance and source strength can be solved. These unknown quantities make this approach difficult. After applying two acoustic loads, the unknowns, $p_{S}$ and $z_{S}$ can be extracted

$$
\left[\begin{array}{ll}
Z_{L}^{(1)} & -p_{L}^{(1)} \\
Z_{L}^{(2)} & -p_{L}^{(2)}
\end{array}\right]\left\{\begin{array}{c}
p_{s} \\
z_{S}
\end{array}\right\}=\left\{\begin{array}{c}
Z_{L}^{(1)} p_{L}^{(1)} \\
Z_{L}^{(2)} p_{L}^{(2)}
\end{array}\right\}
$$

where (1) and (2) indicate the distinct acoustic load [12].

Lastly, Prasad et al. [15] used a four-load approach and avoided the need to place a microphone or pressure transducer inside the duct with flow. This approach is less commonly used today because changing out acoustic loads requires considerable time and effort.

\subsubsection{Transmission Loss Sans Flow Definition}

Transmission loss depends only on the muffler itself at least below the plane wave cutoff frequency. It is defined as the difference in the incident and transmitted powers with an anechoic termination and is equal to insertion loss if both the source and termination are anechoic. It is expressed as

$$
T L(d B)=10 \log _{10} \frac{W_{i}}{W_{t}}
$$


where $W_{i}$ and $W_{t}$ are the incident and transmitted sound power (usually in Watts) respectively [16] which is seen in the following figure.

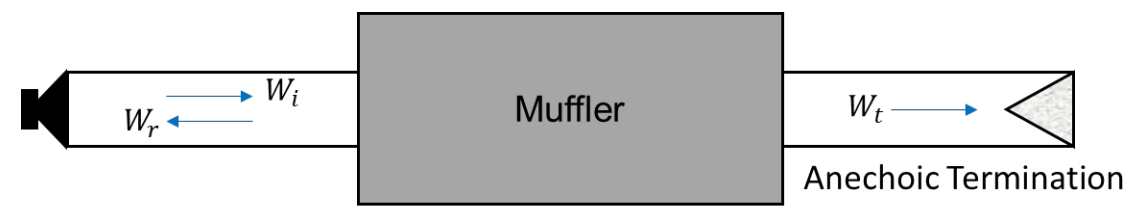

Figure 2.7 Transmission loss definition sans flow [16]

Transmission loss can be measured in several different ways. The most commonly used approaches are indirect measurement approaches using the twoload and two-source methods. The two-load approach [17, 18] is normally preferred without flow whereas the two-source approach [19] has seemingly been used more with flow. If the termination can be assumed to be anechoic, direct measurement is possible using three-microphones on a single configuration [20, 21] Two less commonly used approaches are the scattering matrix [22] and impulse response [3] approaches.

The direct or three-point method is practicable if there is an anechoic termination as shown in Figure 2.8. The incident power can be determined using wave decomposition and the transmitted power can be determined directly from a sound pressure measurement in the outlet pipe.

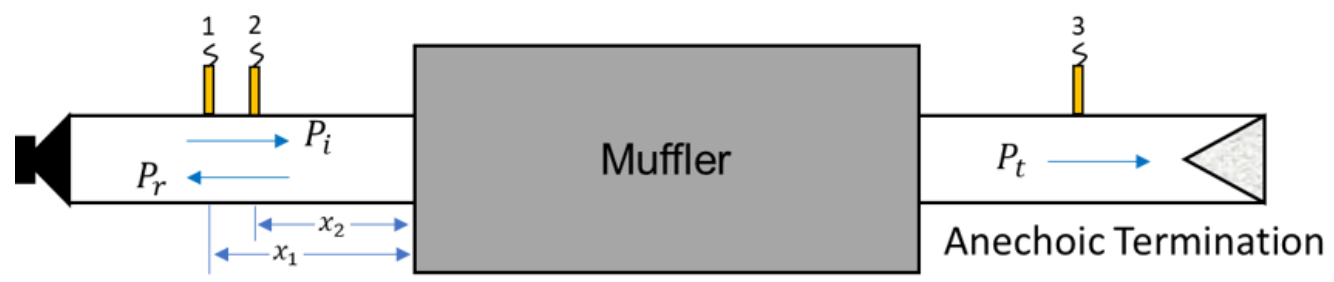

Figure 2.8 Transmission loss measurement with the three-point method The incident power can be expressed in terms of the sound pressures measured at positions 1 and 2 via

$$
p_{i}=\frac{p_{1} e^{j k x_{2}}-p_{2} e^{j k x_{1}}}{2 j \sin k s}
$$


where $s$ is the spacing between microphone 1 and $2\left(x_{2}-x_{1}\right)$. It is more conveniently expressed in terms of the transfer functions. In that case, the ratio of the incident wave sound pressure to the pressure at position 1 is

$$
\frac{p_{i}}{p_{1}}=\frac{e^{j k x_{2}}-H_{12} e^{j k x_{1}}}{2 j \sin k s}
$$

where $H_{12}$ is the transfer function $p_{2} / p_{1}$. A second transfer function is defined as

$$
H_{13}=\frac{p_{3}}{p_{1}}
$$

where $p_{3}$ is the sound pressure at the termination. The transmission loss can be expressed in terms of acoustic pressures as

$$
T L(d B)=10 \log _{10} \frac{\left|p_{i}\right|^{2} \cdot S_{i}}{\left|p_{3}\right|^{2} \cdot S_{o}}
$$

or in terms of transfer functions as

$$
T L(d B)=20 \log _{10}\left|\frac{e^{j k x_{2}}-H_{12} e^{j k x_{1}}}{2 j \sin k s * H_{13}}\right|+10 \log _{10} \frac{S_{i}}{S_{o}}
$$

where $S_{i}$ and $S_{o}$ are the inlet and outlet cross-sectional areas respectively [20, 21]. However, the three-point method is difficult to implement properly because it is difficult to develop an anechoic termination. This becomes even more difficult if measurements are made with flow.

A more robust method is the plane wave decomposition approach using the twoload method. Two microphones are placed upstream and downstream of the test article to decompose the incident and transmitted powers. This procedure is prescribed in the ASTM E2611 standard where four transfer functions are measured using the same reference. Possible loads include an absorptive 
termination and a rigid or open termination [17, 18]. These two acoustic loads should be unique. The methodology is illustrated in Figure 2.9.

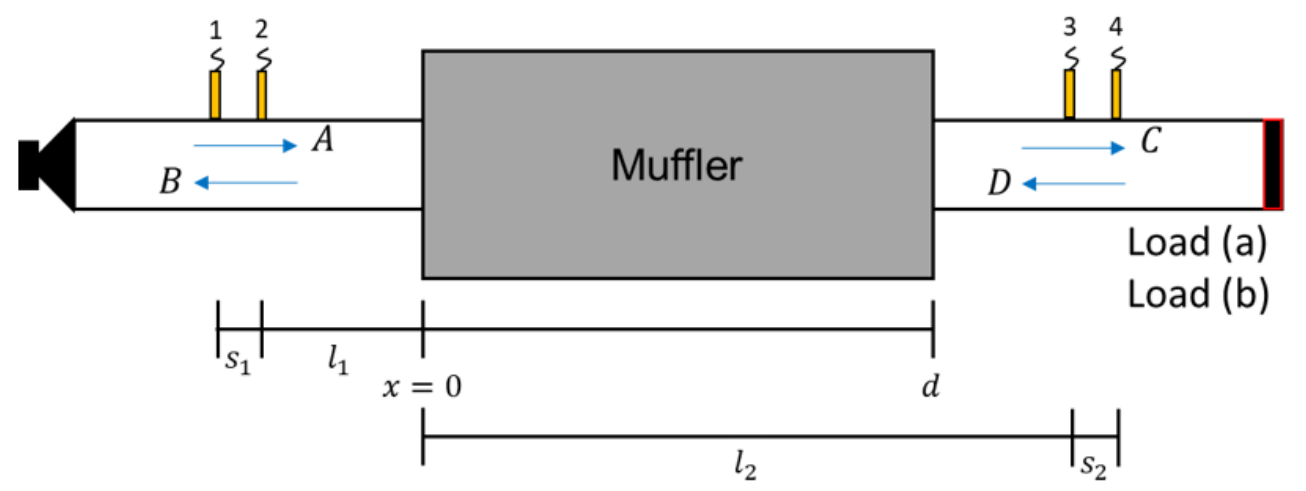

Figure 2.9 Transmission loss measurement with the two-load method According to ASTM E2611, the complex wave amplitudes for $A, B, C$, and $D$ can be expressed in terms of transfer functions as

$$
\begin{gathered}
A=j \frac{H_{r, 1} e^{-j k l_{1}}-H_{r, 2} e^{-j k\left(l_{1}+s_{1}\right)}}{2 \sin k s_{1}} \\
B=j \frac{H_{r, 2} e^{j k\left(l_{1}+s_{1}\right)}-H_{r, 1} e^{j k l_{1}}}{2 \sin k s_{1}} \\
C=j \frac{H_{r, 3} e^{j k\left(l_{2}+s_{2}\right)}-H_{r, 4} e^{j k l_{2}}}{2 \sin k s_{2}} \\
D=j \frac{H_{r, 4} e^{-j k l_{2}}-H_{r, 3} e^{-j k\left(l_{2}+s_{2}\right)}}{2 \sin k s_{2}}
\end{gathered}
$$

where $H_{r, i}$ represents the transfer function between location $i$ relative to the reference, $r$, and $l_{1}, l_{2}, s_{1}$, and $s_{2}$ are defined in the previous figure. These expressions are then combined to determine the acoustic pressure and velocity terms for the muffler inlet $(x=0)$ and outlet $(x=d)$,

$$
p_{0}=A+B
$$




$$
\begin{gathered}
u_{0}=\frac{A-B}{\rho c} \\
p_{d}=C e^{-j k d}+D e^{j k d} \\
u_{d}=\frac{C e^{-j k d}-D e^{+j k d}}{\rho c}
\end{gathered}
$$

where $\rho$ is the density of air and $c$ is the speed of sound. The resulting transfer matrix after applying two acoustic loads is simplified as,

$$
T=\left[\begin{array}{ll}
\frac{p_{0 a} u_{d b}-p_{0 b} u_{d a}}{p_{d a} u_{d b}-p_{d b} u_{d a}} & \frac{p_{0 b} p_{d a}-p_{0 a} p_{d b}}{p_{d a} u_{d b}-p_{d b} u_{d a}} \\
\frac{u_{0 a} u_{d b}-u_{0 b} u_{d a}}{p_{d a} u_{d b}-p_{d b} u_{d a}} & \frac{p_{d a} u_{0 b}-p_{d b} u_{0 a}}{p_{d a} u_{d b}-p_{d b} u_{d a}}
\end{array}\right]
$$

where $p$ is the acoustic pressure, $u$ is the particle velocity, $a$ and $b$ represent different acoustic loads, and $x$ and $d$ represents the muffler inlet and outlet positions. The resulting transmission loss equation is,

$$
T L(d B)=20 \log _{10}\left|\frac{1}{2}\left(T_{11}+\frac{S_{2}}{\rho c} T_{12}+\frac{\rho c}{S_{1}} T_{21}+\frac{S_{2}}{S_{1}} T_{22}\right)\right|+10 \log _{10}\left(\frac{S_{1}}{S_{2}}\right)
$$

where $T_{i, j}$ represents the transfer matrix entries and $S_{1}$ and $S_{2}$ is the cross-sectional area of the inlet and outlet pipe respectively.

The two-source method is another indirect approach for determining transmission loss. The measurement procedure is illustrated in Figure 2.10. Sources are placed on both the inlet and outlet sides of the muffler and measurements are taken with each source turned on. The sources are similar to the loads discussed in the twoload method and are two different conditions that permit the solution of the equations. The algorithms were first developed by Munjal and Doige [19]. However, most researchers now prefer a wave decomposition approach. If a wave decomposition approach is used, the equations are identical to the two-load method. 

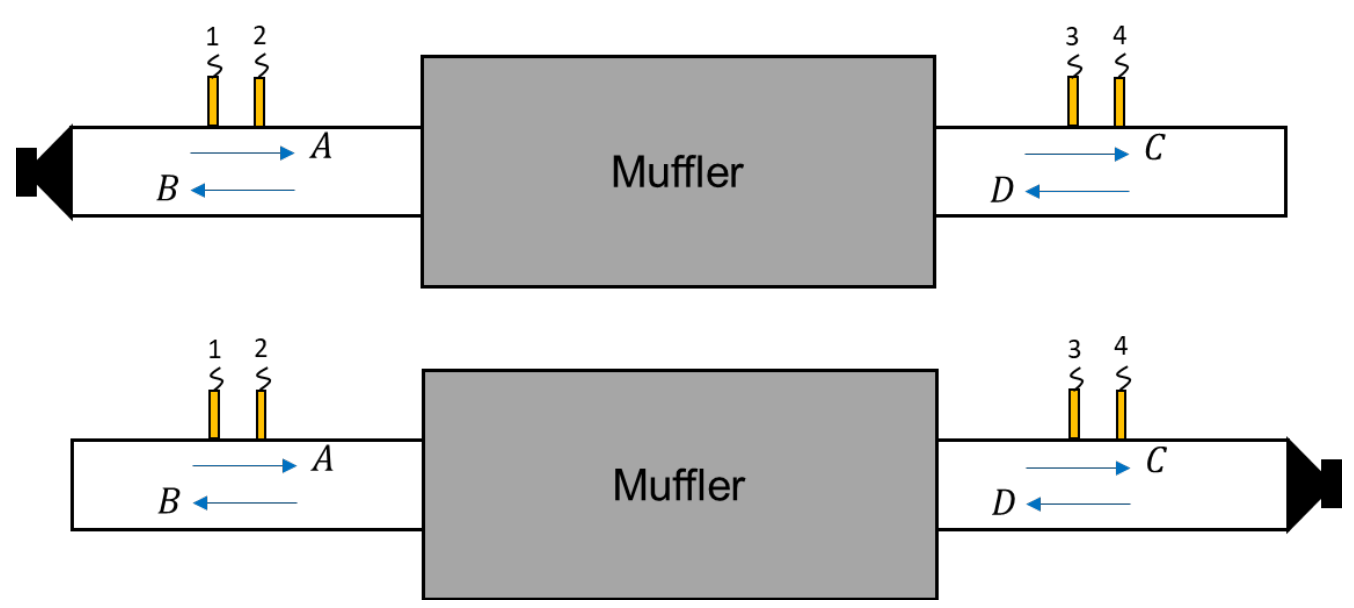

Figure 2.10 Transmission loss measurement with the two-source method

\subsubsection{Noise Reduction Definition}

Noise reduction is the difference in sound pressure level between the upstream and downstream sides of an acoustic element. It is expressed as

$$
N R=S P L_{1}-S P L_{2}
$$

where $S P L_{1}$ and $S P L_{2}$ are the sound pressure levels upstream and downstream respectively. Noise reduction, while simple to measure, provides limited useful information. Since there are standing waves on the upstream and downstream sides of a muffler, the microphone position greatly influences the measured quantity.

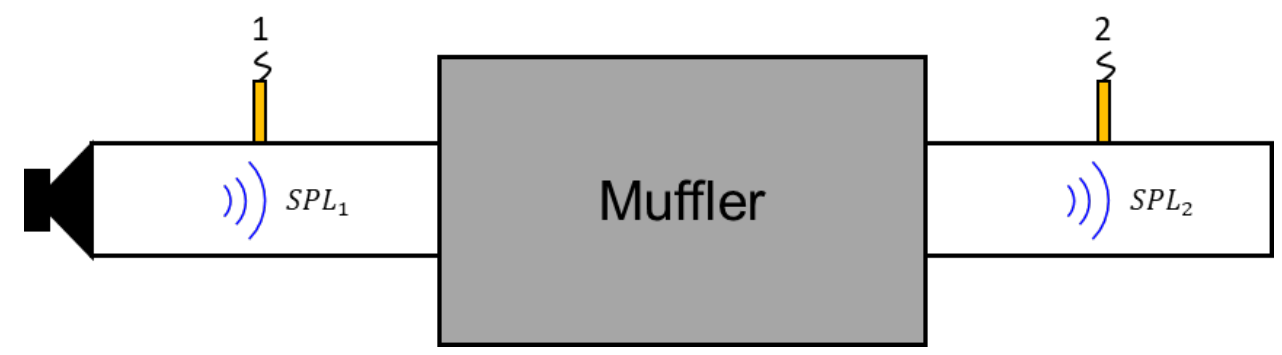

Figure 2.11 Noise reduction measurement setup

A schematic for noise reduction is shown in Figure 2.11. Noise reduction can be expressed as a function of the transfer matrix (between microphones 1 and 2) and the load impedance at microphone 2. It is expressed as 


$$
\frac{P_{1}}{P_{2}}=T_{11}+\frac{T_{12}}{Z_{2}}
$$

where $P_{1}$ and $P_{2}$ are the acoustic pressures upstream and downstream of the acoustic element, $T_{11}$ and $T_{12}$ are entries from the transfer matrix, and $z_{2}$ is the load impedance or termination impedance. Hence, noise reduction can be expressed as

$$
N R=S P L_{1}-S P L_{2}=20 \log _{10}\left|T_{11}+\frac{T_{12}}{z_{2}}\right|
$$

Take special note of the fact that the transfer matrix is between microphones 1 and 2 so the pipe distances from the microphones to the muffler greatly impact the measurement. The metric has limited practical use for this reason.

\subsubsection{Effects of Mean Flow}

In the previous two sections, the effects of mean flow have been ignored in the derivation of transmission loss. Measurement of insertion loss and noise reduction, on the other hand, are unaffected by flow. This section details the necessary modifications to derive transmission loss with mean flow. Insertion loss on the hand avoids this dilemma if measurements are in free-field. This section will summarize the net effects of mean flow on the sound waves inside a duct.

Assuming one-dimensional plane wave propagation inside a duct, the Helmholtz equation can be expressed as

$$
\frac{\partial^{2} p}{\partial x^{2}}+k^{2} p=0
$$

where $p$ represents the acoustic pressure, $x$ is the position, and $k$ is the wave number [16]. The harmonic solution to the Helmholtz equation can be expressed as

$$
p(x)=p_{+} e^{-j k x}+p_{-} e^{+j k x}
$$


where $p_{+}$is the forward and $p_{-}$is the reflected wave portion of the sound wave [16].

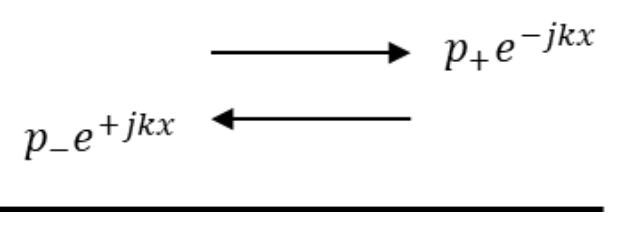

Figure 2.12 Plane waves inside a duct without flow

When mean flow is introduced, the Helmholtz equation is expressed as,

$$
\left(1-M^{2}\right) \frac{\partial^{2} p}{\partial x^{2}}+k^{2} p-2 j k M \frac{\partial p}{\partial x}=0
$$

where $M$ is the Mach number [23].

The harmonic solution is

$$
p(x)=p_{+} e^{-j k_{+} x}+p_{-} e^{+j k_{-} x}
$$

where the wave number is split into a forward $\left(k_{+}\right)$and reflected $\left(k_{-}\right)$parts [23].

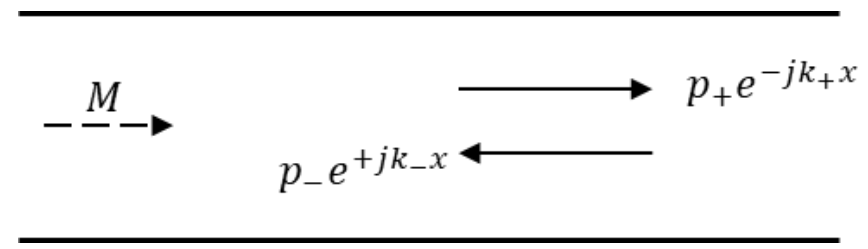

Figure 2.13 Plane waves inside a duct with flow

The introduction of mean flow alters the speed of sound based on the direction of propagation. The forward portion of the sound wave increases in speed while the reflected part is slower. The respective wave number components can be expressed as

$$
k_{+/-}=\frac{k_{o}}{1 \pm M}
$$


where $k_{o}$ is the wave number without flow, and $M$ is the Mach number [23]. The effect of flow on the wave number is important when making measurements inside the duct.

\subsection{Testing Apparatuses in Literature}

Flow has been introduced into a number of different test rigs. The earliest measurements of this type were made inside engine exhaust piping. For instance, Alfredson and Davies [24] measured the reflection coefficient inside a diesel engine exhaust and its radiated sound power. They used water-cooled transducers due to the extreme temperatures and conditions.

Munjal and Doige [19] introduced flow into a transmission loss bench test using the two-source approach. Researchers at KTH have developed a similar twosource test rig [1]. Elnady [2] commercialized a transmission loss flow rig based on the KTH design. Roeck and Desmet [25] also developed a similar rig to investigate the aeroacoustics of expansion chambers.

A schematic showing the layout of the Elnady rig is shown in Figure 2.14. Flow is introduced using an industrial blower and the flow noise is attenuated to an acceptable level using a large silencer. A similar silencer is positioned at the end of the rig. The KTH rig uses a wind tunnel for the flow generation. Acoustic sources are loudspeaker arrays upstream and downstream of the test muffler. Three microphone measurements are made on each side of the muffler.

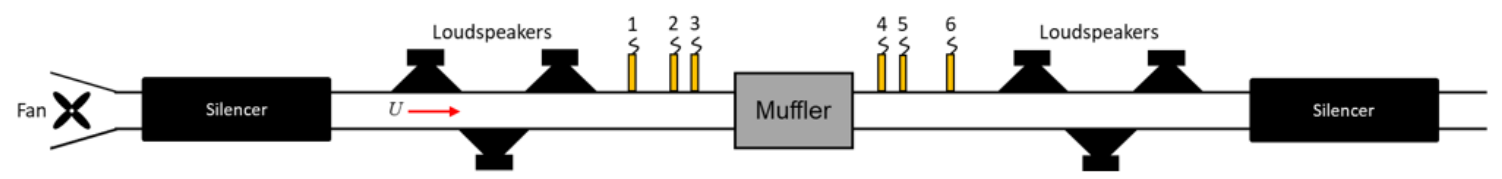

Figure 2.14 General schematic of a two-source transmission loss flow rig [1, 2] Another notable rig was developed by Singh and Katra [3] at the Carlyle Compressor Company in 1978 using the impulse technique. An impulse excitation is applied on the upstream side and pressure transducers are used to measure the transmission loss. 


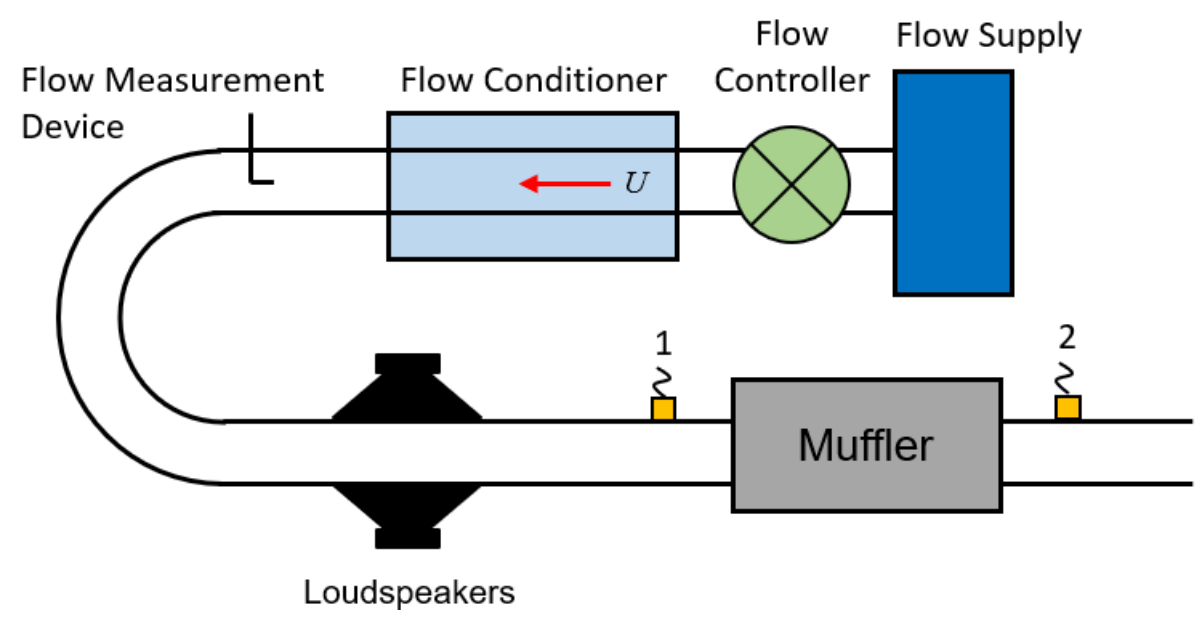

Figure 2.15 Impulse technique transmission loss flow rig at the Carlyle Compressor Company [3]

Selamet et al. [4, 26] built on this prior work and used a wave decomposition approach when processing. A schematic of the developed rig is shown in Figure 2.16. The flow is silenced, and two loudspeakers are used for the source. An anechoic termination was developed so that transmission loss can be measured directly with no need to change the acoustic load.

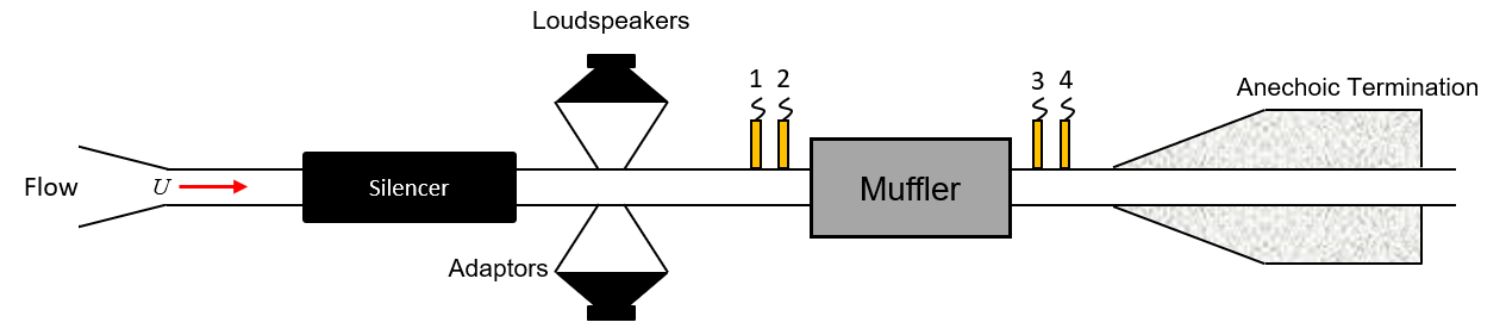

Figure 2.16 Wave decomposition and impulse technique transmission loss flow rig at the OSU $[4,26]$

Howell and Sullivan [27] developed a rig which can be used to measure both insertion and transmission loss. The approach is similar to the Selamet et al. [4, 26] rig since an anechoic termination is used if transmission loss is measured. A schematic of the rig is shown in Figure 2.17 and Figure 2.18. Flow is introduced using an industrial blower and a silencer is used to attenuate the flow noise. Separate low and high frequency sources are positioned just downstream of the 
silencer. The low frequency source is a large subwoofer and the high frequency source is a compression driver. This design serves as the guide for the current research effort. Alternatively, the two-load method can be used. Figure 2.19 illustrates how acoustic loads can be varied.

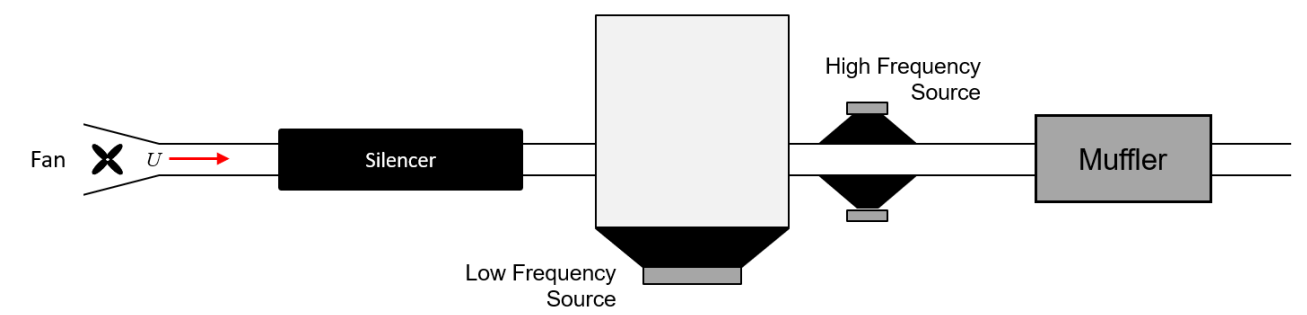

Figure 2.17 Industry schematic of an insertion loss flow rig

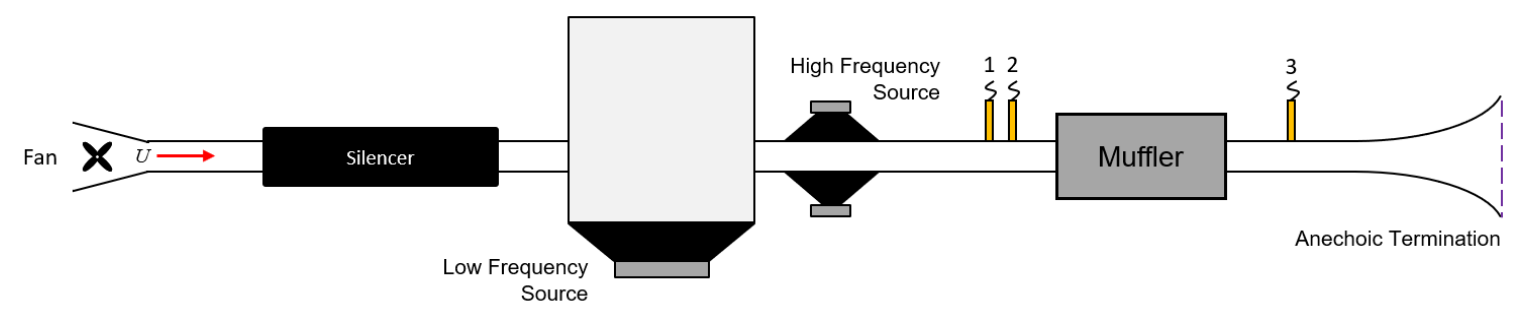

Figure 2.18 Industry setup using a three-point transmission loss flow rig

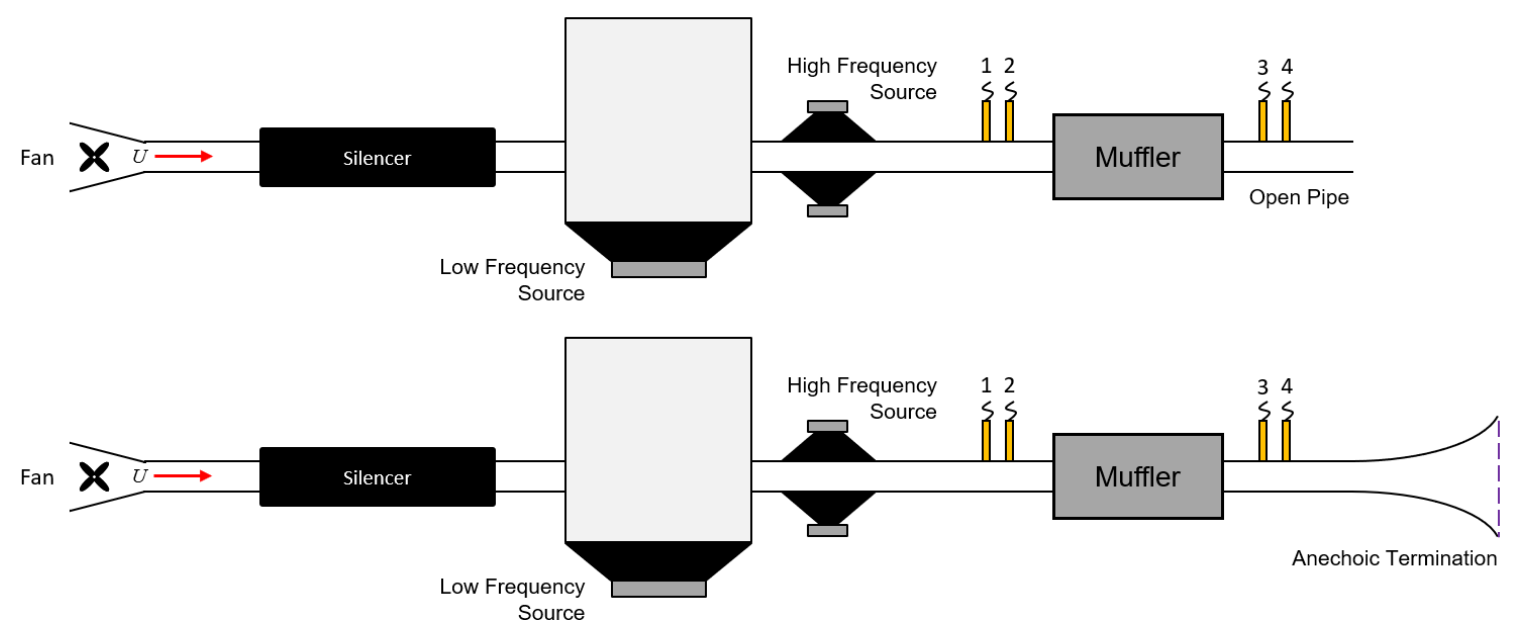

Figure 2.19 Alternative setup using of two-load transmission loss flow rig 


\subsection{Summary}

Mufflers are characterized by their acoustic performance through insertion and transmission loss, and noise reduction. Each metric is defined and measured differently. Insertion loss is the difference with and without a muffler installed on a given system. Predicting insertion loss requires the measurement of the system parameters, source and termination impedance. These parameters can be found by either direct or indirect methods. Transmission loss is defined solely by the physical aspects of the muffler. Noise reduction represents the difference between the upstream and downstream sound pressure levels. Insertion loss and noise reduction measurements unlike transmission loss are not influenced by flow. The net effects of flow can be avoided if insertion loss is measured in free-field. The derivation of transmission loss must reflect the changes to the wave number for accurate determination.

Early work on the effects of flow on muffler performance was studied in the engine exhaust. These environments were harsh on equipment and often difficult to characterize. Test rigs were later formed to improve the control of different parameters. Munjal and Doige [19] introduced flow equation for the two-source transmission loss method which served as the theoretical basis for many of the current rigs. KTH researchers [1] and Elnady [2] built and popularized the current two-source framework. Alternatively, Singh and Katra [3] used an impulse technique which mixed a time and frequency domain approach. Wave decomposition methods through an anechoic termination have been used at OSU $[4,26]$ and by Howell and Sullivan [27] in industry. The latter serving as the guide for the research presented in this thesis. Each design was analyzed and incorporated into the development of this fixture. 


\section{CHAPTER 3 TEST RIG DEVELOPMENT}

(Note: Some of this research in this chapter is adapted from [28])

\subsection{Introduction}

The main objective of this research is to develop and qualify a test rig to measure muffler insertion loss. Note that insertion loss is dependent on the source and termination impedances. Whereas the termination of the application (engine, compressor, etc.) can be replicated, the source itself is not. Hence, insertion loss measured on the rig will not be the same as that installed in the actual application (i.e., engine, compressor). However, it will permit the engineer to identify flow noise generation problems and will provide a useful attenuation metric. In addition, the designed rig can be used to measure transmission loss with flow after some simple modifications.

The test rig was designed and built in stages where each component transitioned from proof of concept to a finalized product. In Figure 3.1, a functional diagram denotes the major components used in this design. Flow is produced by a variable speed regenerative blower and then through a duct where the flow is smoothed for accurate flow velocity measurement before exiting into a silencer. The silencer is in place to quiet the flow generated noise from the blower. A Pitot tube is equipped with a digital manometer to measure stagnation pressure from which flow velocity can be derived. Following the flow noise silencer, two acoustic sources are side mounted to the pipe; one is for low frequencies and the other for high. The sources are integrated into the system so that broadband frequency content at sufficient amplitude to overwhelm flow generated noise is produced. A temperature gauge is also placed in the low frequency source cabinet to monitor flow temperature. The test muffler is mounted between static pressure gages so that the pressure drop can be monitored. Sound pressure measurements using microphones can be made on both sides of the muffler. If insertion loss is measured, the sound power radiated into an anechoic chamber is measured by using a microphone hemisphere or sound intensity scan. Flow direction is reversed so that both 
exhaust and intake muffler components can be evaluated. Directions are indicated in Table 3.1.

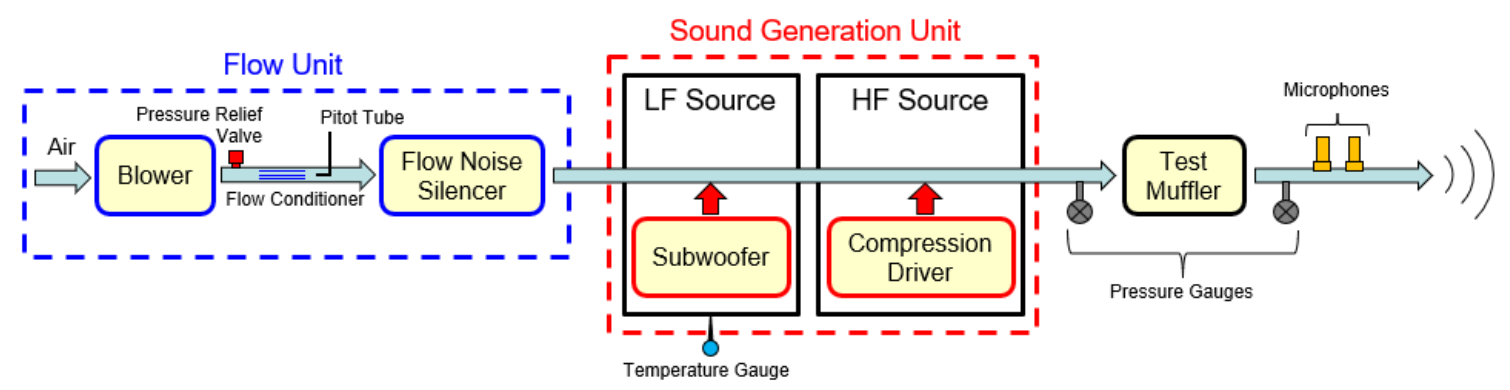

Figure 3.1 Functional diagram

Table 3.1 Test muffler flow direction

\begin{tabular}{|c|c|}
\hline Test Muffler Application & $\begin{array}{c}\text { Muffler } \\
\text { Flow Direction }\end{array}$ \\
\hline Exhaust & $\rightarrow$ \\
\hline Intake & $\leftarrow$ \\
\hline
\end{tabular}

\subsection{Flow Source}

Flow is generated by a regenerative blower which provides high volumetric flow rate and pressure drop. The electric blower selected is capable of up to $110 \mathrm{inH}_{2} \mathrm{O}$ $(27.4 \mathrm{kPa})$ which provides an acceptable range for many mufflers. When unloaded, the blower is capable of a Mach number of 0.19 in a 2" $(5.1 \mathrm{~cm})$ diameter pipe. After mounting the rig components, the Mach number is reduced to 0.17 . These flow velocity values are based on the original diameter of the test rig. However, higher flow rates are likely possible if the muffler inlet and outlet pipes are smaller and a long conical adapter is used to transition from the larger to smaller crosssectional area pipe.

\subsubsection{Flow Rate Determination}

Flow rate is measured using a Pitot tube. The flow rates of interest are within the incompressible range $(M a<0.3)$ inside the pipe. Flow velocity is inferred from the pressure difference using Bernoulli's equation which can be expressed as 


$$
p+\frac{1}{2} \rho v^{2}+\rho g h=\text { constant }
$$

where $p$ is the pressure, $\rho$ is the density of the fluid, $v$ is the flow velocity, $h$ is the elevation, and $g$ is the gravitational acceleration. The flow velocity $(v)$ can be expressed as

$$
v=\sqrt{\frac{2 \Delta p}{\rho}}
$$

where $\Delta p$ is the pressure difference, and $\rho$ is the density. The flow velocity due to a contraction or expansion can be found utilizing the conservation of mass. This can be expressed as

$$
A_{1} v_{1}=A_{2} v_{2}
$$

where $A_{1}$ and $A_{2}$ are the respective cross-sectional areas and $v_{1}$ and $v_{2}$ are the respective flow velocities.

Since Bernoulli's equation is only valid when the flow is laminar, a flow conditioner is used to stabilize the flow. The resulting Pitot tube midstream measurement is approximately $94 \%$ of the average value. Without the presence of a flow conditioner, flow instabilities lead to less accurate measurement. Similar to approaches used in wind tunnels, drinking straws are arranged into a honeycomblike structure. Kaplan and others [29, 30] suggested using a tube bundle flow conditioner to reduce turbulence a short distance from the conditioner's outlet. In this application, the tube bundle is placed approximately 6" $(15.2 \mathrm{~cm})$ away from the Pitot tube inlet. Loehrke and Nagib [30] noted that an application of a mesh screen at the flow conditioner inlet reduces turbulence further. A final rule of thumb is to place the flow conditioner approximately ten times the inner diameter downstream from the flow source or disruptive flow element. After applying the flow conditioner, the resulting flow profiles are closer to a parabolic turbulent profile as seen in the literature and shown in Figure 3.2 [31]. 


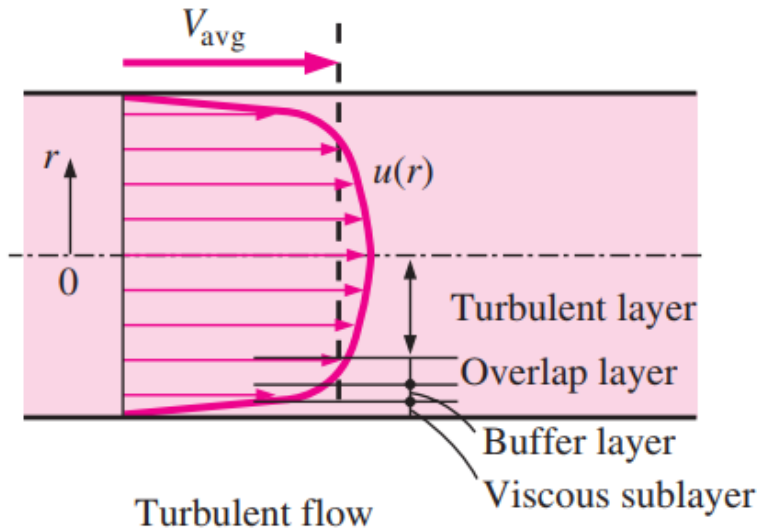

Figure 3.2 Fully developed turbulent flow pattern [31]

The flow pattern was mapped by traversing the Pitot tube across the four planes, shown in Figure 3.3. Seven positions were measured in each case. 2D flow patterns show a relatively uniform profile where the midstream value is approximately $94 \%$ of the average stream value. Based on the results, it can be concluded that the flow conditioner provides an inexpensive and effective way to guide flow with negligible pressure drop.

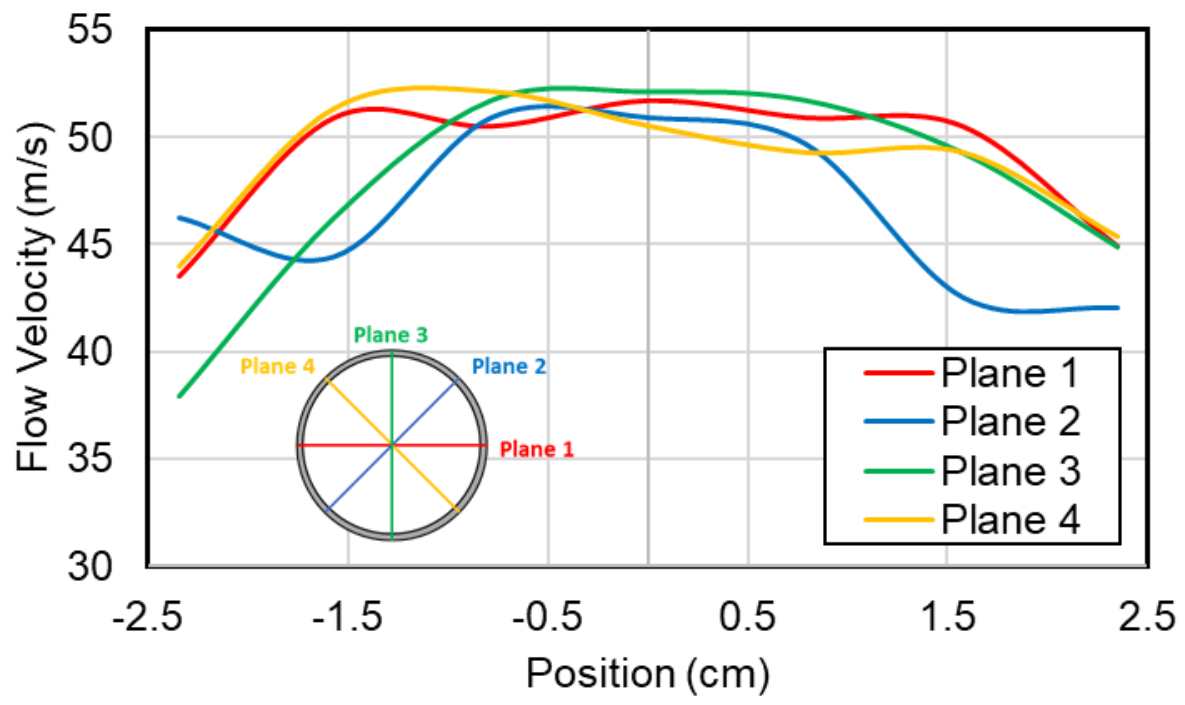

Figure 3.3 2D Flow profile inside a 1.87" $(4.75 \mathrm{~cm})$ ID pipe 


\subsubsection{Flow Noise Suppression}

The flow from the electric blower travels through a series of components that might generate flow noise. As seen in Figure 3.1, the flow passes first through a pressure relief valve located at a pipe tee where flow noise is likely to be generated [32]. The flow conditioner which expands and contracts the flow generates additional noise. These effects were detected using a sound intensity scan (ISO 9614-2 [33]) to measure sound power at the outlet. The measurement procedure is illustrated in Figure 3.4 and the measured sound power level for each flow rate is displayed in Figure 3.5. It can be seen that the generated noise was concentrated in narrow frequency bands at $822 \mathrm{~Hz}(0.05 \mathrm{Ma}), 1561 \mathrm{~Hz}(0.1 \mathrm{Ma})$, and $2352 \mathrm{~Hz}(0.15 \mathrm{Ma})$ Both the flow noise level and the tones caused by the side branch whistle are undesirable and must be dealt with.

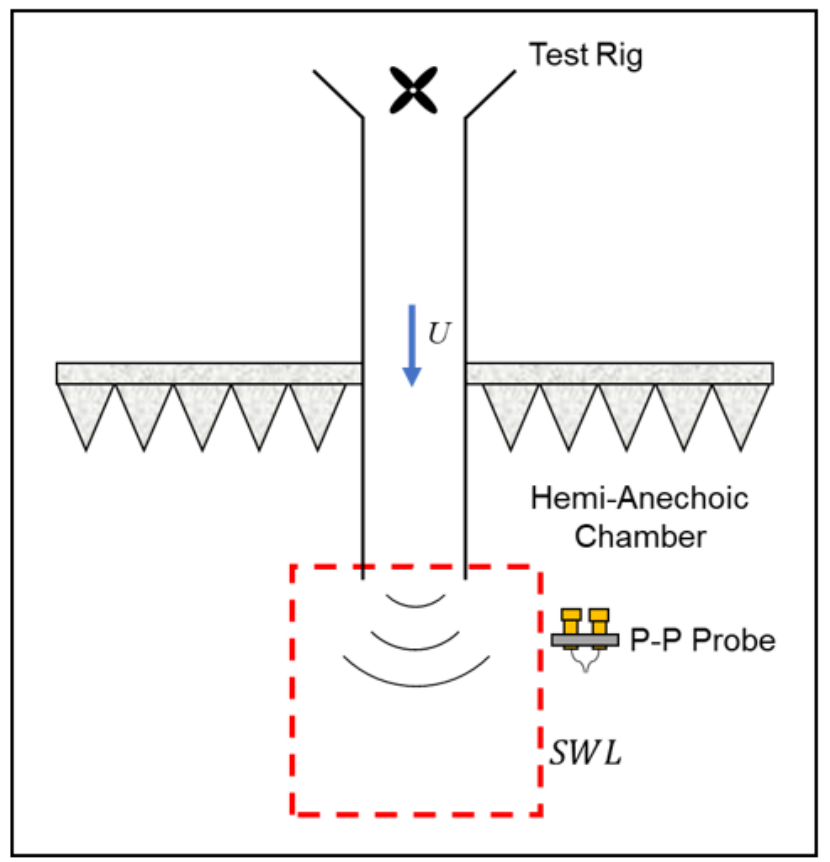

Figure 3.4 Experimental setup for flow noise intensity scan at end of the pipe 


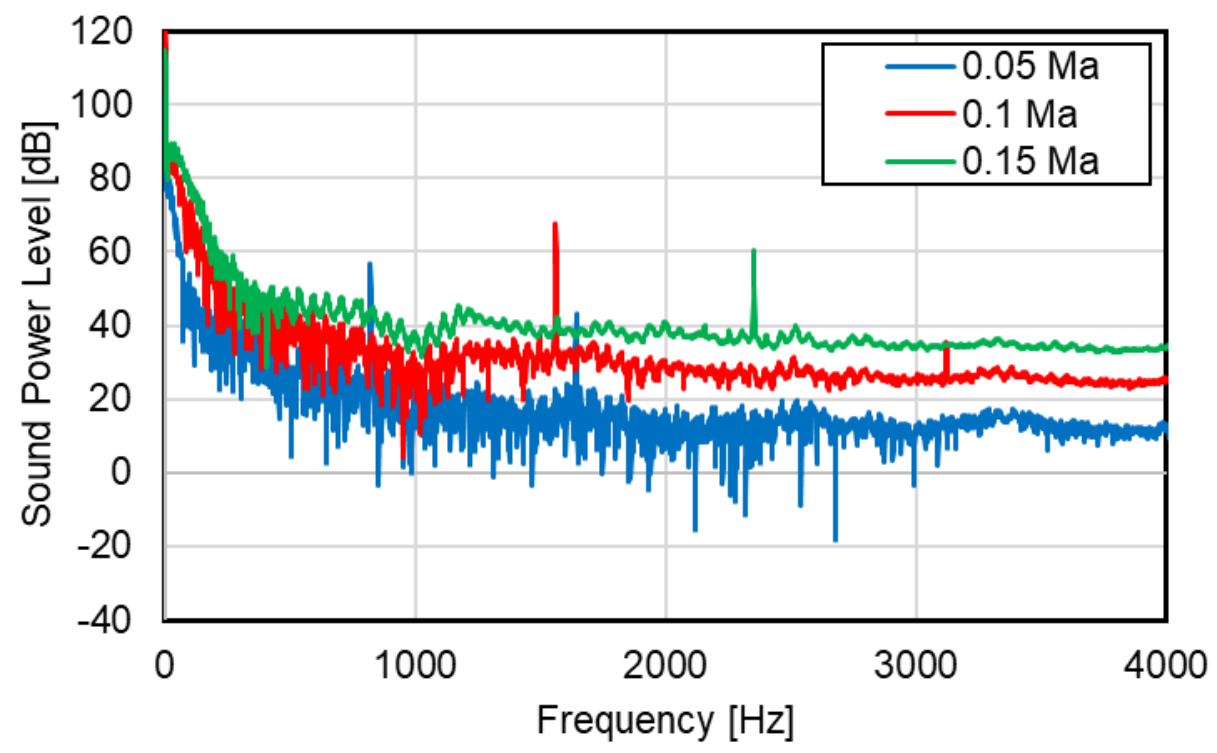

Figure 3.5 Flow noise before outlet silencer implementation

The flow generated noise is attenuated by a silencer placed downstream of the flow conditioner. The flow silencer is a simple expansion chamber incorporating a 24-gauge stainless steel micro-perforated 2" $(5.1 \mathrm{~cm})$ diameter pipe with nonwoven glass fiber surrounding it. The expansion chamber is approximately 48 " $(1.2 \mathrm{~m})$ in length with a diameter of 6" $(15.2 \mathrm{~cm})$. The transmission loss sans flow was measured by the two-load method described in Section 2.1.2. Results are shown in Figure 3.6 and were correlated with an analytical [34] and finite element model [35].

After the application of the silencer, the subsequent flow generated noise is attenuated $10-25 \mathrm{~dB}$ and is broadband above $400 \mathrm{~Hz}$. Low frequency flow noise is difficult to mitigate with a dissipative muffler application and may require another solution. Nonetheless, flow noise is reduced significantly, and it is now feasible for the acoustic sources selected to overwhelm the flow generated noise making a measurement of insertion loss possible as shown in Figure 3.7. 


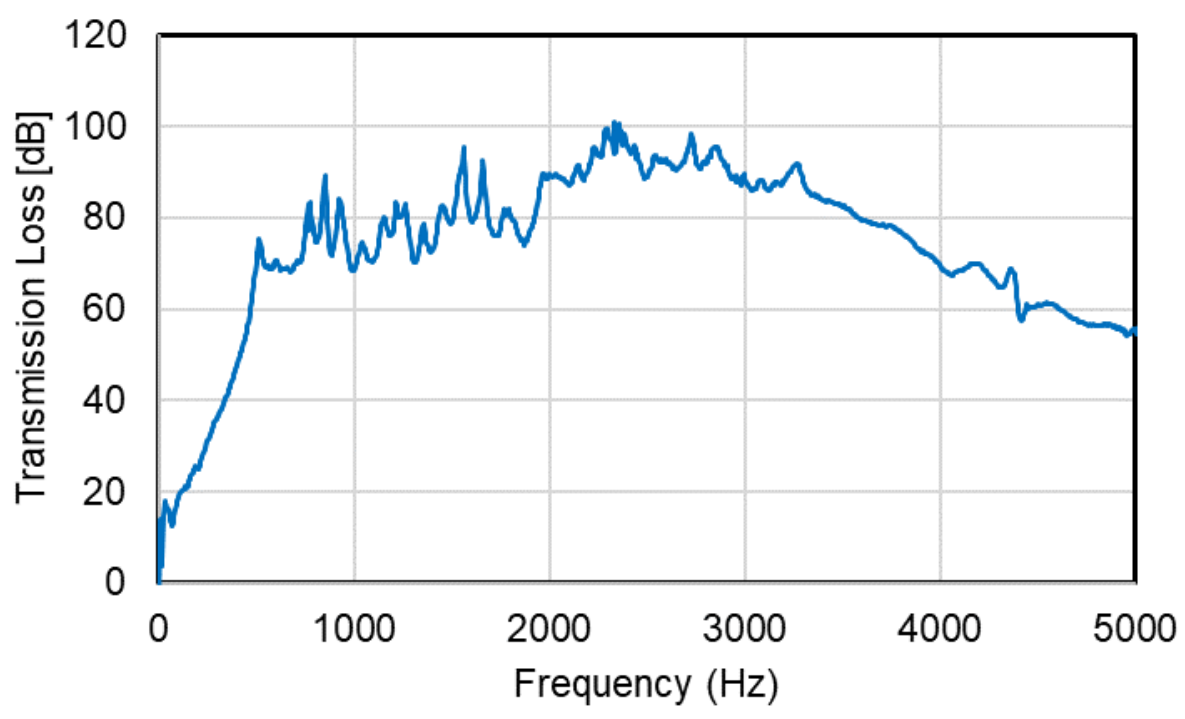

Figure 3.6 Outlet silencer transmission loss

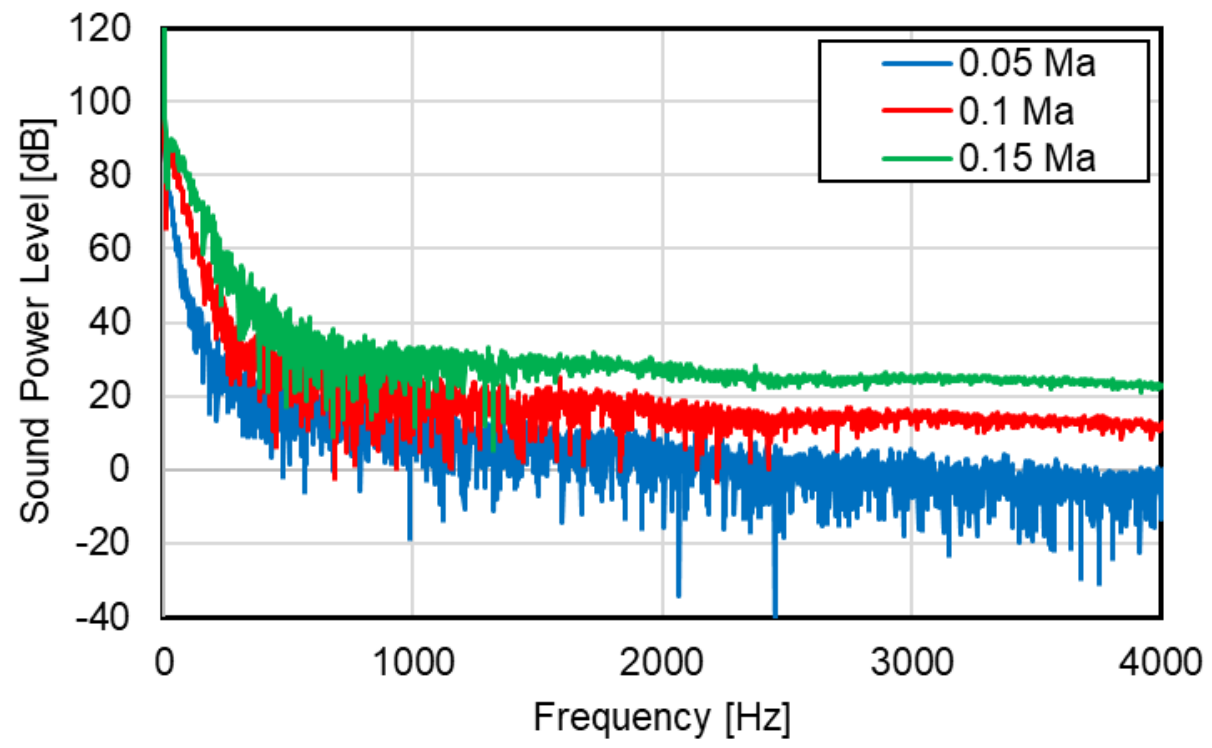

Figure 3.7 Flow noise after outlet silencer application

\subsection{Low Frequency Source}

The low frequency source is a JBL subwoofer $(2226 \mathrm{H})$ with a frequency range of $30-2500 \mathrm{~Hz}$. The desired working frequency range is 50 to $600 \mathrm{~Hz}$ with a crossover range of 600 to $1000 \mathrm{~Hz}$ with the high frequency source (discussed later). A Siemens SCADAS Mobile data acquisition system is used to control the source. Excitation signals used so far include white and pink noise, swept sine, and 
stepped sine. A cabinet was constructed to house the loudspeaker. The first design was rectangular in shape but was not massive enough to prevent breakout noise corrupting the measurement at the end of the pipe. The second iteration of the cabinet design was much stiffer and made from stainless steel consisting of a cylindrical pressure vessel with dish head caps on both ends [36, 37]. A crosssectional view of the cabinet is shown in Figure 3.8. Even at the ends, wall transmission loss was much higher since there were no flat surfaces.

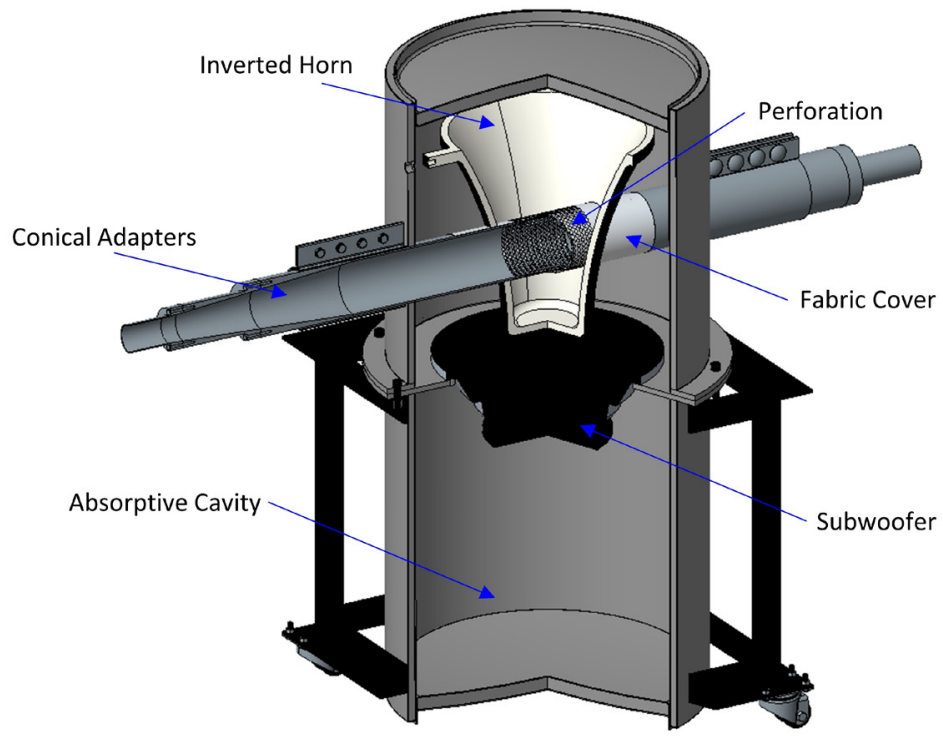

Figure 3.8 Low frequency source final design

Sound produced by the large diameter $(15$ " or $38.1 \mathrm{~cm}$ ) subwoofer must segue into the smaller diameter piping. This might be accomplished via a cone, but the cone would need to be very long for there not be an impedance difference that will lead to strong standing waves due to reflections in the cone. It was elected to instead transition from the loudspeaker to the perforated pipe using an inverted exponential horn.

The inverted horn should be highly damped, dense, and acoustically rigid. Rather than manufacturing from metal which would have been expensive, a 15-pound $(\sim 6.8 \mathrm{~kg})$ inverted horn was 3D printed out of polylactic acid or PLA. The PLA is highly damped and relatively stiff. However, the density of the PLA was not sufficient, so it was coated with polyurethane to increase the mass which 
correspondingly increases the transmission loss through the material [38]. The horn is mounted to the cylindrical cabinet at 4 positions as shown in Figure 3.9 and then intersects with the 2" $(5.1 \mathrm{~cm})$ outer diameter pipe.
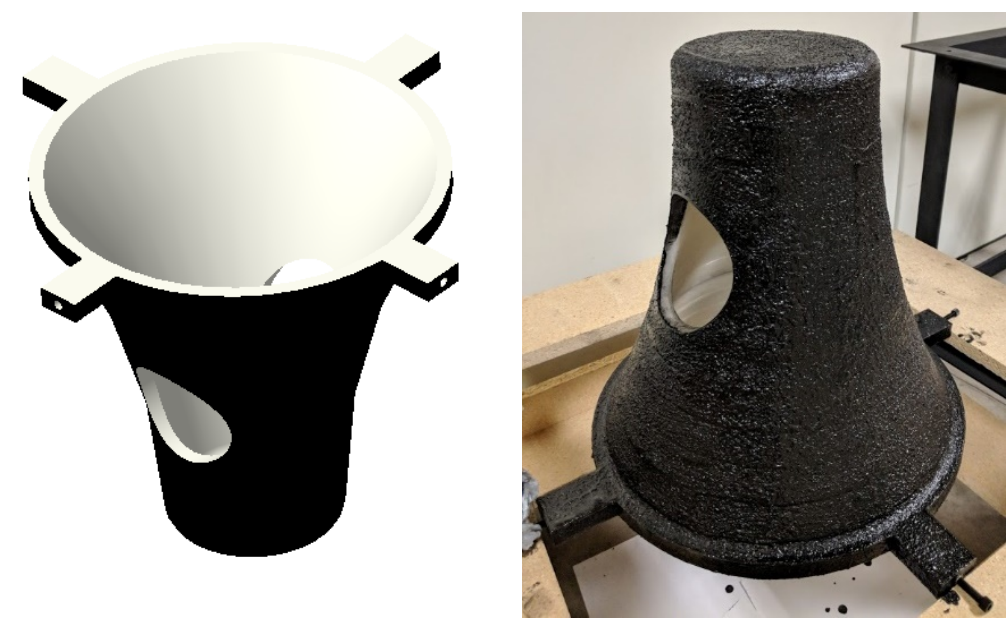

Figure 3.9 Inverted exponential horn

The speaker cabinet and cone can be considered as a single input multiple output muffler. Figure 3.10 shows a schematic of the speaker cabinet design. Note that sound can propagate both upstream and downstream of the low frequency source. The inverted horn serves to minimize impedance differences. Notice that the piping running through the cabinet is expanded using conical adapters on each side. The conical adapters are long to prevent low frequency acoustic attenuation [39] and flow separation.

The inverted horn was designed and analyzed prior to manufacturing. The plane wave simulation software SIDLAB [40] was used for the initial design. The SIDLAB model is shown in Figure 3.10 and consists of ducts, cones, and perforated elements. A schematic of the way the horn is broken up into plane wave components is shown in Figure 3.10 and Table 3.2 identifies the selected components.

After design using plane wave simulation, acoustic finite element simulation was used to validate the plane wave model and confirm the design prior to printing. The simulation was performed using Siemens Virtual.Lab [41] and compared to 
plane wave simulation in Figure 3.11. Correlation between plane wave and finite element simulation is generally good. More importantly, both models confirm that the acoustic attenuation due to the horn is below $10 \mathrm{~dB}$ at most frequencies. Moreover, attenuation is relatively constant as a function of frequency.

The sound power level was then measured in a microphone hemisphere [42] with the flow turned off. Figure 3.12 compares the sound power of the loudspeaker and flow. It can be seen that the acoustic source level is much higher at most frequencies.

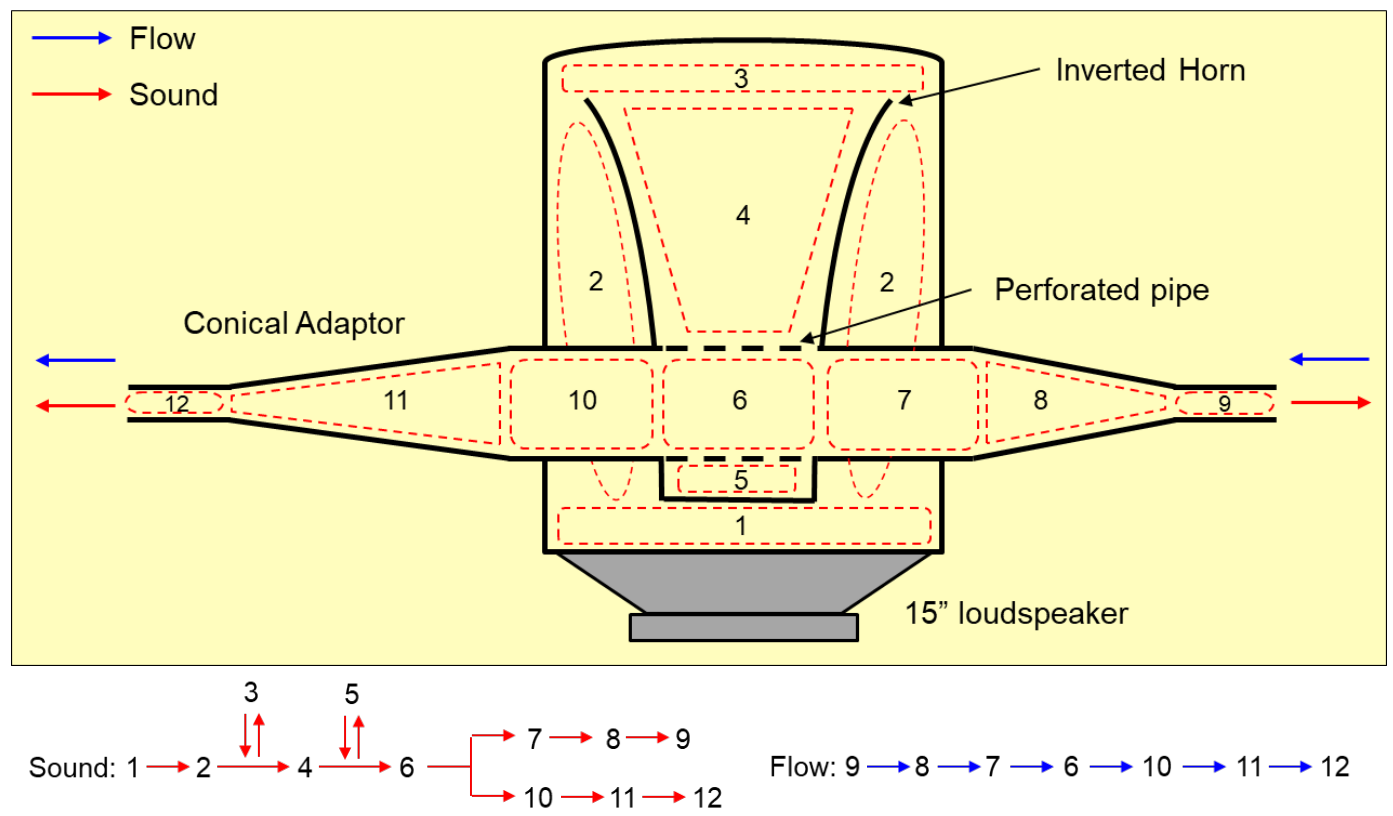

Figure 3.10 1D plane wave model of the low frequency source cabinet Table 3.2 Acoustic components in the cabinet

\begin{tabular}{|c|c|}
\hline Element & Type \\
\hline $1,7,9,10,12$ & Duct \\
\hline $2,4,8,11$ & Cones \\
\hline 3,5 & Quarter Wave \\
\hline 6 & Perforate $(\phi \geq 30 \%)$ \\
\hline
\end{tabular}




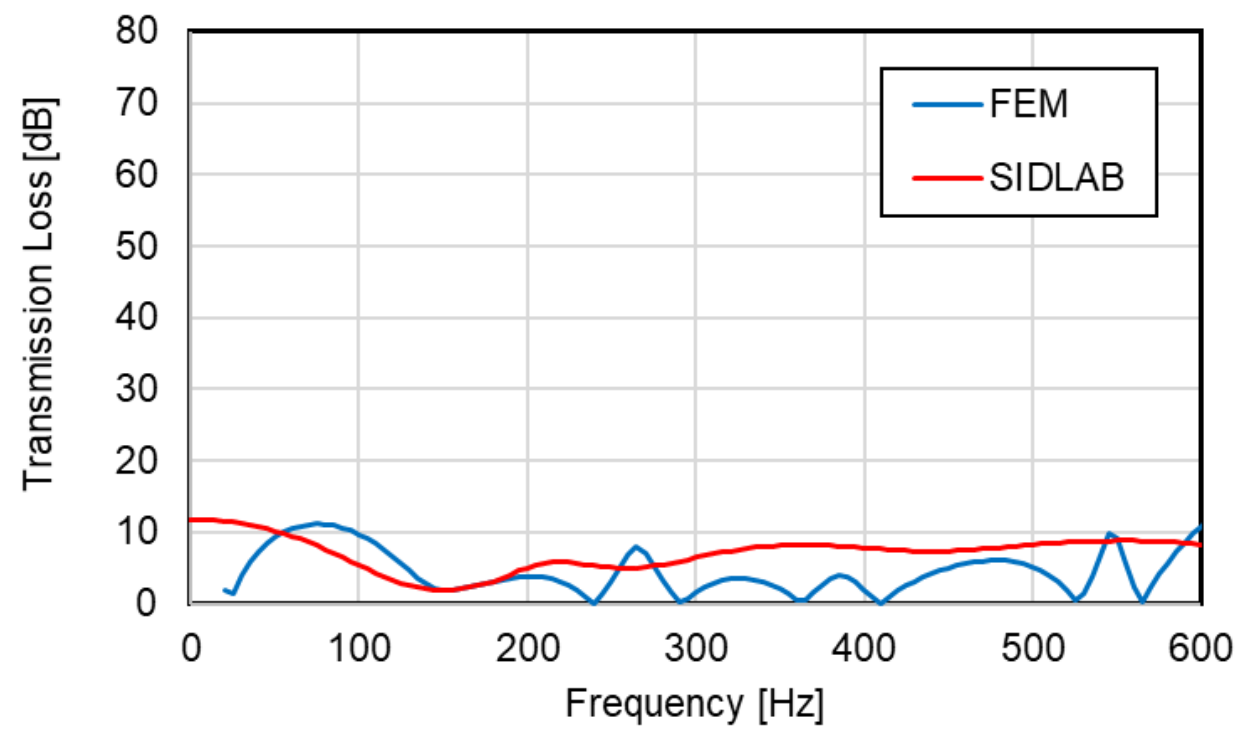

Figure 3.11 FEM and SIDLAB models for cabinet transmission loss without flow

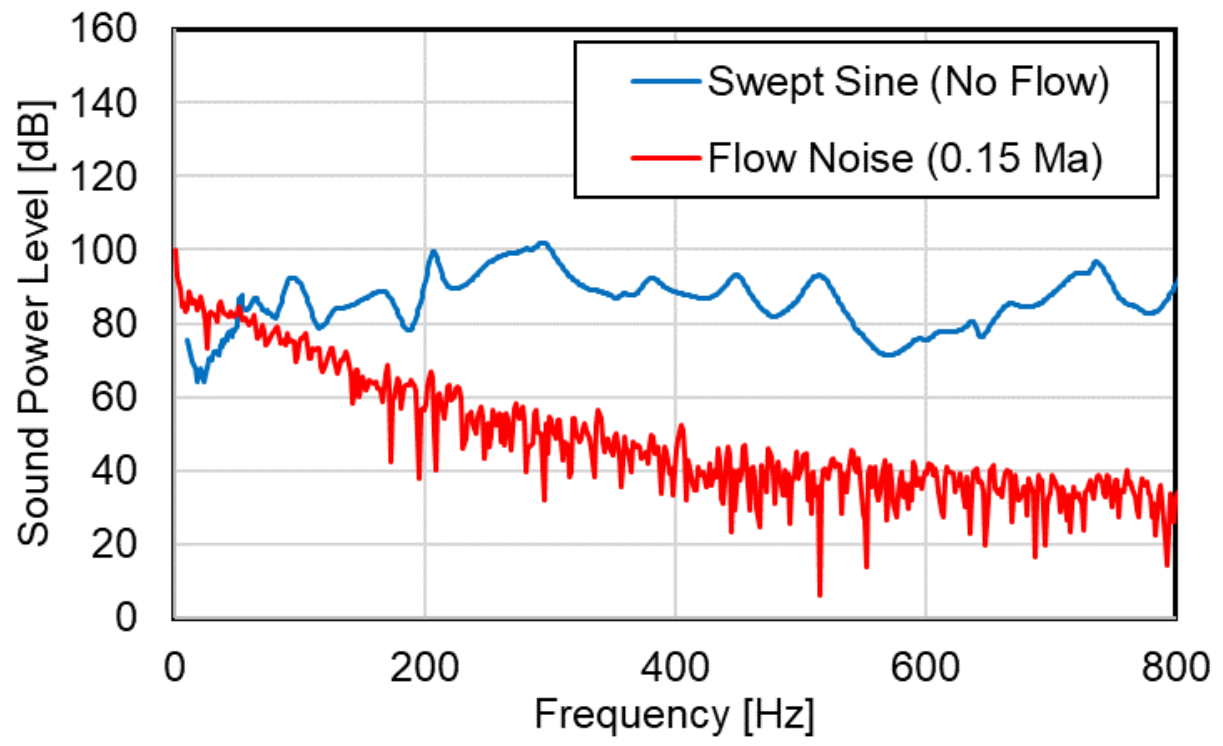

Figure 3.12 Final low frequency response with a swept sine excitation

Sound radiates from both sides of the speaker diaphragm. The waves coming off the rear are approximately 180 degrees out of phase with those from the front. As Beranek [43] explains, the loudspeaker can be thought of as two sound sources of equal strength having opposite phase. It is best to minimize the sound coming off the rear of the diaphragm. However, the performance of the loudspeaker will be compromised if there is not sufficient volume in the back of the diaphragm. Due to size constraints, the volume is on the lower end of what is recommended. 
In order to attenuate the sound from the rear, a layered absorber was positioned behind the loudspeaker as shown in Figure 3.13. The layered absorber is a combination of polyurethane foam, a mixed polyester fiber, and loose fill fiber. The sound absorber is sufficiently thick to attenuate some of the sound waves at the lower frequencies. The sound absorption for each layer and for the layered absorber is shown in Figure 3.14. It can be seen that the sound absorption is effective except at the lowest frequencies.

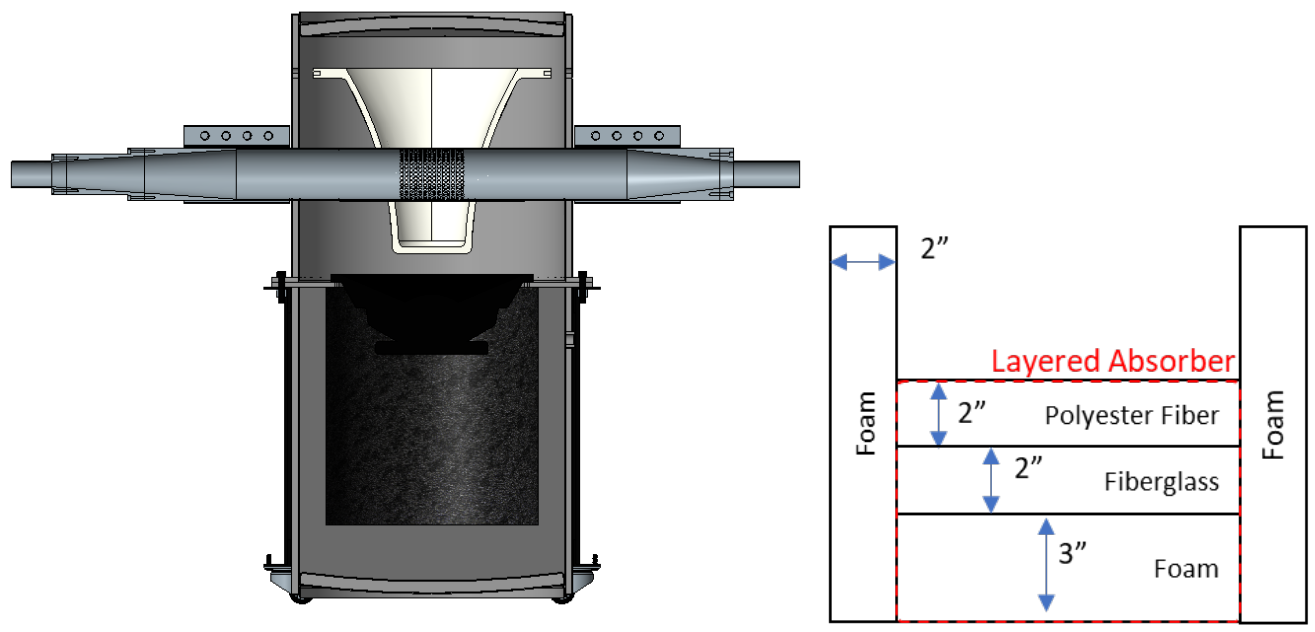

Figure 3.13 Speaker cavity absorption

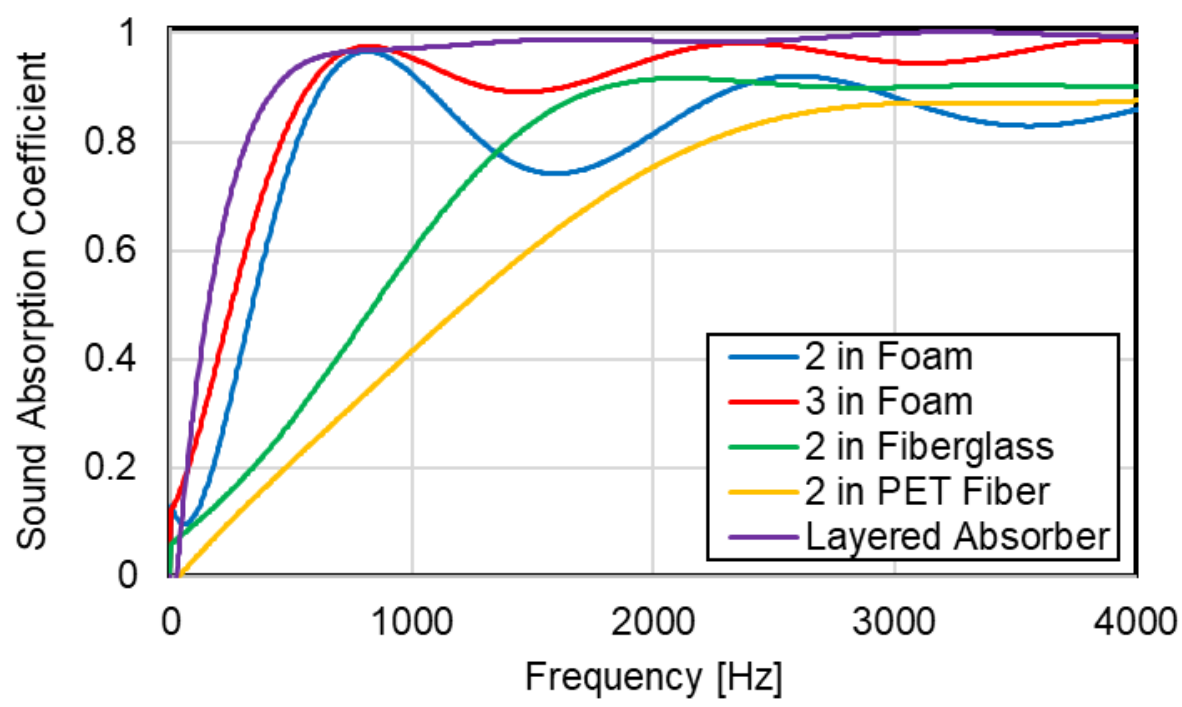

Figure 3.14 Sound absorption coefficient of the layered absorber 
Sound passes from the cone into the piping through a perforated tube. The porosity of the tube exceeds $30 \%$ and is relatively acoustically transparent. The perforations were designed to be acoustically transparent where porosity was above $30 \%$. The tube serves another purpose by providing structural support for the inverted horn. The initial design implemented a 2" $(5.1 \mathrm{~cm})$ outer diameter steel pipe with approximately $36 \%$ porosity. The intent was to keep the diameter constant throughout the rig and prevent flow separation. However, when mean flow was introduced into this pipe, significant flow noise was generated due to the perforations. Microphone measurements were made 8.9 inches $(22.7 \mathrm{~cm})$ away from the pipe outlet as shown in Figure 3.15. The sound pressure level at the end of the tube is compared to that of a straight pipe in Figure 3.16. It was evident that flow generated noise was too high and needed to be reduced.

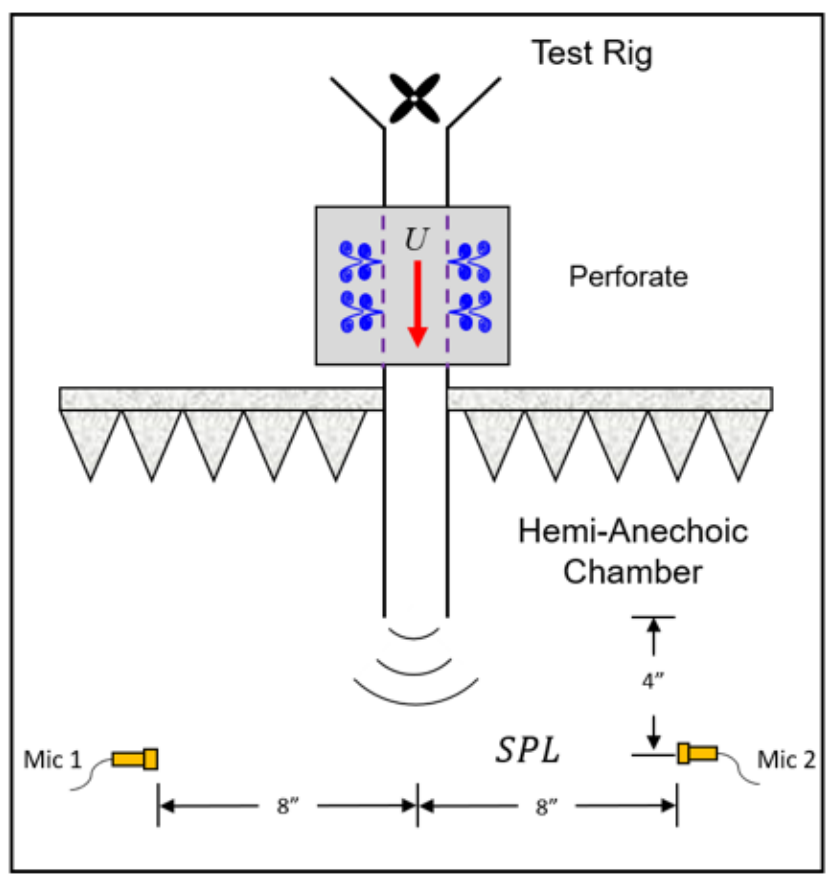

Figure 3.15 Experimental setup for perforate studies 


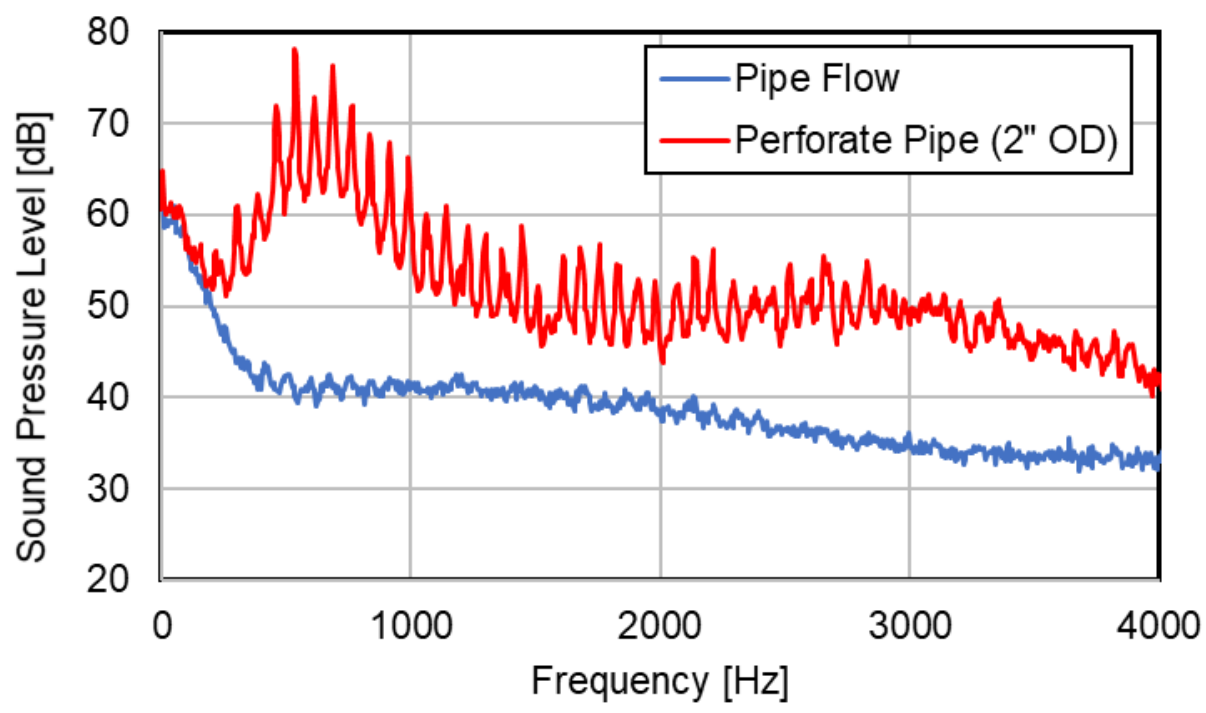

Figure 3.16 Perforate flow-induced noise at $0.15 \mathrm{Ma}$

Several strategies to reduce the flow noise were attempted including reducing the size of the perforations, increasing the length of the perforations by increasing the pipe thickness, and covering the perforation with a fabric. To evaluate these strategies, microphone measurements were made at the end of the pipe as shown in Figure 3.15. Reducing the perforate diameter while keeping the porosity the same had minimal impact on the flow noise. Increasing the perforate length also proved unsatisfactory.

Covering the perforations was effective but the implementation had to be optimized. Using a cover seemingly prevents vortex generation or other flow mechanisms, but also attenuates the source which is undesirable. A sensitivity study was performed to identify an appropriate cover. Table 3.3 shows the different materials examined. 
Table 3.3 Covers used for flow-induced noise mitigation

\begin{tabular}{|c|c|c|c|c|}
\hline Material & Density $\left[\mathbf{k g} / \mathbf{m}^{3}\right]$ & $\begin{array}{c}\text { Surface Mass } \\
\text { Density }\left[\mathbf{k g} / \mathbf{m}^{2}\right]\end{array}$ & Thickness [mm] & Porous \\
\hline $\begin{array}{c}\text { Polyethylene Terephthalate } \\
\text { (Mylar) }\end{array}$ & $1370-1455$ & $0.027-0.029$ & 0.02 & No \\
\hline Paper & $250-1500$ & $0.02-0.12$ & 0.08 & No \\
\hline Polyvinyl Chloride (PVC) & $1100-1350$ & $0.83-1.01$ & 0.75 & Yes \\
\hline Polyethylene & $880-960$ & $0.14-0.15$ & 0.16 & No \\
\hline Polypropylene w/ Adhesive & $855-946 \uparrow$ & $0.051-0.057$ & 0.06 & No \\
\hline Polyolefin & 930 & 1.3 & 1.4 & No \\
\hline
\end{tabular}

Nonporous membranes had the best flow-induced noise control and matched preperforate levels as shown in Figure 3.17. However, these covers reduced acoustic excitation significantly. These losses are explained by region 1 of the thin panel theory where stiffness defines the panel transmission loss. A higher cover stiffness results in an increased transmission loss and therefore higher insertion loss which is reflected in Figure 3.18.

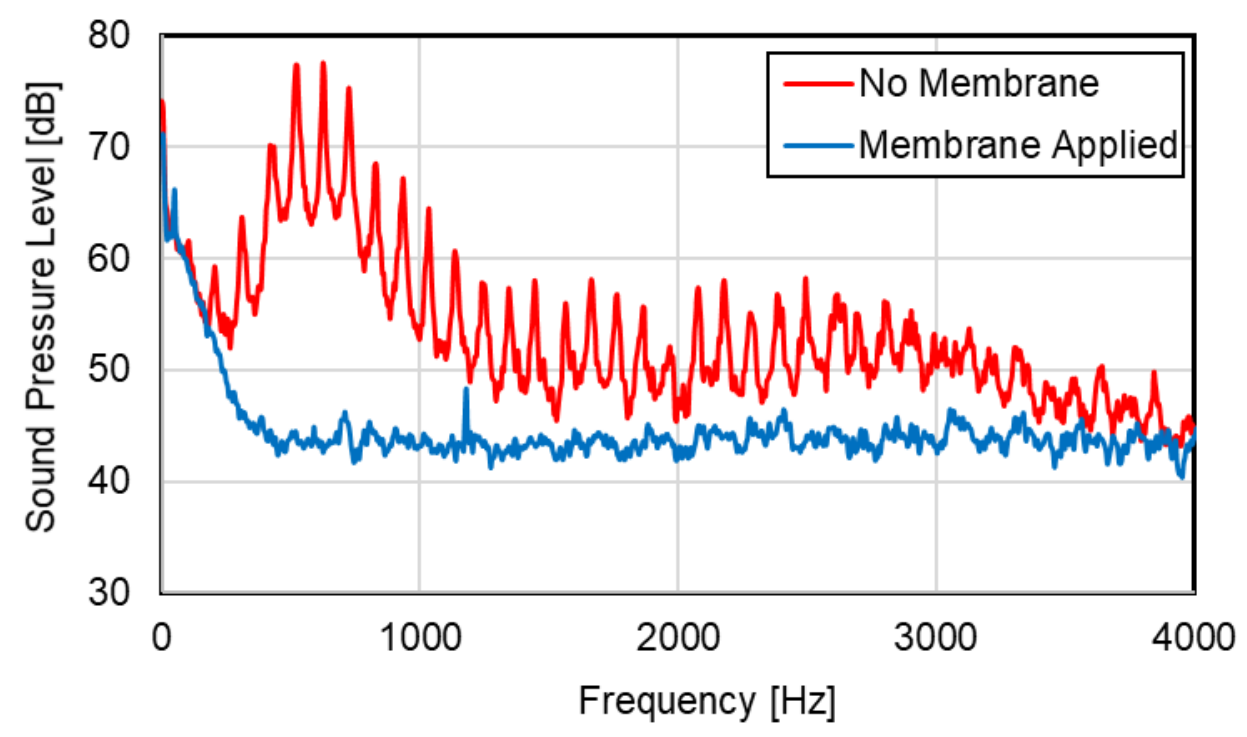

Figure 3.17 Flow noise suppression using a paper cover at $0.15 \mathrm{Ma}$ 


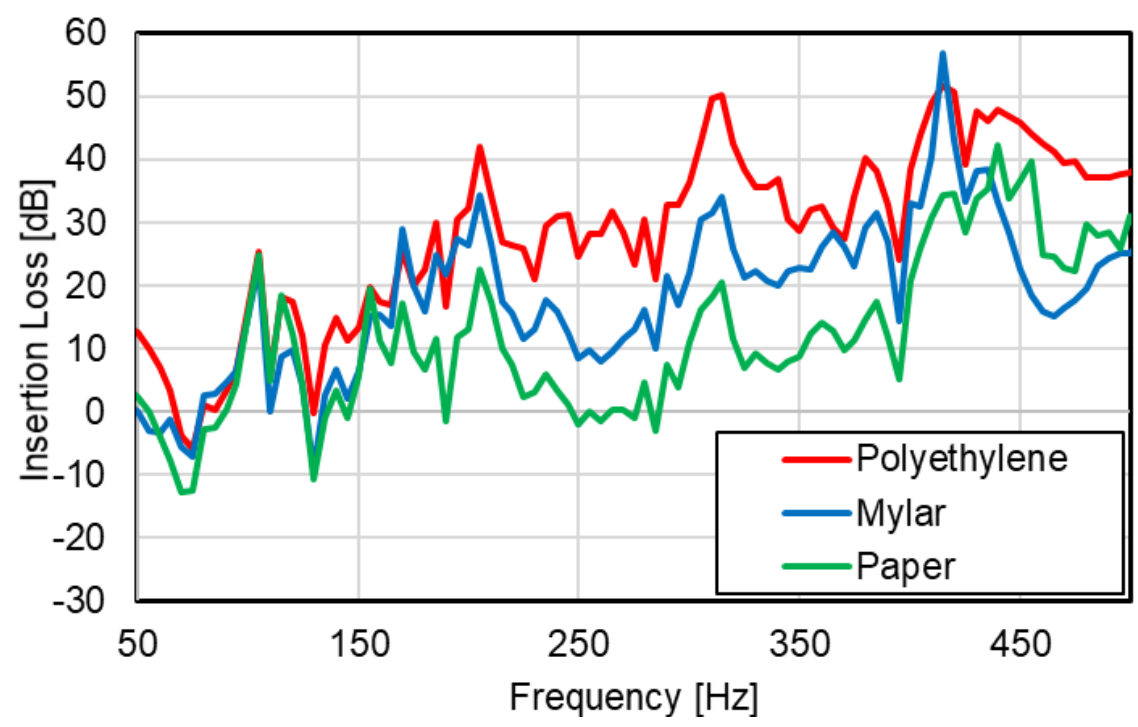

Figure 3.18 Acoustic insertion loss of a few cover materials

A porous PVC fabric was eventually settled on because it provided a suitable balance between reducing flow noise generation while not greatly attenuating the source. Figure 3.19 compares the sound pressure level at the end of the pipe without and with the acoustic fabric applied. Flow generated noise is reduced to an acceptable level of between 40 and $50 \mathrm{~dB}$ above $250 \mathrm{~Hz}$. Small peaks remain as a result of flow, but the level is low. The associated insertion loss due to the fabric cover is shown in Figure 3.20. Attenuation is well below $10 \mathrm{~dB}$ except at a few frequencies.

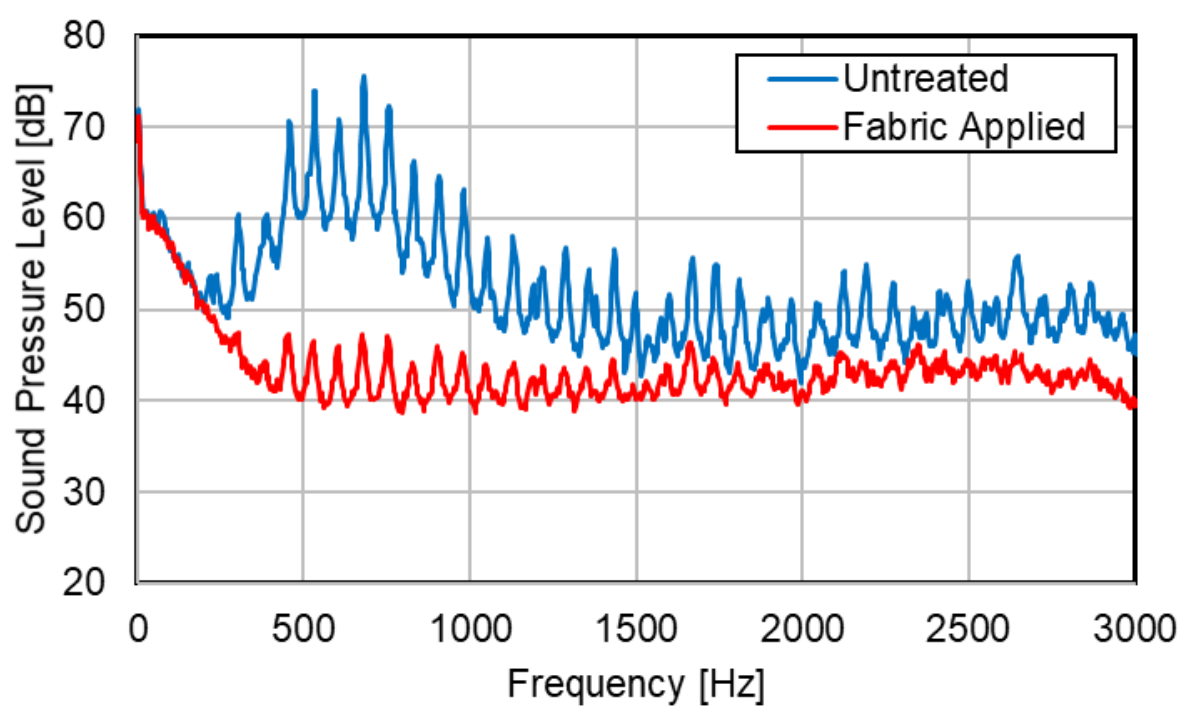

Figure 3.19 Flow noise suppression using a porous fabric at $0.15 \mathrm{Ma}$ 


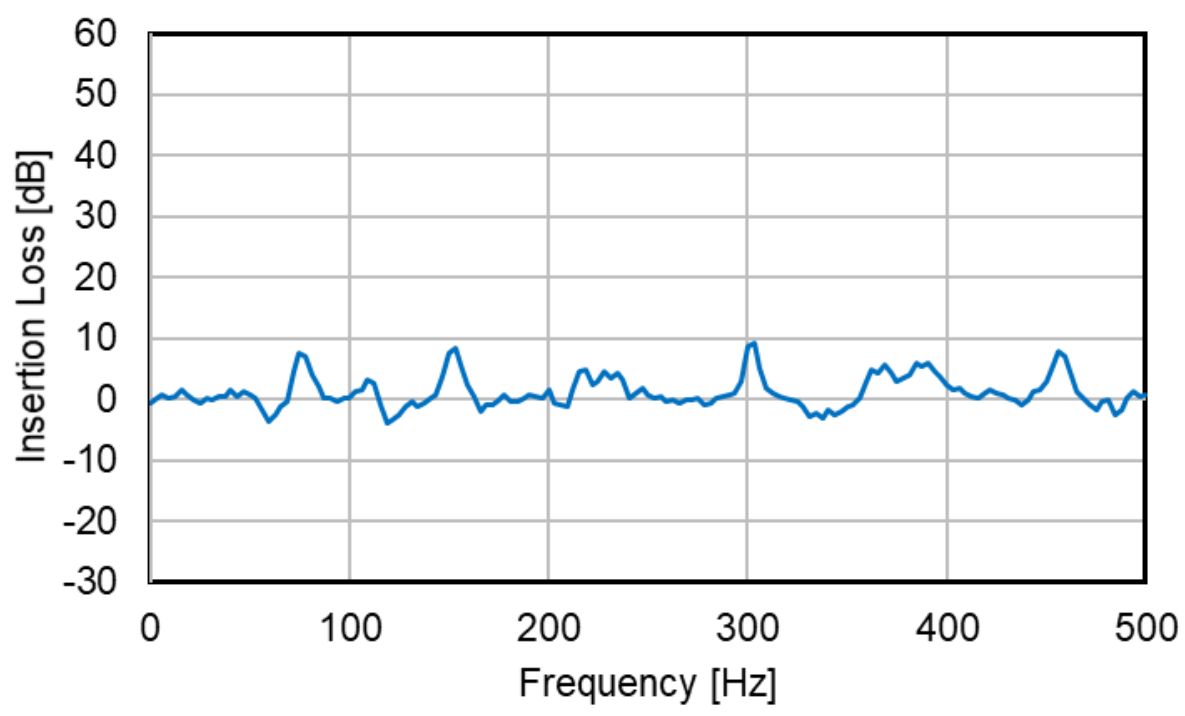

Figure 3.20 Acoustic insertion loss of a fabric cover.

Therefore, a tightly woven fabric is affixed to the perforated tube on the periphery in the final design. In addition, the pipe diameter is expanded inside the speaker cabinet. This allows for easier mating between the reverse horn and piping. More importantly, the flow velocity is reduced by a factor two. Since flow noise generation is proportional to flow speed raised to the 4th or 6th power for a dipole or quadrupole source in one-dimension respectively [16], any sizeable reduction in flow velocity should significantly reduce the flow noise generation.

Sound power measurements were performed with and without the low frequency source to verify design techniques used for flow. The one-third octave analysis showed the cabinet did not significantly increase flow noise in comparison to the existing flow source. There is no distinguishable difference at 0.1 and $0.15 \mathrm{Ma}$ flow speeds with some deviation at $0.05 \mathrm{Ma}$. Therefore, the usage of the acoustic fabric and the expanded pipe diameter helped alleviate potential flow noise generation. 


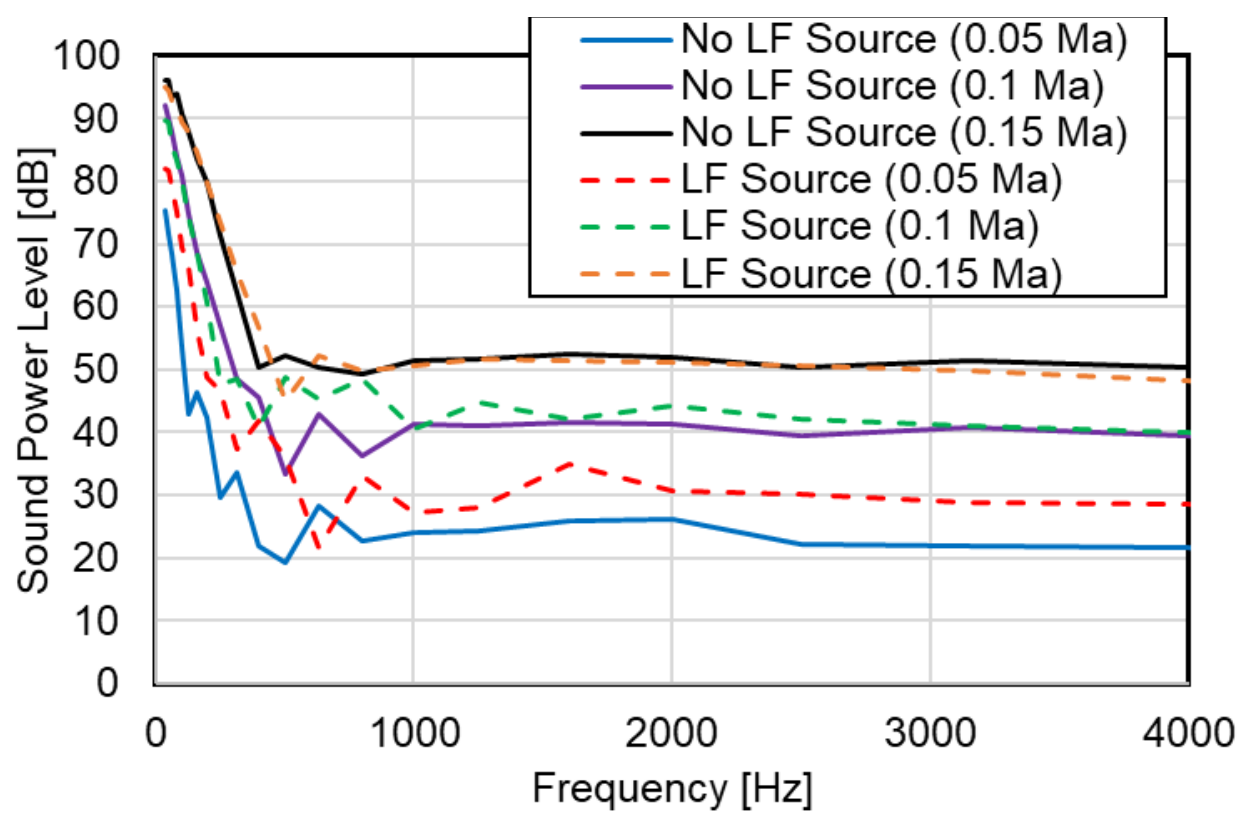

Figure 3.21 One-third octave band comparison of flow noise between the existing flow source and an addition of a low frequency source cabinet

\subsubsection{Summary}

The design of the low frequency source and cabinet has been described. The frequency response of the source is relatively flat and the source is capable of providing sufficient sound power above $100 \mathrm{~Hz}$ and perhaps lower. There are several interesting design characteristics including 1) an inverse horn to transition between the loudspeaker and the piping, 2) an acoustic fabric cover over the perforations to reduce flow generated noise, and 3) a cylindrical stainless steel speaker cabinet packed with sound absorption behind the loudspeaker to minimize any breakout noise from the cabinet housing. 


\subsection{High Frequency Source}

The high frequency source is a compression driver (JBL 2446H) with an effective frequency range of $500 \mathrm{~Hz}$ to $20 \mathrm{kHz}$. The crossover range between the low and high frequency sources is from 600 to $1000 \mathrm{~Hz}$. The desired maximum frequency for muffler testing is $4000 \mathrm{~Hz}$ though this can likely be extended. When mounted to the tube, the output sound pressure level of the compression driver is $118 \mathrm{~dB}$ at $1 \mathrm{~mW}$.

The compression driver is attached to the test rig via a pipe tee. However, tees introduce problems of their own because they introduce a side branch resonance and may also generate flow noise. Measurements were performed to better understand the effect of the tee. First, the sound pressure level was measured with methods presented in Figure 3.15 with the pipe tee and compared to the baseline case. Results are compared in Figure 3.22 where it can be seen that there is a significant reduction in sound pressure level at higher frequencies due to the expansion in the area. Though significant, the flow noise generation at the pipe tee is even more concerning. The sound pressure level due with the blower turned on was measured without and with the pipe tee in position. Figure 3.23 compares the sound pressure levels. It is evident that flow generated noise is unacceptably high for several frequencies ranging from $250 \mathrm{~Hz}$ to $1250 \mathrm{~Hz}$. Similar acoustic behavior was seen by Karlsson and Åbom [32] in their aeroacoustic studies of T-junctions.

If a perforated steel cover is placed over the pipe tee, the flow generated noise is reduced appreciably as shown in Figure 3.24. Similar studies were done by Holmberg at. al [44] to reduce tee flow noise. Based on the success of this experiment, other covers were tried, and the sound pressure levels are compared in Figure 3.25. Mylar was selected as a cover because it attenuated the sound the least between 0 and $2000 \mathrm{~Hz}$ and is nonporous. 


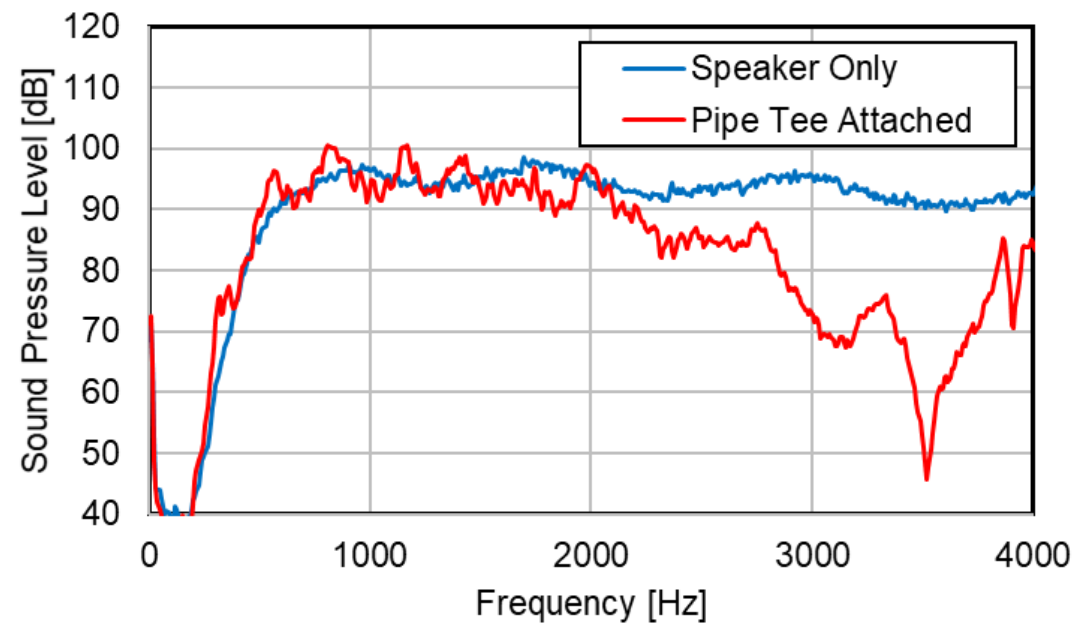

Figure 3.22 Pipe tee frequency response

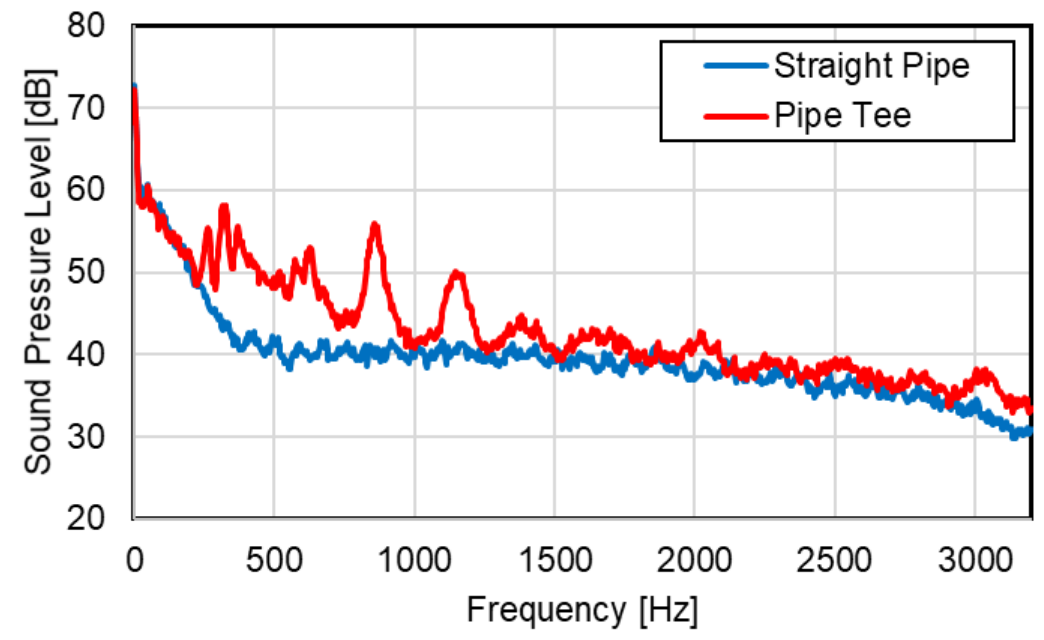

Figure 3.23 Pipe tee flow-induced noise at $0.15 \mathrm{Ma}$

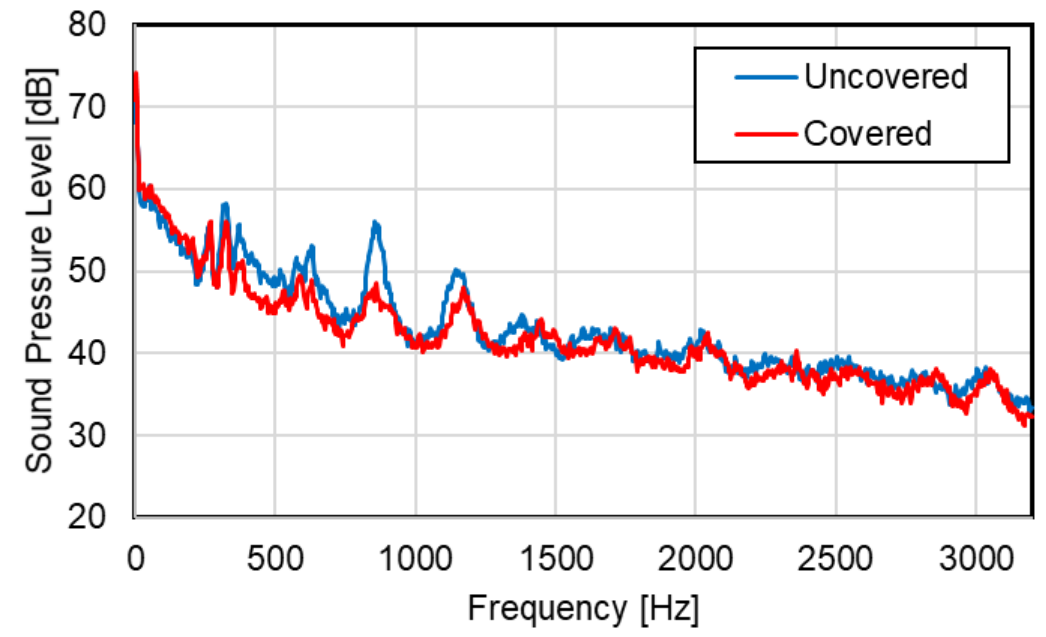

Figure 3.24 Perforated cover applied to the side branch with $0.15 \mathrm{Ma}$ flow 


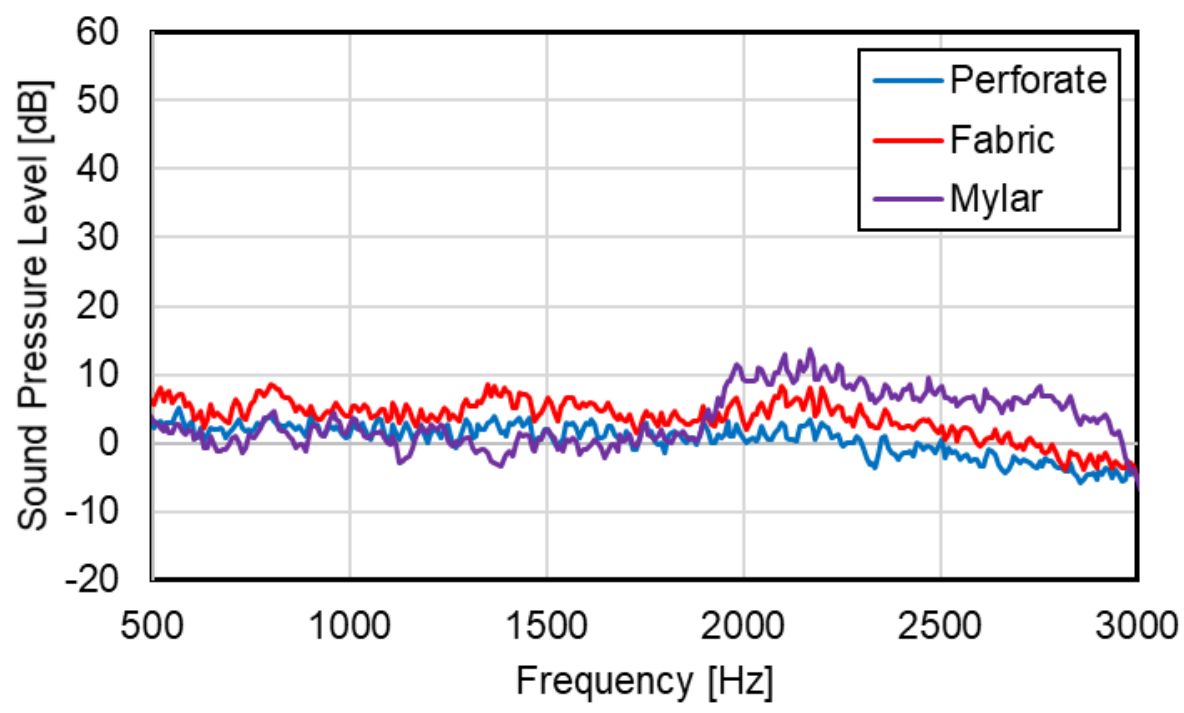

Figure 3.25 Acoustic insertion loss of various covers

Thus, the compression driver is flush mounted to the pipe. To protect the driver and reduce flow noise, a Mylar cover was placed between the compression driver and pipe as shown in Figure 3.26. The cover is supported by a wire mesh and prevents whistling that occurs with flow. The Mylar cover without a mesh backing will burst if the static pressure exceeds approximately $32.2 \mathrm{kPa}\left(130 \mathrm{inH}_{2} \mathrm{O}\right)$. The mesh backing reinforces the Mylar while being acoustically transparent. To understand the effect of the cover on the compression driver output, a cover insertion loss was defined as the difference in sound pressure level at the end of the pipe without and with the cover. The measured insertion loss does not deviate significantly from Figure 3.25 where it can be seen that the cover does not unacceptably reduce the compression driver output.

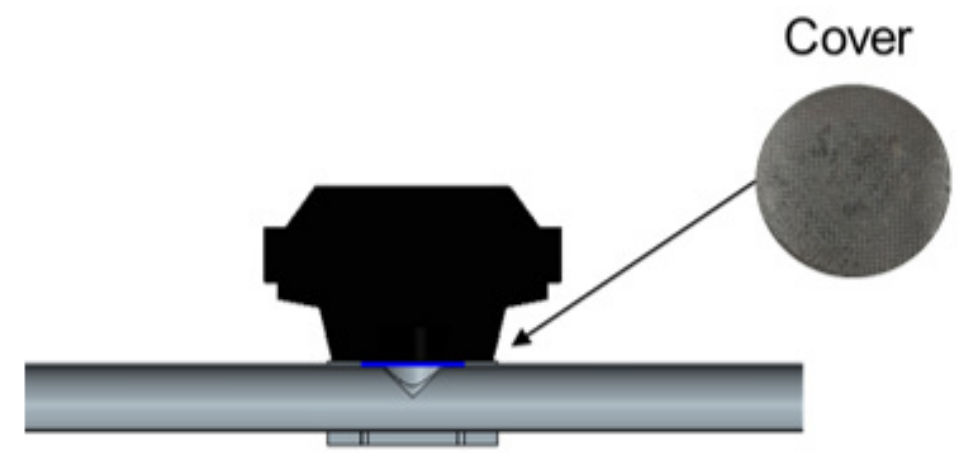

Figure 3.26 Final high frequency source attachment 
The flow noise without and with the smaller tee junction including the high frequency source was compared. Results are shown in one-third octave bands in Figure 3.27 and it can be seen that the noise levels are only slightly elevated with flow. By flush mounting the compression driver and adding a Mylar cover, flow noise can be minimized. The final acoustic output compared to flow noise is shown in Figure 3.28.

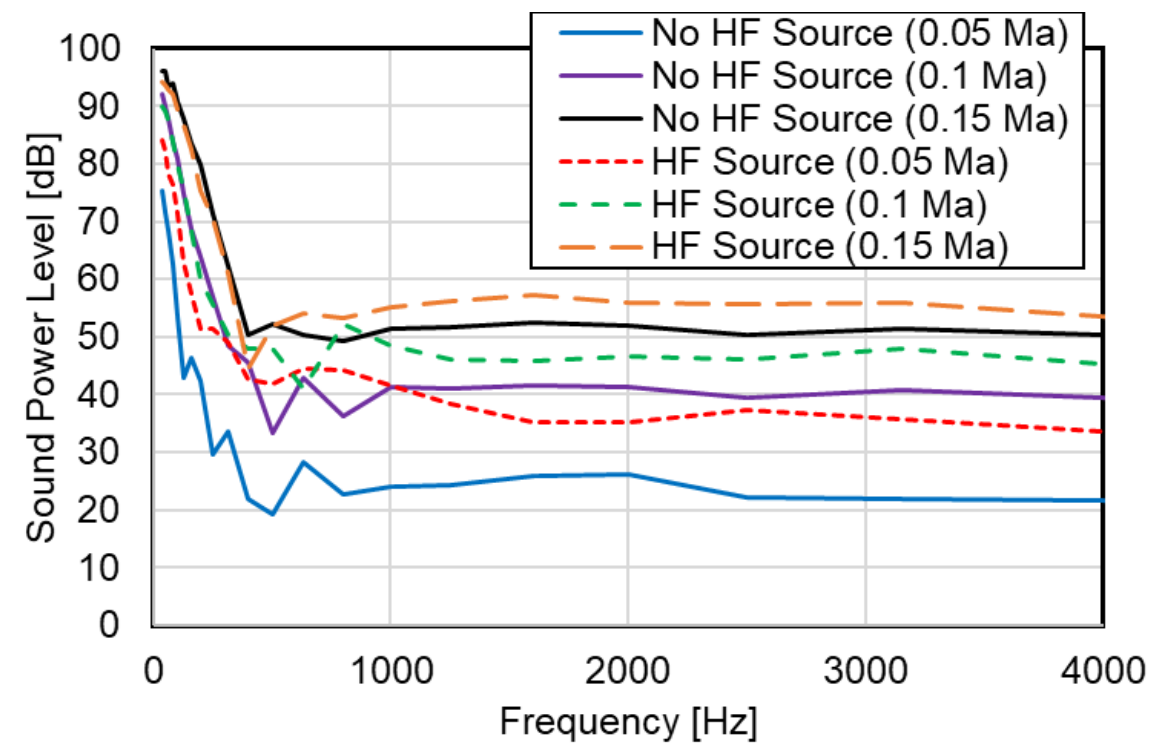

Figure 3.27 One-third octave band comparison of flow noise between the existing flow source and an addition of a high frequency source

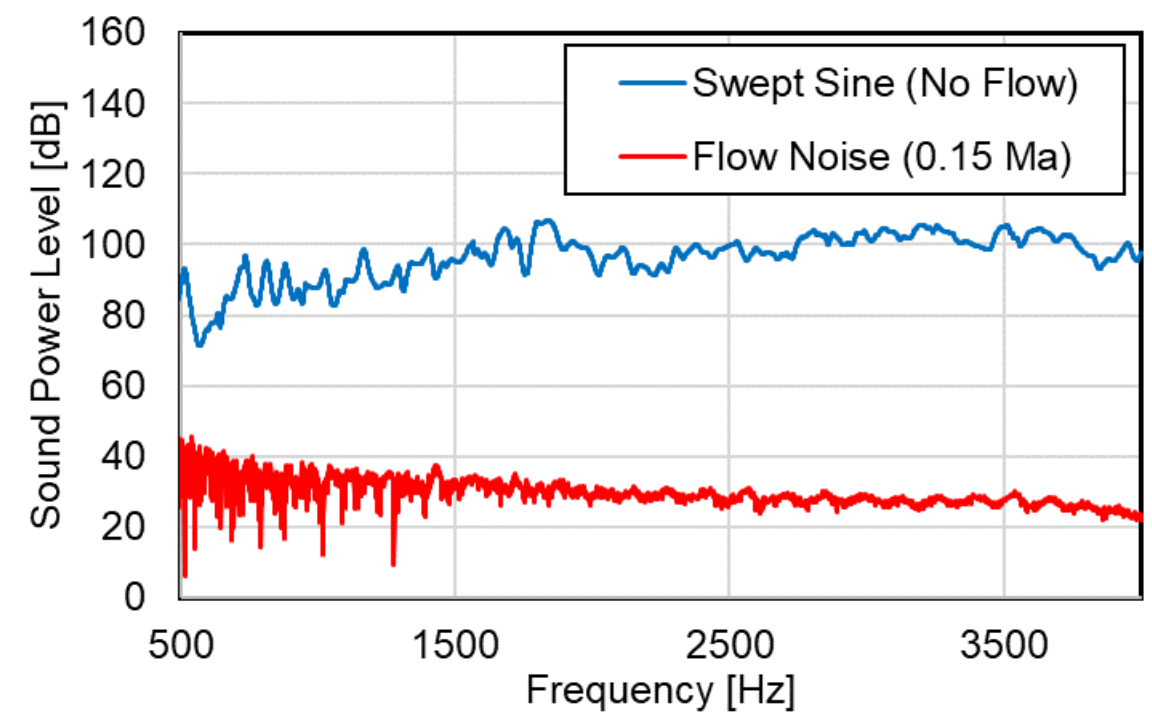

Figure 3.28 Final high frequency output 


\subsection{Finalized Test Fixture}

The completed test rig is shown in Figure 3.29. The test rig is modular in design and is capable of being reassembled for various purposes. Each component is clamped together using couplers, and a flex coupler isolates the sources downstream from the blower. As seen in Figure 3.30, the test rig is mounted on rollers and sound power measurements can be performed inside the hemianechoic chamber. The controls and major components are shown in Figure 3.31.

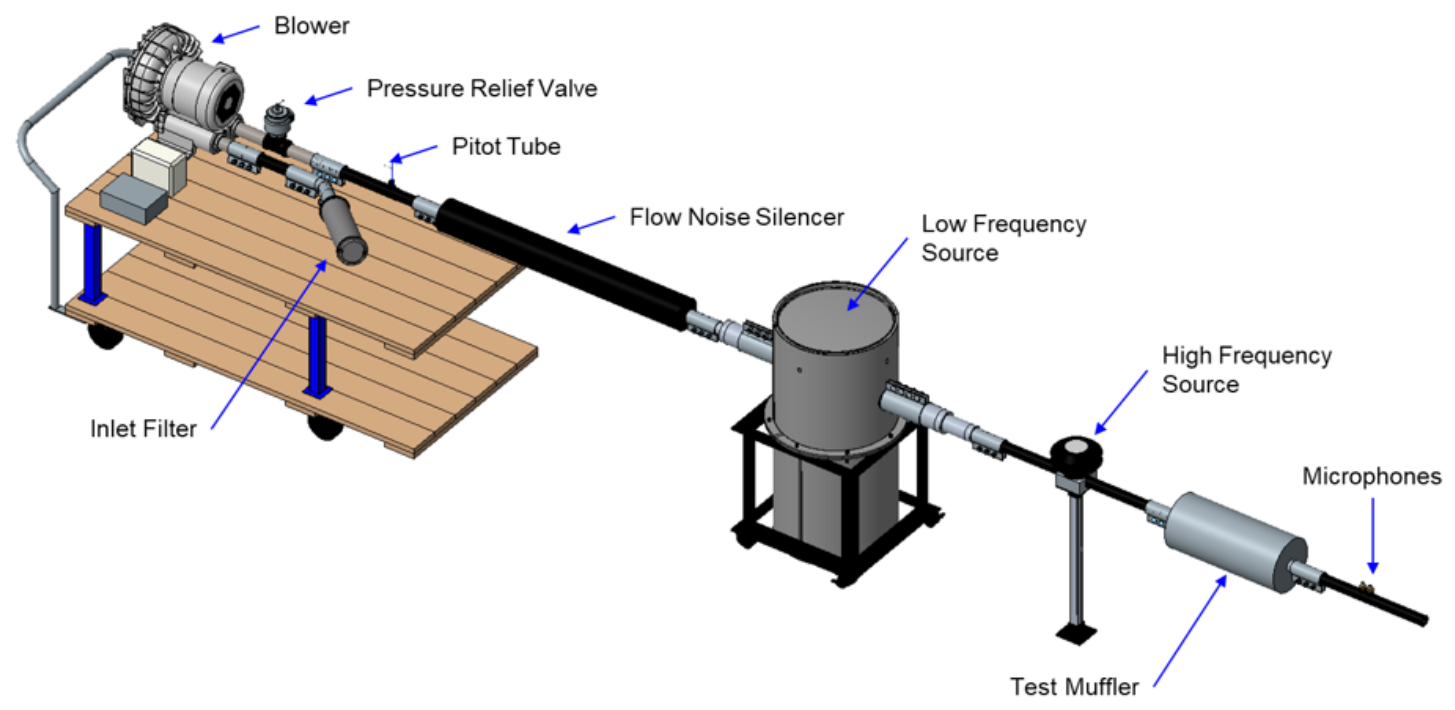

Figure 3.29 Completed insertion loss flow rig CAD
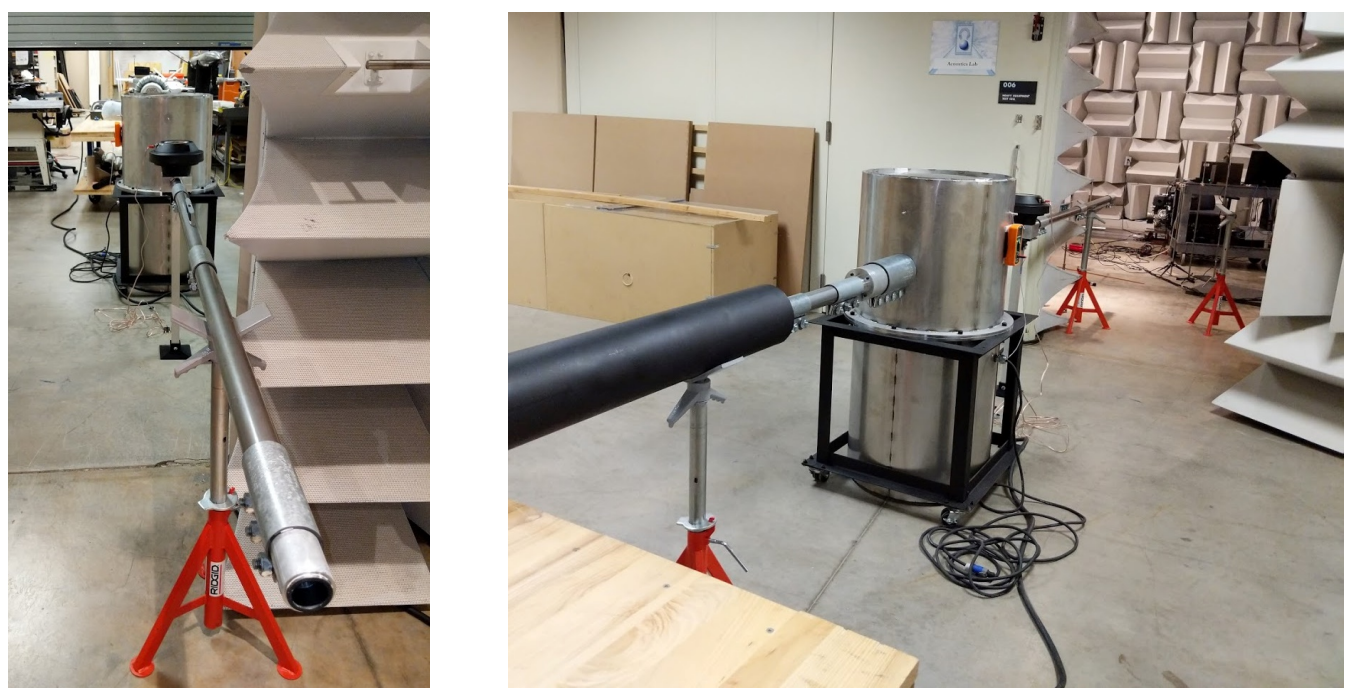

Figure 3.30 Picture of the completed test fixture 


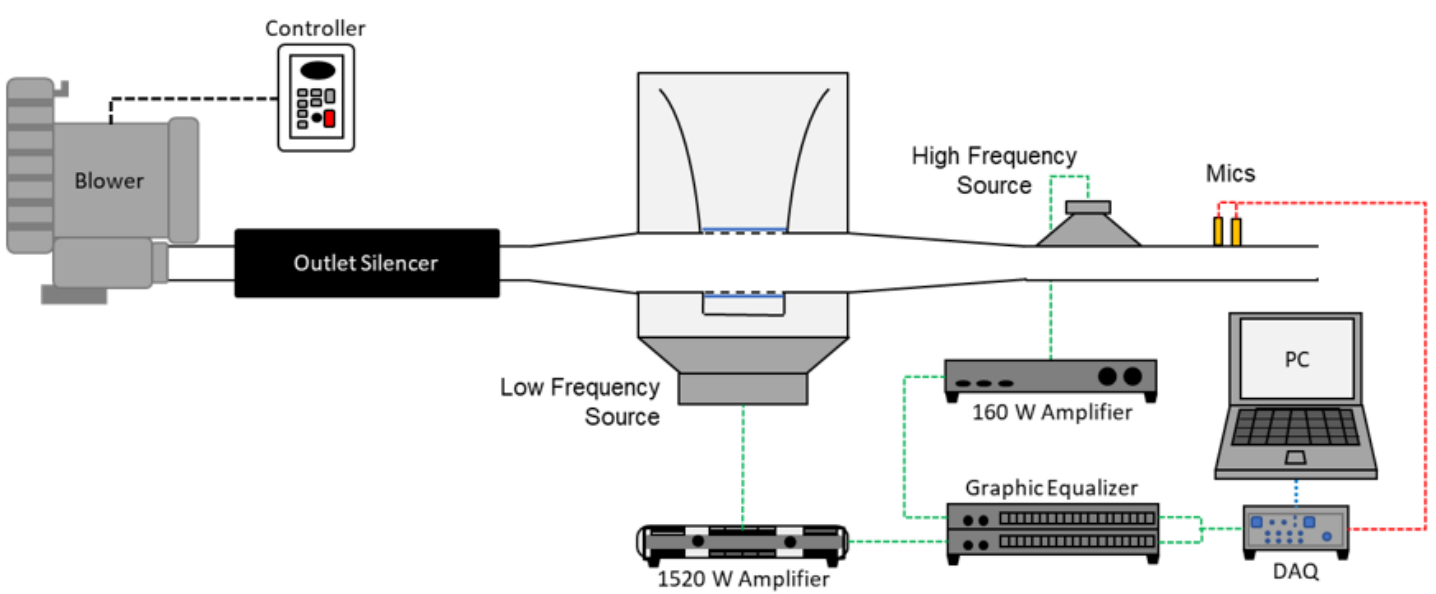

Figure 3.31 Test rig source control

The test rig can generate a broad range of frequency content up to $6000 \mathrm{~Hz}$. Utilization of the rig is straightforward below the plane wave cutoff. A different measurement protocol may be in order to measure above the cutoff frequency and this may be a topic for future research. According to Mason $[45,46]$, the plane wave cutoff frequency with flow is equal to

$$
f_{\text {cutoff }}=\frac{1.84 c}{\pi D_{o}} \sqrt{1-M^{2}}
$$

where $c$ is the speed of sound and $D_{o}$ is the outer diameter of the circular duct. The cutoff frequency for different Mach numbers is shown in Table 3.4. It can be seen that the cutoff frequency is approximately $4000 \mathrm{~Hz}$. The test rig is capable of in duct measurements of impedance to approximately $4500 \mathrm{~Hz}$ using the current microphone spacing of $1.5 "(3.81 \mathrm{~cm})[9,17]$. The microphone spacing is determined by the expression

$$
s \ll \frac{c}{2 f_{u}}
$$

where $s$ is the microphone spacing $(\mathrm{m}), c$ is the speed of sound, and $f_{u}$ is the upper frequency limit. 
Table 3.4 Test rig cutoff frequency

\begin{tabular}{|c|c|}
\hline Mach Number [Ma] & Cutoff Frequency - 2" OD - [Hz] \\
\hline 0 & 3957 \\
\hline 0.05 & 3952 \\
\hline 0.1 & 3936 \\
\hline 0.15 & 3911 \\
\hline
\end{tabular}

\subsubsection{Experimental Methods}

The test rig is flexible enough to permit the use of different methods to obtain the performance metrics: transmission loss, noise reduction, and insertion loss. Measurements can be performed inside or outside of the impedance tube. Measurements inside the tube will be affected by pseudo-sound if flow is present. Measurements of sound power at the outlet can be performed using sound intensity scanning or sampling sound pressure levels on a hemispherical surface. Sound intensity scans in this thesis were performed using ISO 9614-2 [33] on a $0.5 \mathrm{~m}$ cube at the pipe outlet as shown in Figure 3.32. Care should be taken to scan the measurement surfaces evenly.

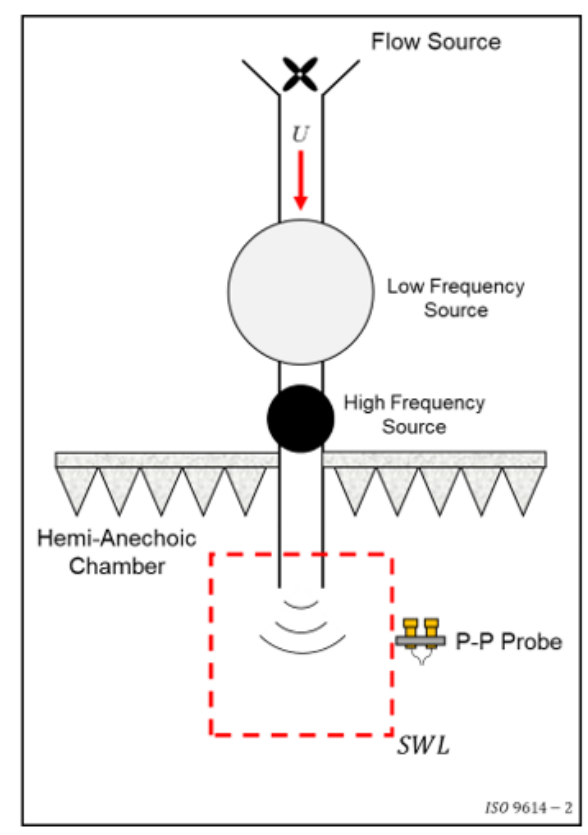

Figure 3.32 Intensity scan used to measure test rig output 
The resulting sound intensity from each side is used to determine the sound power by summing up as expressed in

$$
W_{s}=\sum_{i=1}^{N} \bar{I}_{n} \Delta S_{i}
$$

where $\Delta S_{i}\left(m^{2}\right)$ is the surface area and $\bar{I}_{n}\left(\frac{W}{m^{2}}\right)$ is the normal incident sound intensity. The sound power in $\mathrm{dB}$ can be found using

$$
L_{w}=10 \log _{10} \frac{W_{s}}{W_{\text {ref }}}
$$

where $W_{\text {ref }}$ is $10^{-12}(W)$.

Sound power can be measured another way by using a microphone hemisphere as shown in Figure 3.33. Utilizing six to twelve the sound power level can be measured to engineering accuracy [42]. The average sound pressure level is measured in a free field and then converted to sound power using

$$
L_{w}=\left(\overline{L_{p}}\right)_{\text {source }}+10 \log _{10} S
$$

where $\overline{L_{p}}$ is the average sound pressure level in $\mathrm{dB}$ and $S$ is the surface area of the hemisphere. 


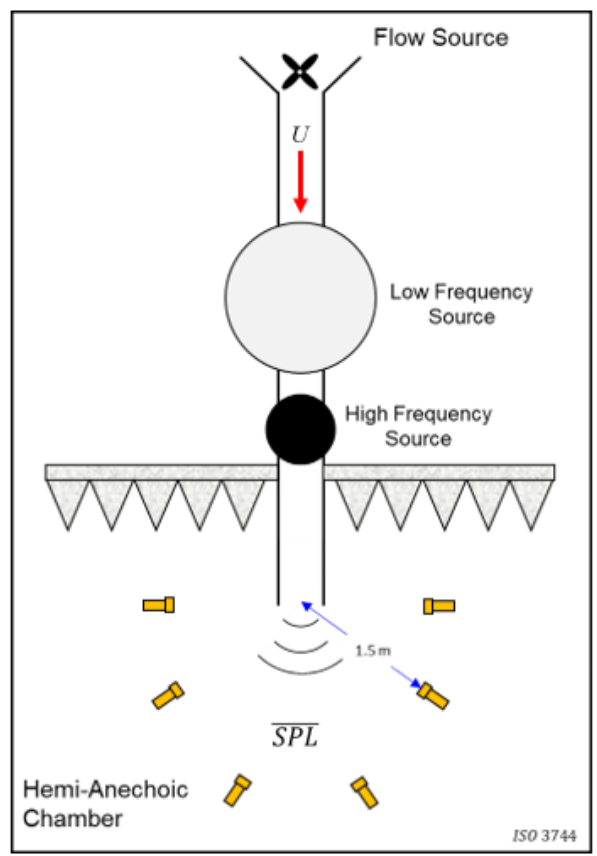

Figure 3.33 Microphone hemisphere to measure test rig output

\subsubsection{Validation Testing}

The equipment including the loudspeaker, compression driver, two amplifiers to power the sources, data acquisition, and sensors is summarized in Table 3.5. The data acquisition system is capable of using white/pink noise, periodic chirp, and swept sine excitation. If swept sine excitation is used, all the energy is concentrated in narrow frequency bands. However, care must be taken to not blow out the drivers. Figure 3.34 shows the sound pressure level measured inside the pipe with a $1 / 4$ inch microphone (PCB model 426B03). Swept sine excitation should be similar to the level of exhaust noise in automotive applications. 
Table 3.5 Equipment used for validation testing

\begin{tabular}{|c|c|}
\hline Equipment & Model Number \\
\hline Subwoofer & JBL 2226H \\
\hline Compression Driver & JBL 2446H \\
\hline Power Amplifier & Behringer NU3000 \\
\hline Power Amplifier & AudioSource Amp100 \\
\hline Graphic Equalizer & Dbx 231 \\
\hline Data Acquisition & Siemens SCADAS Mobile \\
\hline $1 / 2$ inch microphone & PCB 378B11 \\
\hline $1 / 4$ inch microphone & PCB 426B03 \\
\hline
\end{tabular}

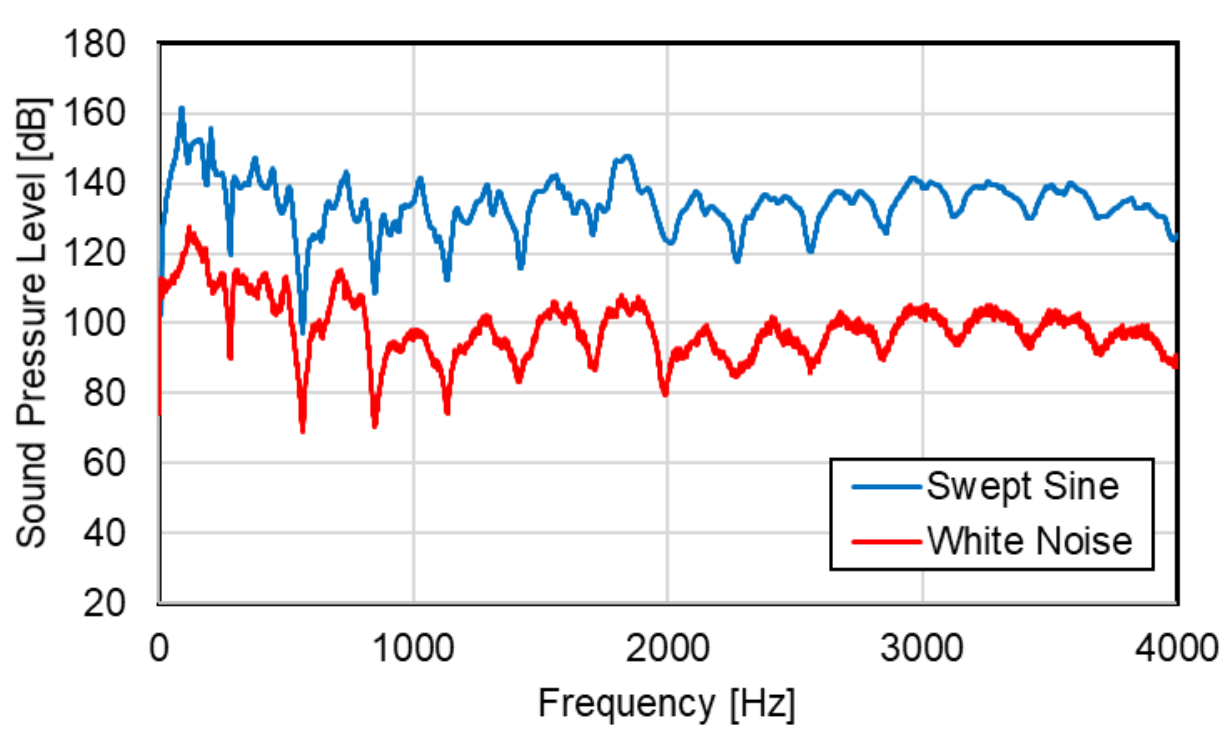

Figure 3.34 Sound pressure level inside the duct

The sound power level was measured at the outlet for swept sine and white noise excitation and compared to the flow noise at $0.15 \mathrm{Ma}$ as shown in Figure 3.35. It can be observed that levels are significantly higher than the flow generated noise except at the very low frequencies. If low frequency measurements are desired, an additional reactive silencer may need to be added to the system. 


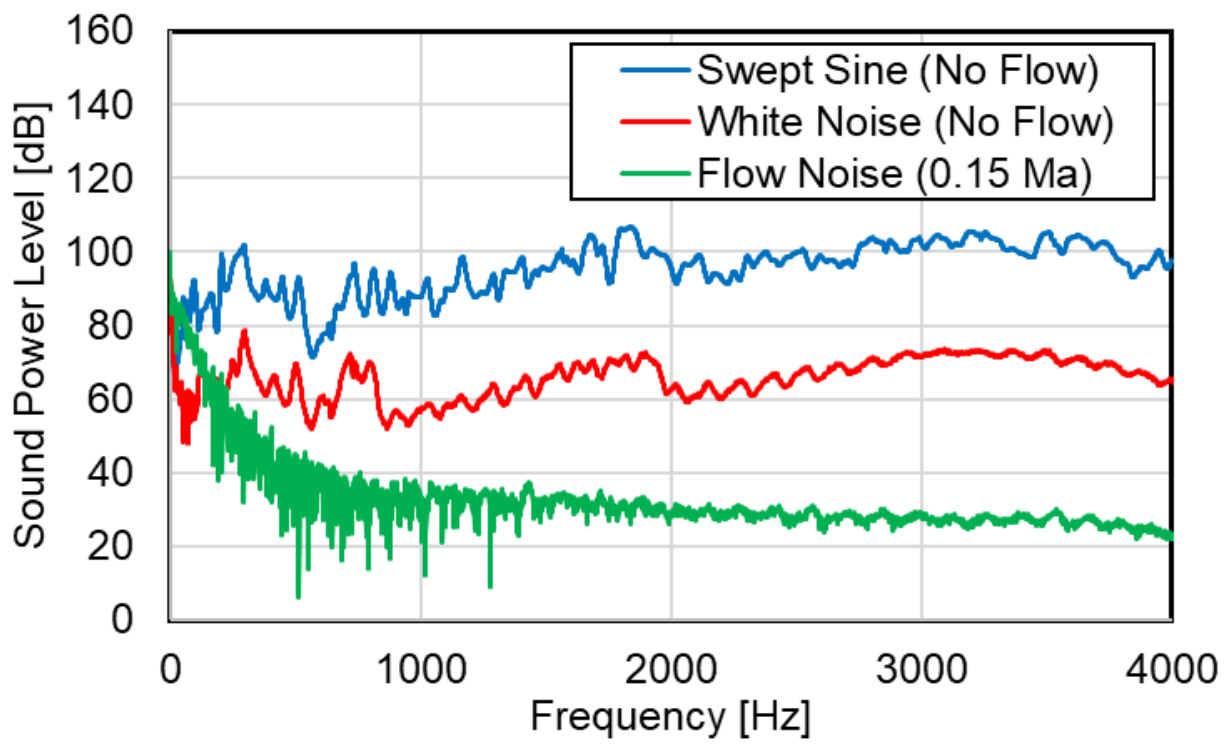

Figure 3.35 Sound power levels of acoustic excitations against flow noise If swept sine excitation is used, broadband sound power levels ranging from 90 to $130 \mathrm{~dB}$ are produced over the frequency range from 30 to $4000 \mathrm{~Hz}$. These levels greatly exceed that of the flow generated noise from the blower. In this study, a $1 \mathrm{~V}$ RMS excitation was used for the sine sweep. These levels are sufficient for many mufflers but may be increased if needed. However, at currently shown levels, this is sufficient for low-performance mufflers. Table 3.6 shows the frequency where swept sine and white noise excitations exceed the flow noise by $15 \mathrm{~dB}$. This is a good indicator of the low frequency cutoff for the rig.

Table 3.6 Low frequency limit defined as when acoustic sources exceed flow noise by $15 \mathrm{~dB}$.

\begin{tabular}{|c|c|c|}
\hline Mach Number & Swept Sine & White Noise \\
\hline 0.05 & $<52 \mathrm{~Hz}$ & $<128 \mathrm{~Hz}$ \\
\hline 0.1 & $<68 \mathrm{~Hz}$ & $<184 \mathrm{~Hz}$ \\
\hline 0.15 & $<84 \mathrm{~Hz}$ & $<240 \mathrm{~Hz}$ \\
\hline
\end{tabular}




\section{CHAPTER 4 TEST RIG QUALIFICATION}

(Note: Some of this research in this chapter is adapted from [28] and [47])

\subsection{Introduction}

The test rig was qualified in a methodical manner. The procedure is summarized in Figure 4.1. Static pressure drop was measured and validated first. This was followed by testing for the acoustic metrics: transmission loss, noise reduction, and insertion loss without flow. Insertion loss was then measured with flow for a couple of examples. The predicted metrics are determined using one-dimensional acoustic models. Additional factors are tested at each test stage as illustrated in Figure 4.1. System effects like termination and source impedance are included in the later tests. A hard-straight duct of a constant cross-sectional area is used as the first qualification case where transmission loss without flow and insertion loss are measured. An expansion chamber muffler was used as the last qualification case.

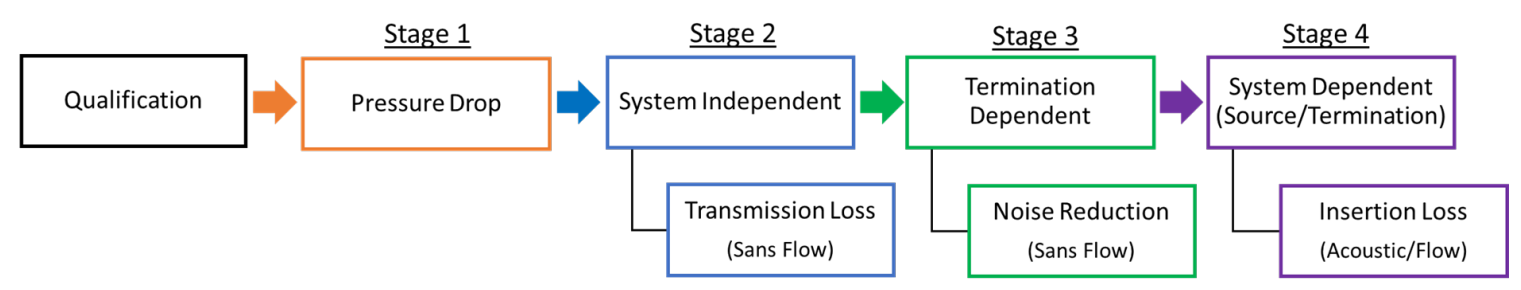

Figure 4.1 Test fixture qualification process

\subsection{Pressure Drop Qualification}

Pressure drop measurements were performed on two cases that are easily checked via theory. Measurements were compared to simulated and theoretical models. The first validation case is for a conical adapter. The one-dimensional software SIDLAB [40] was used to predict the pressure drop across the element and Bernoulli's equation calculations (See Section 3.2.1) are also shown for comparison purposes. The results show that predicted values compare well to measurement for different Mach numbers. Theoretical models were done using equation (3-3) where Bernoulli's equation was used. Dynamic losses in the conical 
section were ignored because the area change is gradual, and the reducer angle is under 7 degrees. Measured pressure drop results are compared to SIDLAB and theory for different Mach numbers in Figure 4.3 with good agreement. The increased outlet length will allow for the pressure to stabilize. The SIDLAB model matches the experimental setup.

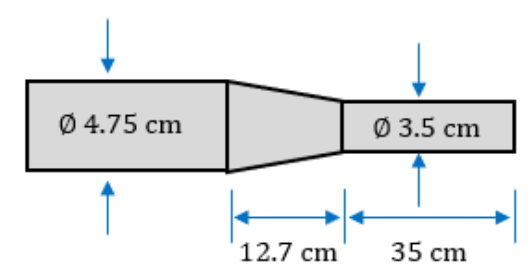

Figure 4.2 Reduced area qualification case

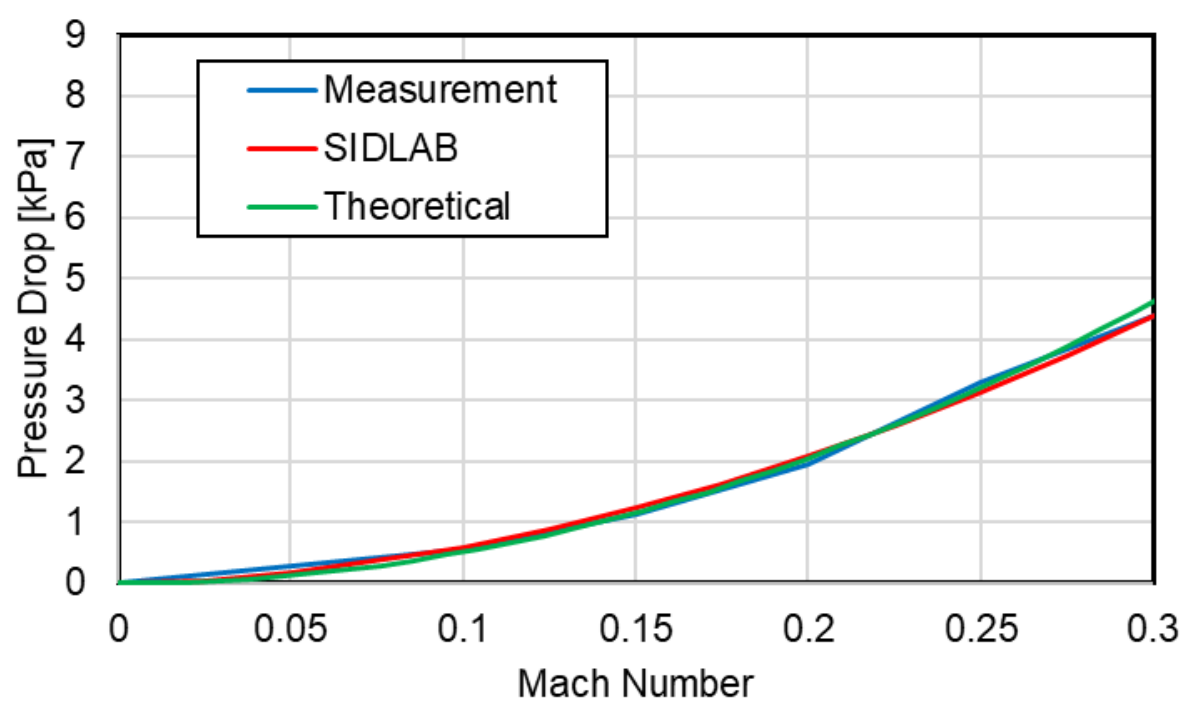

Figure 4.3 Area change pressure drop

The second example is a simple expansion chamber. SIDLAB was used to predict the pressure drop and predictions are compared with measurement for different Mach numbers. Measured and predicted values of pressure drop compare well with some minor deviation at the higher flow rates. Pressure drop measurements were capped at approximately $0.28 \mathrm{Ma}$. 


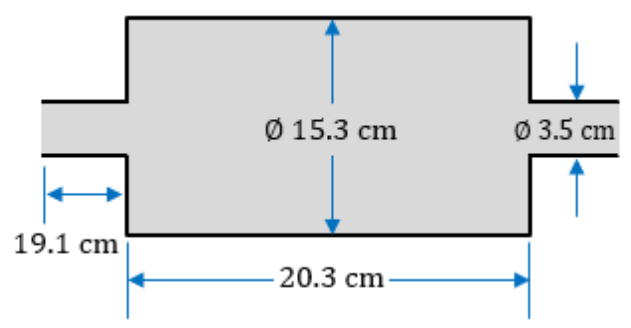

Figure 4.4 Open expansion chamber test case

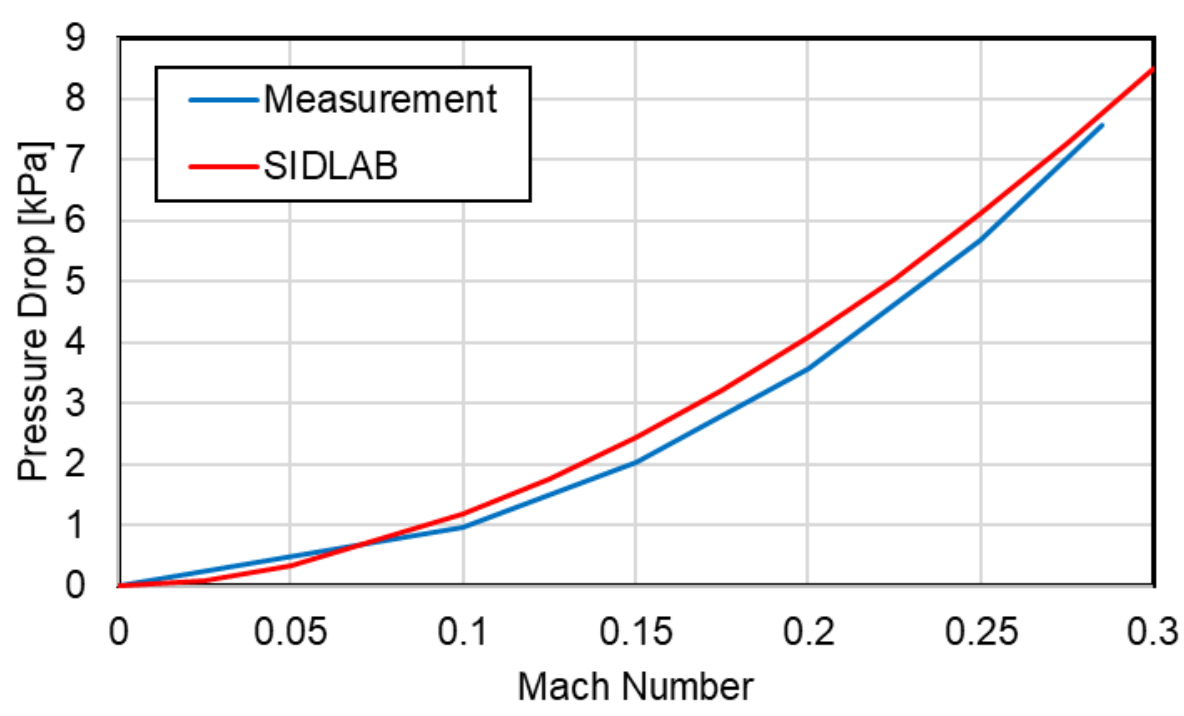

Figure 4.5 Open expansion chamber pressure drop

\subsection{Open Pipe Termination - Transmission Loss Qualification (Sans Flow)}

Transmission loss is defined as the difference between incident and transmitted acoustic powers in dB. Since transmission loss is a system independent metric, these measurements can be replicated in any system. Two examples are considered: an open pipe termination and a simple expansion chamber.

For the open pipe, transmission loss is defined as the difference between incident sound power in the pipe and radiated sound power. The attenuation at the opening is a result of an impedance change. The theoretical transmission loss is classically defined as

$$
T L(d B)=10 \log _{10}\left|\frac{1}{\tau}\right|
$$


where $\tau$ is the transmission coefficient. Kinsler et al. [48] defined the sound power transmission coefficient for an open termination as

$$
\tau=1-\left|\frac{Z_{T} / \rho c S-1}{z_{T} / \rho c S+1}\right|^{2}
$$

where $z_{T}$ is defined as the radiation impedance from the duct outlet. The termination impedance of an unflanged open pipe without flow per Levine and Schwinger [49] is

$$
\begin{gathered}
z_{T}=\left[\frac{1}{4}(k a)^{2}+j k \delta_{0}\right]^{\rho c} / S \\
\delta_{0}=0.6133 a
\end{gathered}
$$

where $k$ is the wave number, $a$ is the radius of the pipe, and $S$ is the cross-sectional area. Termination impedance was measured by the two-microphone method and checked against the theory. It was found that the impedance compared well with theory except at high frequencies. Theoretical values are used for the calculation. By plugging Equation (4-3) into (4-2), the sound power transmission coefficient can be expressed as

$$
\tau=\frac{(k a)^{2}}{\left[1+\frac{1}{4}(k a)^{2}\right]^{2}+(0.6 k a)^{2}}
$$

where $k$ is the wave number, and $a$ is the radius of the pipe.

The transmission loss is measured by using wave decomposition to determine the incident power as seen in Equation (2-13) and the transmitted power via a sound intensity scan (ISO 9614-2 [33]). Using Equation (2-12), the measured transmission loss is found. The experimental setup is shown in Figure 4.6. Microphone 1 is positioned 11.25 " $(28.6 \mathrm{~cm})$ from the termination with a spacing of $1.5 "(3.81 \mathrm{~cm})$ from the Microphone 2 . The measured and theoretical 
transmission loss are compared in Figure 4.7. There are a few pipe resonances below $700 \mathrm{~Hz}$ but the correlation is excellent above $700 \mathrm{~Hz}$. It was confirmed that the resonances were indeed pipe resonances by increasing the length of the pipe and noting that the peaks shifted lower in frequency.

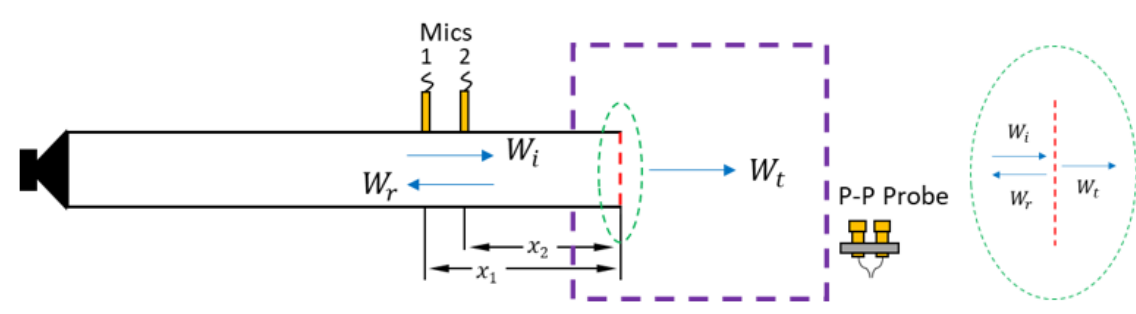

Figure 4.6 Transmission loss measurement of an open termination

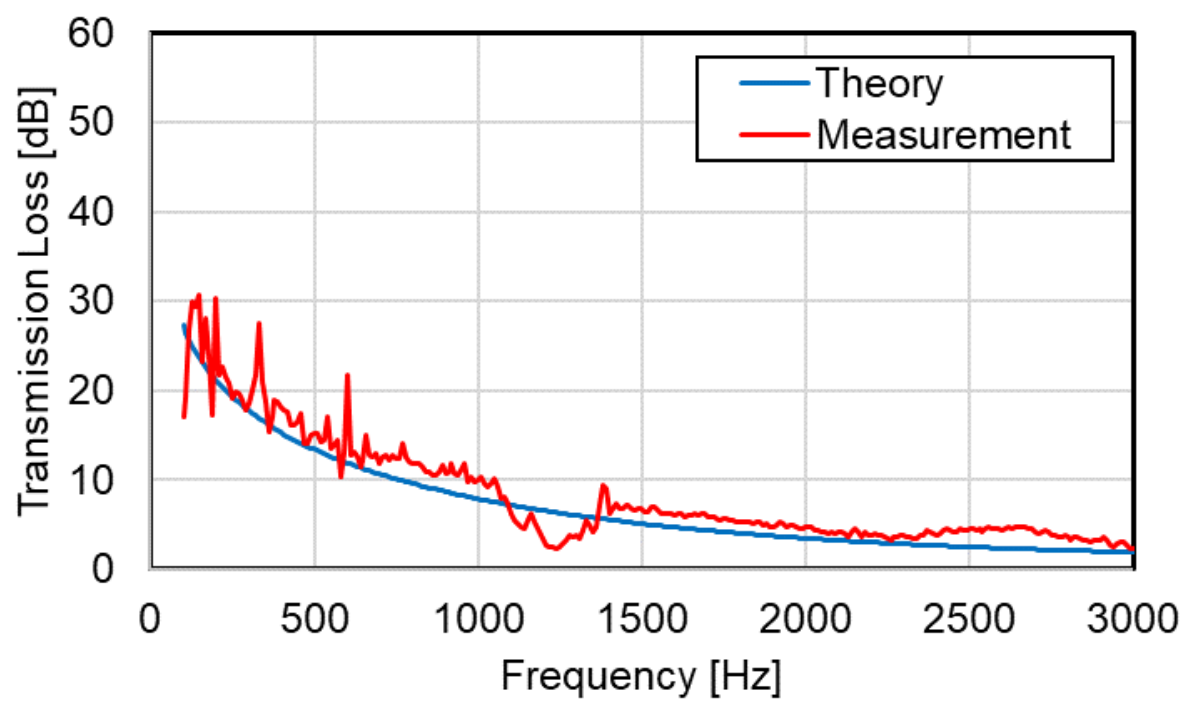

Figure 4.7 Open termination transmission loss

\subsection{Traditional Transmission Loss Qualification (Sans Flow)}

Using methods from Section 2.1.2, the traditional two-load method [17] was then used to assess the transmission loss for the expansion chamber muffler shown in Figure 4.8. Measurements were without flow, and the two acoustic loads were a rigid and sound absorbing termination. Long conical transitions were attached on either side and should only affect the transmission loss at very low frequencies. 
The inner diameter was $6.035 "(15.3 \mathrm{~cm})$ with a length of 8" $(20.3 \mathrm{~cm})$. Measured and predicted transmission loss correlates well above $200 \mathrm{~Hz}$.

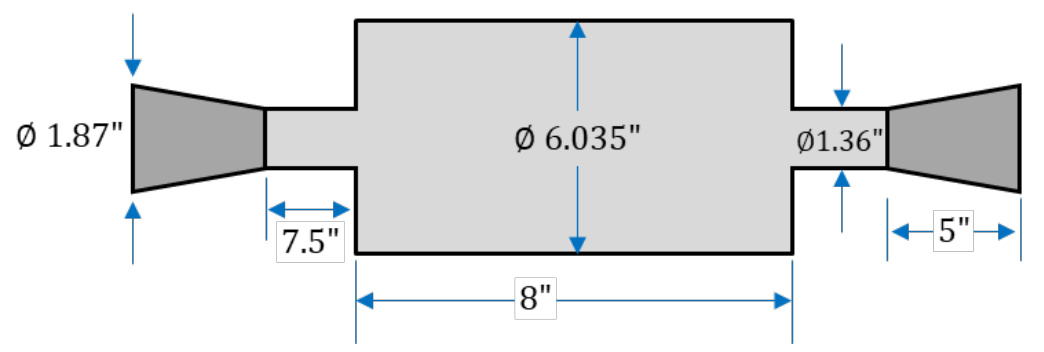

Figure 4.8 Transmission loss expansion chamber test case

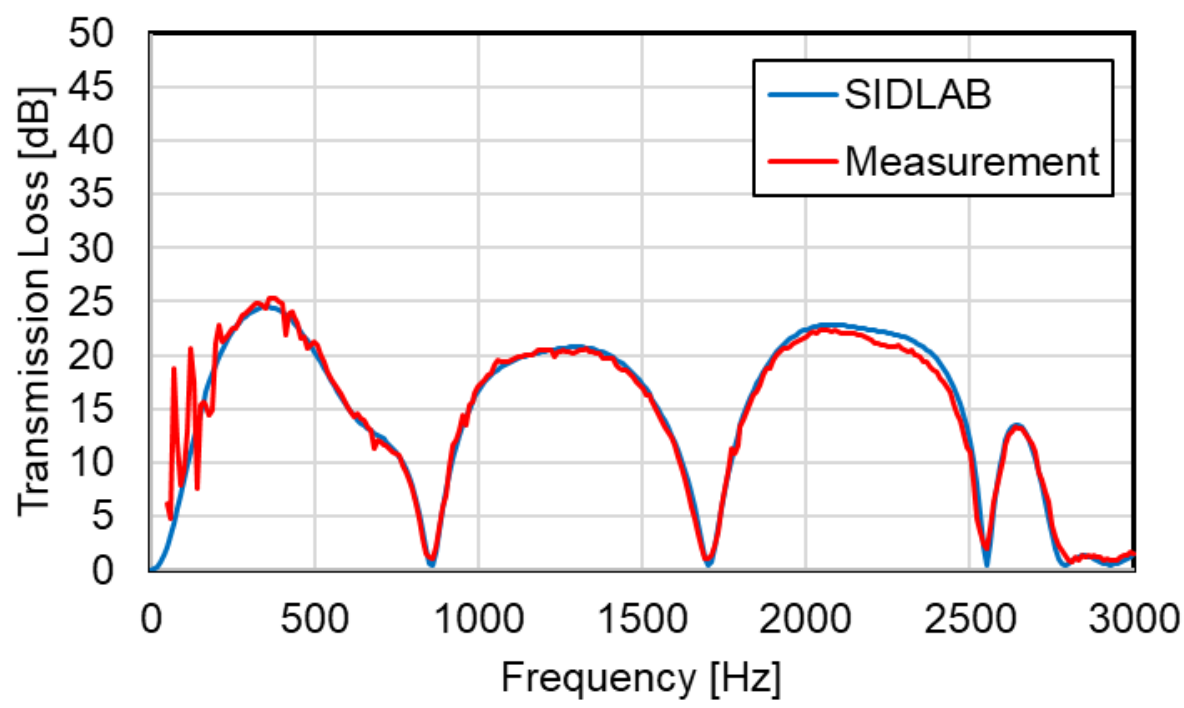

Figure 4.9 Open expansion chamber transmission loss

\subsection{Noise Reduction Qualification (Sans Flow)}

The next qualification stage is to determine noise reduction which is defined as the difference in sound pressure levels upstream and downstream of the attenuating element. Noise reduction is independent of the source but will include the effect of termination or load impedance as shown in Equation (2-30). Figure 4.10 shows a schematic for the measurement of load impedance using the two-microphone method. The load impedance can either be measured by using the twomicrophone method or using plane wave theory. The first approach is used for this study though correlation should be similar if plane wave theory is used. The 
real and imaginary parts of the measured normalized impedance are shown in Figure 4.11.

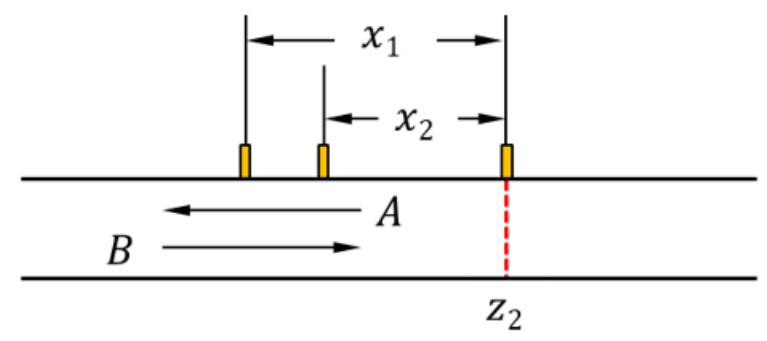

Figure 4.10 Two-microphone method to measure load impedance at location 2

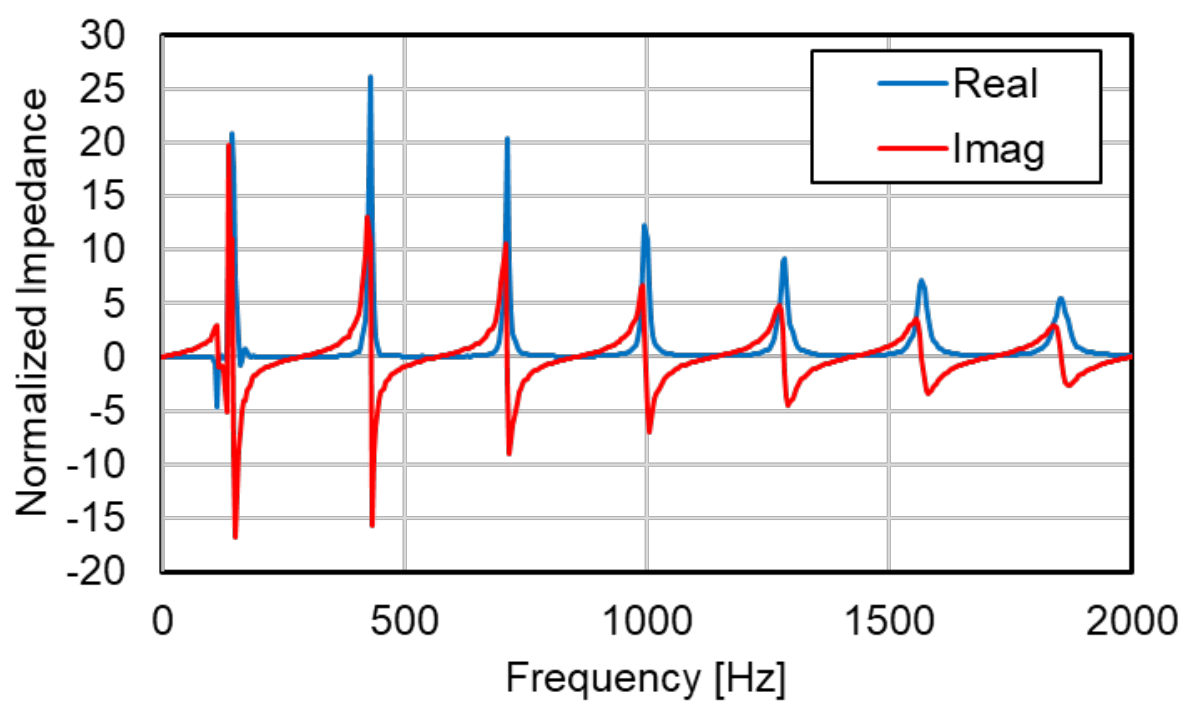

Figure 4.11 Measured load impedance at microphone 2

The noise reduction was computed for the system shown in Figure 4.12. Three cases were considered including a) no perforate element (i.e., open expansion chamber), b) $45.3 \%$ porosity perforate, and c) $3.3 \%$ porosity perforate. The length from Location 2 (See Figure 4.12) to the termination is 11.25 " $(28.6 \mathrm{~cm})$. Measured and predicted noise reductions are compared for cases a), b), and c) in Figures $4.13,4.14$, and 4.15 respectively. Correlation is good up to and above $1000 \mathrm{~Hz}$ in each case. 


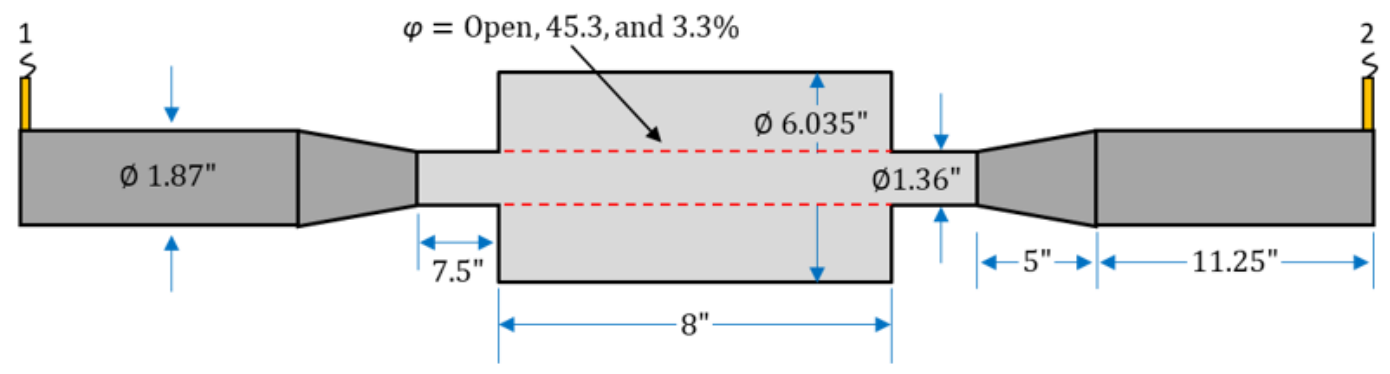

Figure 4.12 Muffler noise reduction test cases

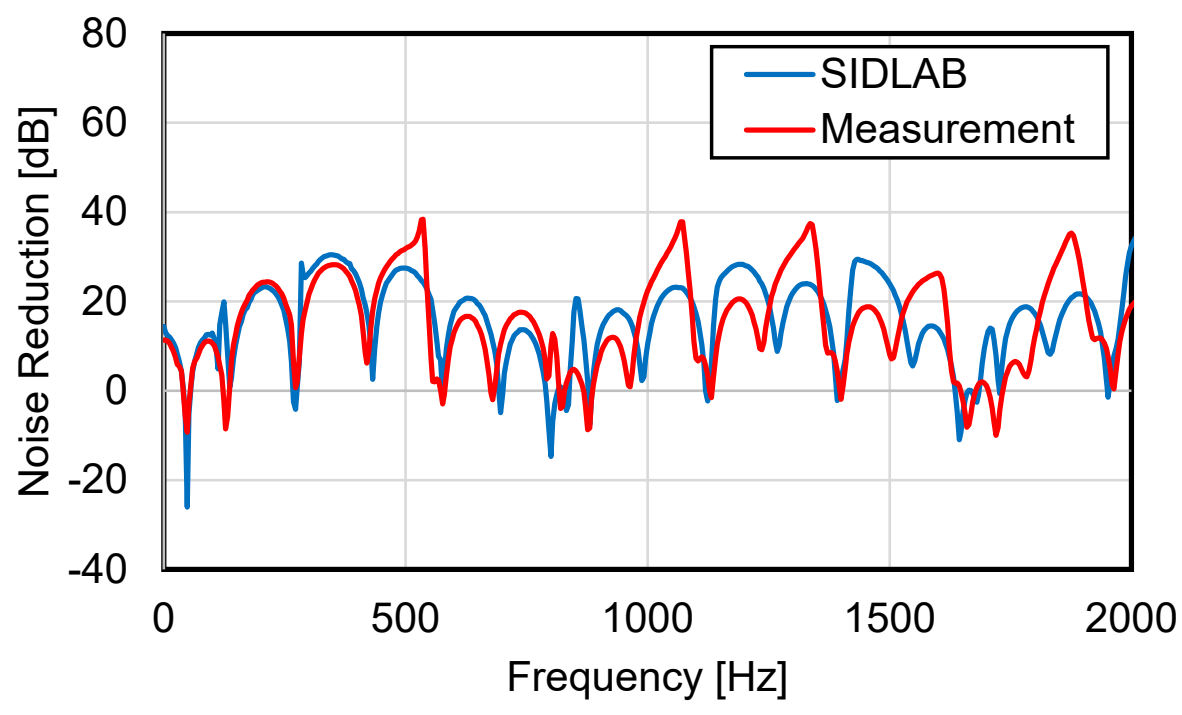

Figure 4.13 Open expansion chamber noise reduction

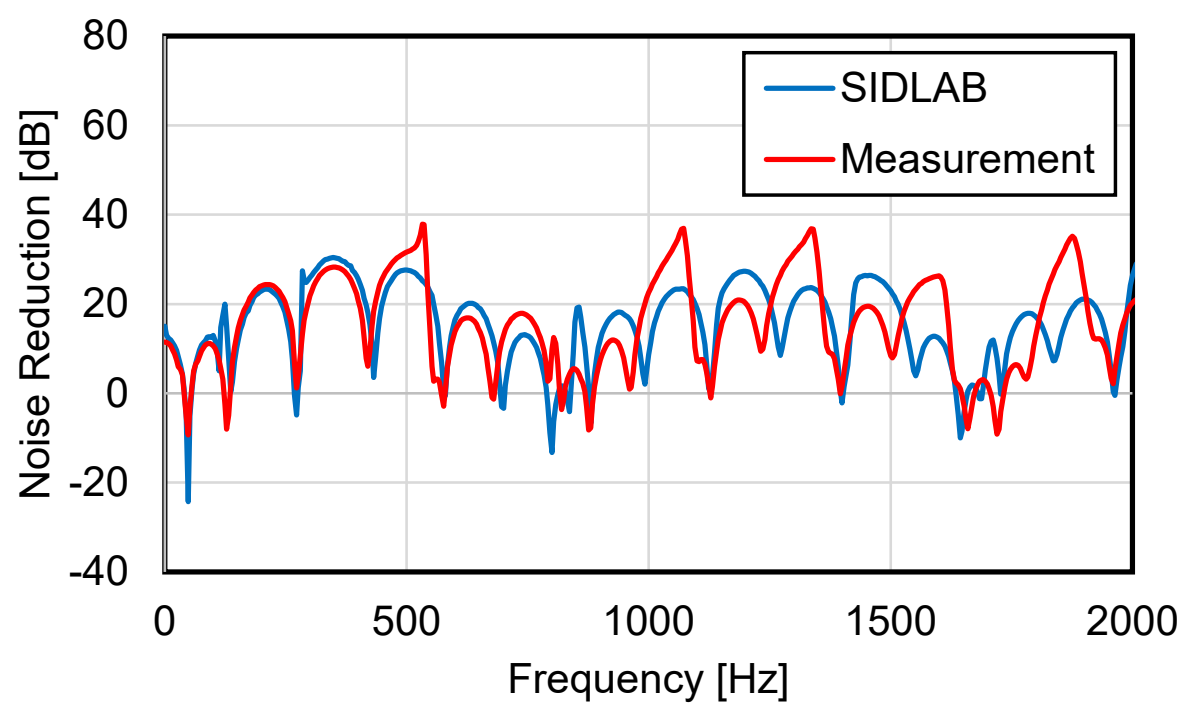

Figure $4.14\{45.3 \%\}$ Expansion chamber noise reduction 


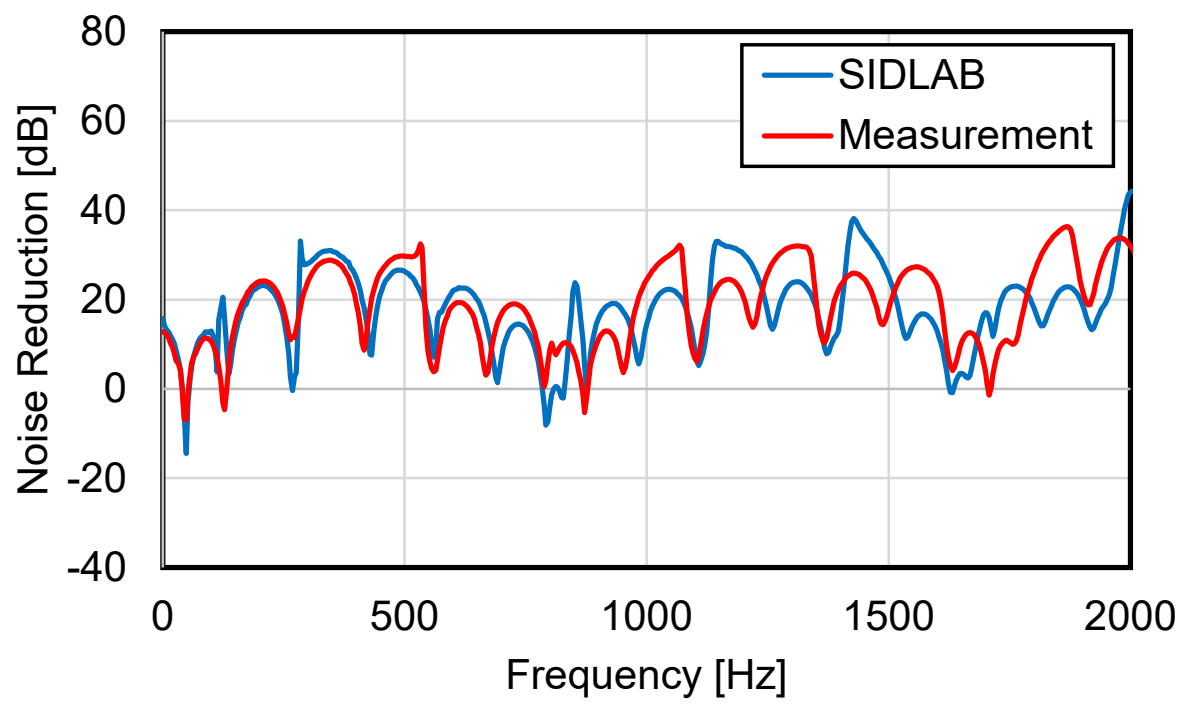

Figure $4.15\{3.3 \%\}$ Perforated expansion chamber noise reduction

\subsection{Insertion Loss Qualification}

The last qualification is the comparison of measured and predicted insertion loss with and without flow. Mean flow typically reduces the absorption of the open termination and impacts muffler behavior. Muffler components such as perforates can improve attenuation with flow. An expansion chamber case seen in Bies et al. [5] illustrated that flow can damp muffler resonances. This flow effect will be noted in the results.

Insertion loss was determined by measuring the sound power without and with the attenuating element in place. Sound power was estimated using 8 microphones positioned outside the flow around the end of the pipe. Theoretical predictions of insertion loss depend on the transfer matrix for the muffler system as well as the termination and source impedances. The initial qualification case is an expansion chamber with an inlet diameter of 1.36 " $(3.5 \mathrm{~cm})$ resulting in a maximum Mach number of 0.3 .

\subsubsection{Source Impedance}

Insertion loss is hard to predict due to the challenges of characterizing the source. Unlike termination impedance, very few empirical models exist. Source impedance 
relates to how much acoustic energy is absorbed and reflected back by the source. Source impedance is described using plane wave theory as detailed earlier in Section 2.1.1.1. Sound waves will travel away from the source, and the attenuating element reflects a portion of the energy back towards the source. The source will absorb a portion of the reflected sound waves and then reflect again. This loop will influence the level of energy the attenuating element will see and therefore influence its insertion loss [11].

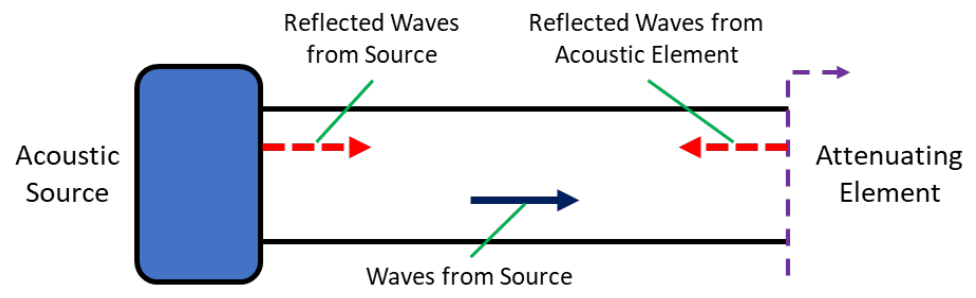

Figure 4.16 Sound wave behavior inside a duct of a generic source

Source impedance is often difficult to measure due to harsh operating conditions in systems like internal combustion engines. Three different methods of measuring source impedance through direct and indirect methods were described in Section 2.1.1.1. In this research, source impedance for the rig was measured directly by placing a more powerful source downstream. A compression driver was used as the source and the source impedance was measured from the end of the rig. Source impedance was calculated using wave decomposition as described in the ASTM E1050 [9]. The source and measurement schematic are shown in Figure 4.17. The effect of turning the blower on was assumed to be negligible in the hope that the flow silencer should dominate the source impedance. Measurements without flow are much easier and do not have pseudo noise present. The real and imaginary parts of the normalized source impedance are shown in Figure 4.18. From the source impedance, the source absorption was calculated (See ASTM E1050 [9]) and is shown in Figure 4.19. Note that the source is highly absorbing above $200 \mathrm{~Hz}$. 


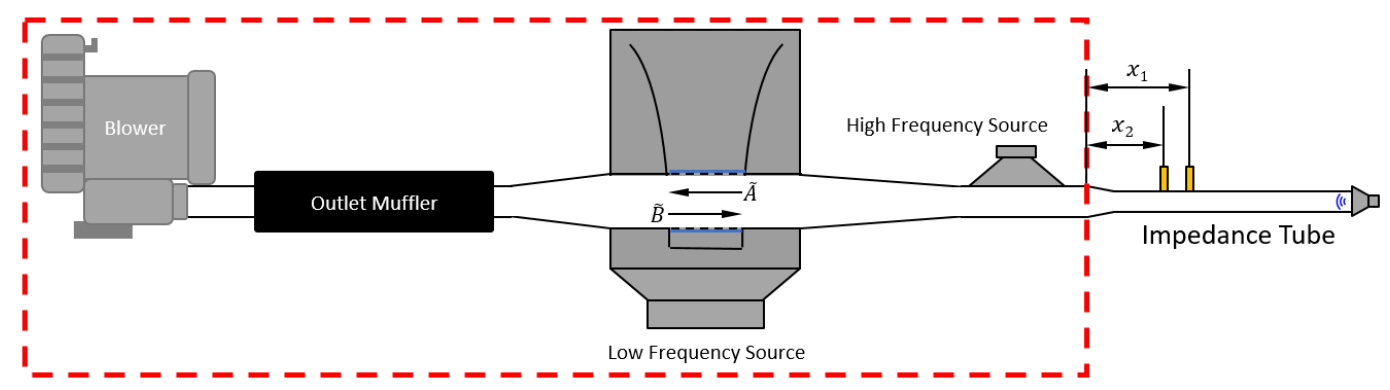

Figure 4.17 Source impedance measurement setup

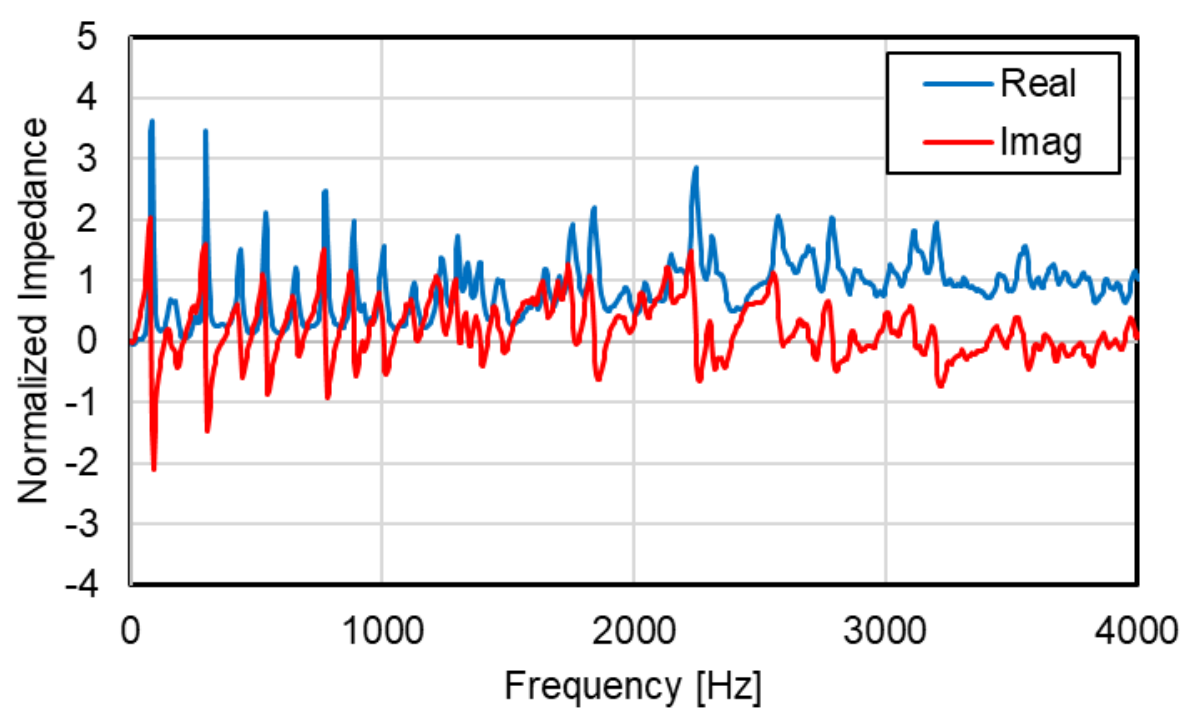

Figure 4.18 Test rig normalized source impedance

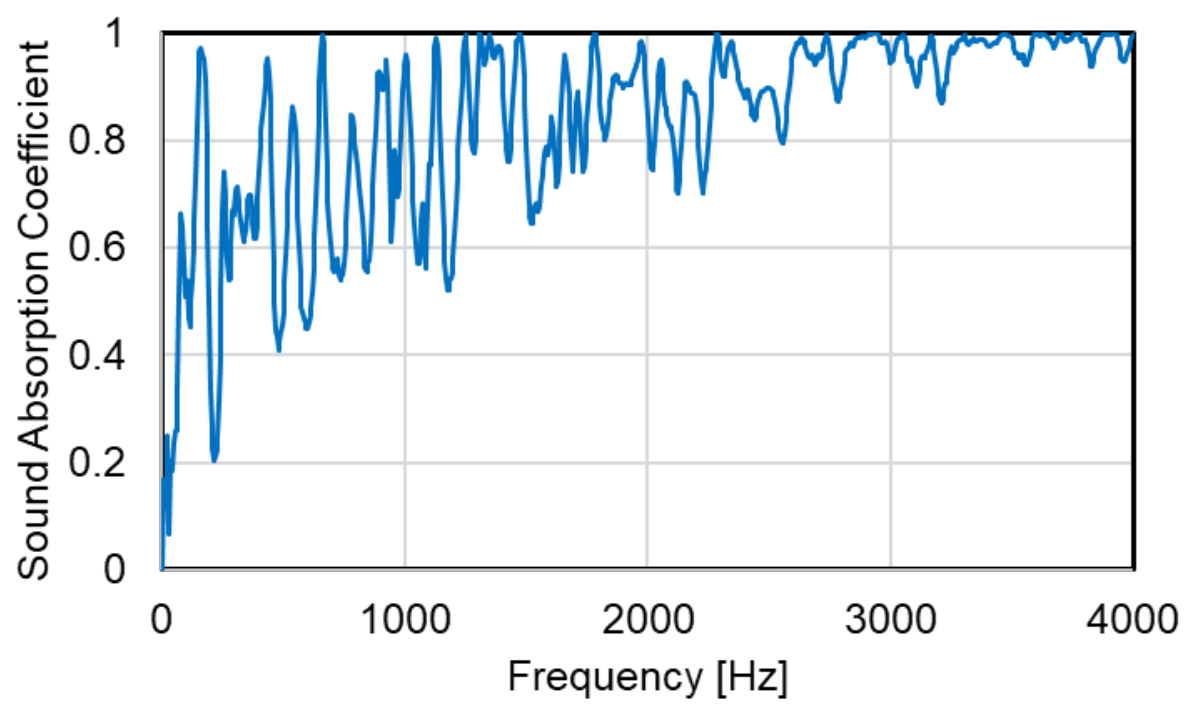

Figure 4.19 Test rig sound absorption based on the source impedance 


\subsubsection{Termination Impedance with Flow}

There is a sudden change in the area at the pipe opening, and the wave will be reflected back as a result. This change in the area can be mathematically characterized as radiation (or termination) impedance. This impedance is necessary for insertion loss prediction. Several researchers [24, 49, 50, 51] have investigated the effect of flow on the radiation impedance. Carrier [50,51] modified the Levine and Schwinger [49] theoretical equation by exchanging the $k a$ with $k a \sqrt{1-M^{2}}$. However, this equation small disturbances and lossless flow [51]. The termination impedance can be expressed as

$$
\begin{gathered}
z_{\text {Carrier }}=\left[\frac{1}{4}\left(k a \sqrt{1-M^{2}}\right)^{2}+j k \delta_{0}\right] \rho c / S \\
\delta_{0}=0.6133 \mathrm{a}
\end{gathered}
$$

Alfredson and Davies [24] measured the effect of flow in engine exhaust and observed the reflection coefficient increased by a factor of $1+2 M$ with no change in phase. Panicker and Munjal [51] developed empirical for Mach numbers under 0.25 at ambient temperature. They concluded that the phase is relatively unaffected in agreement with Alfredson and Davies, and that the imaginary part of the impedance does not change as a function of flow. However, the same cannot be said of the real part of the reflection coefficient

$$
\begin{aligned}
& R(M)=R_{0}(\text { Real })+X(\text { Imag }) \\
& R_{0}(\mathrm{M})=\mathrm{R}-2 M^{2} ; X(M)=X
\end{aligned}
$$

where $R(M)$ is the reflection coefficient with flow, $R_{0}(M)$ is the real part of the reflection coefficient with flow, $X(M)$ is the imaginary part of the reflection coefficient with flow, and $M$ is the Mach number [51]. The termination impedance can be calculated from the reflection coefficient using Equation (2-6).

Theoretical and flow empirical formulas were used to find the termination impedance of the rig and qualification muffler. The flow is steady with small deviations from the room temperature. Mean flow decreases the low frequency 
sound absorption as seen in Figures 4.20 and 4.21. The termination impedance is dependent on the diameter of the pipe where qualification muffler outlet has a smaller diameter as seen in Figure 4.21.

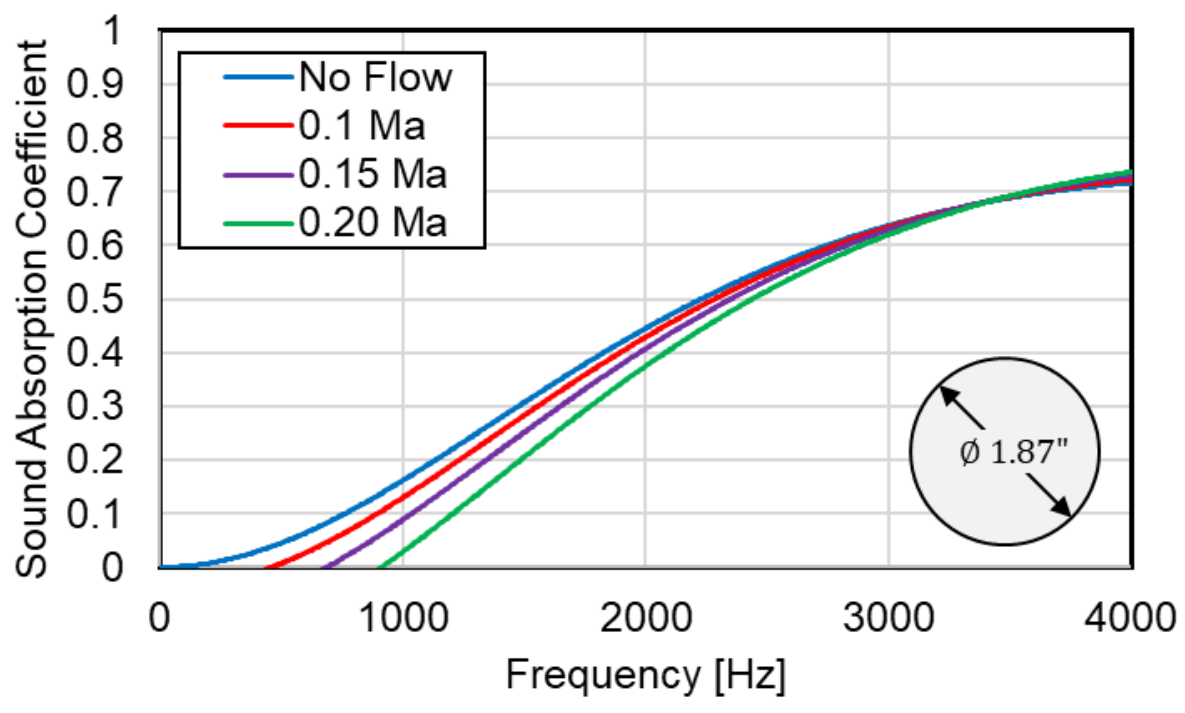

Figure 4.20 Test rig termination impedance with flow

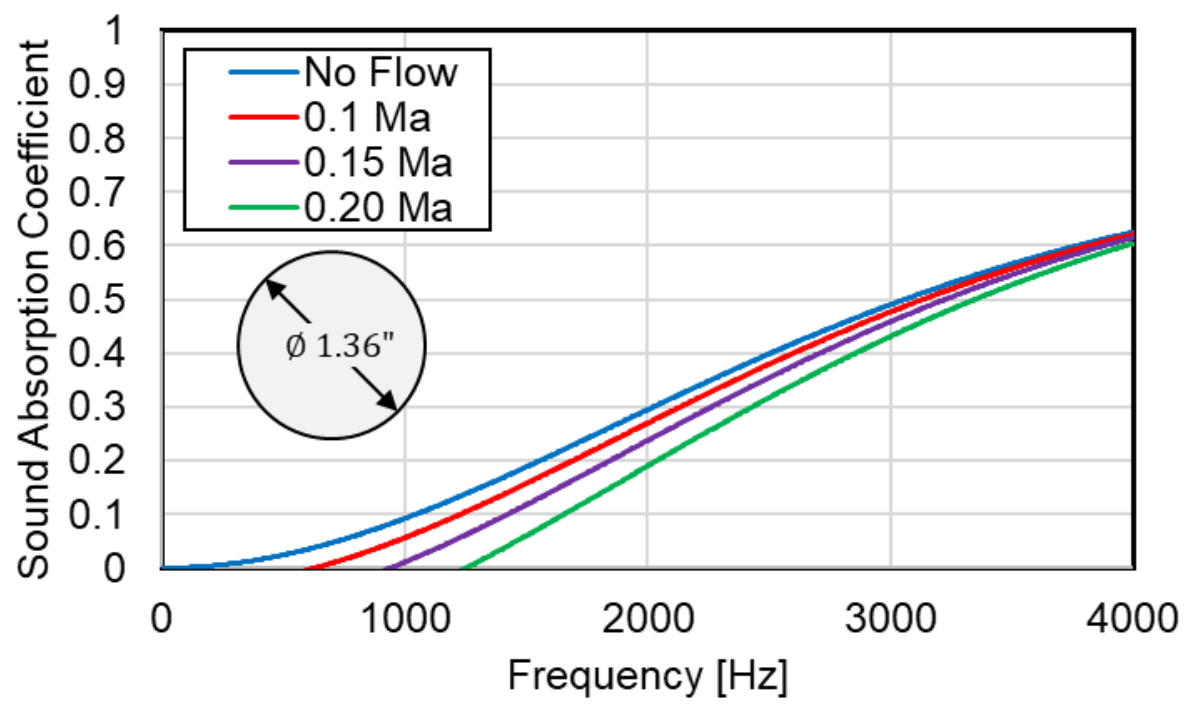

Figure 4.21 Expansion chamber termination impedance with flow 


\subsubsection{Qualification Cases}

The insertion loss was predicted and measured for several test mufflers. The base muffler considered is a simple expansion chamber. Variations of the same expansion chamber were tested by running various perforated pipes between the inlet and outlet of the chamber. As shown in Figure 4.23, the muffler had an inner diameter of $6.035 "(15.3 \mathrm{~cm})$ and a length of $8 "(20.3 \mathrm{~cm})$. Theoretical predictions of the insertion loss depend on the transfer matrix for the muffler system as well as the termination and source impedances. These quantities were input into the one-dimensional plane wave software SIDLAB for insertion loss prediction. Flow generated noise is ignored in this simulation. Sound power was estimated using 8 microphones positioned on a hemisphere outside the flow surrounding the end of the pipe. Flow rates tested were $0.1 \mathrm{Ma}, 0.15 \mathrm{Ma}$, and $0.2 \mathrm{Ma}$. Operating temperatures were approximately $3^{\circ} \mathrm{C}$ above room temperature, so temperature effects are negligible.

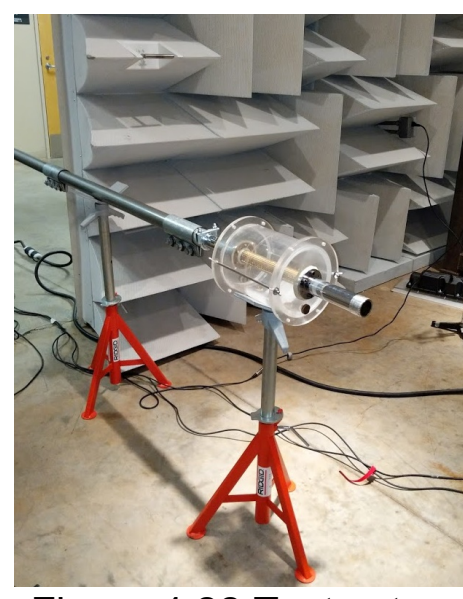

Figure 4.22 Test setup

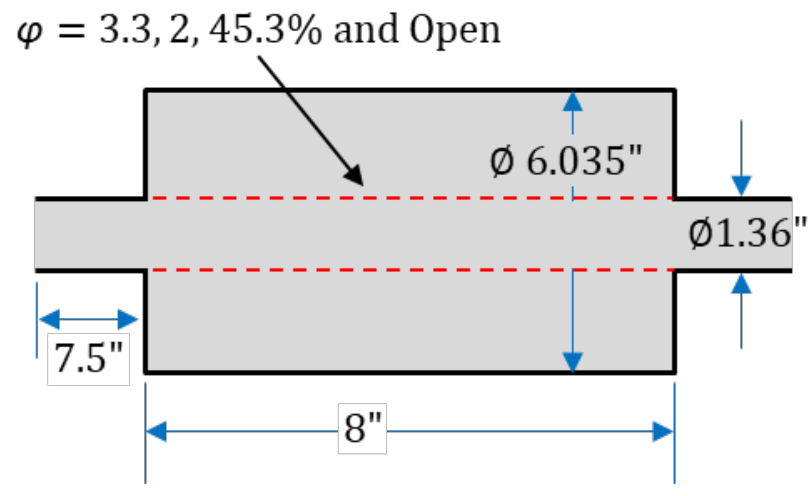

Figure 4.23 Expansion chamber muffler cases

The first case consisted of an open expansion chamber where insertion loss sans flow and a mean flow of 0.1 Ma were considered. The expansion chamber muffler used in the prior test cases was used again. Predicted and measured values are compared in Figure 4.24 and 4.25 for no flow and 0.1 Ma respectively. Results compare well except for some variation at low frequencies. These differences are likely due to errors in the measurement of source impedance, but this will need to 
be confirmed via further testing. This trend is reflected in the rest of the expansion chamber test cases. Note that the effect of flow is minimal on muffler performance in this example.

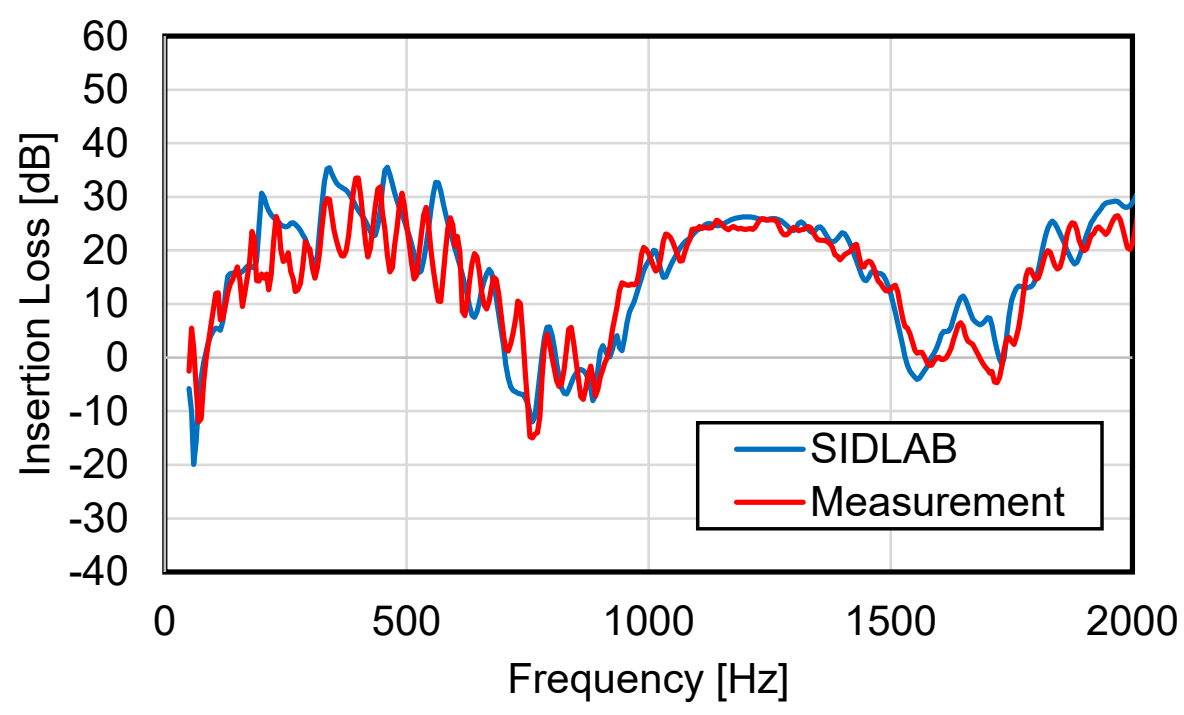

Figure 4.24 Acoustic insertion loss for an open expansion chamber

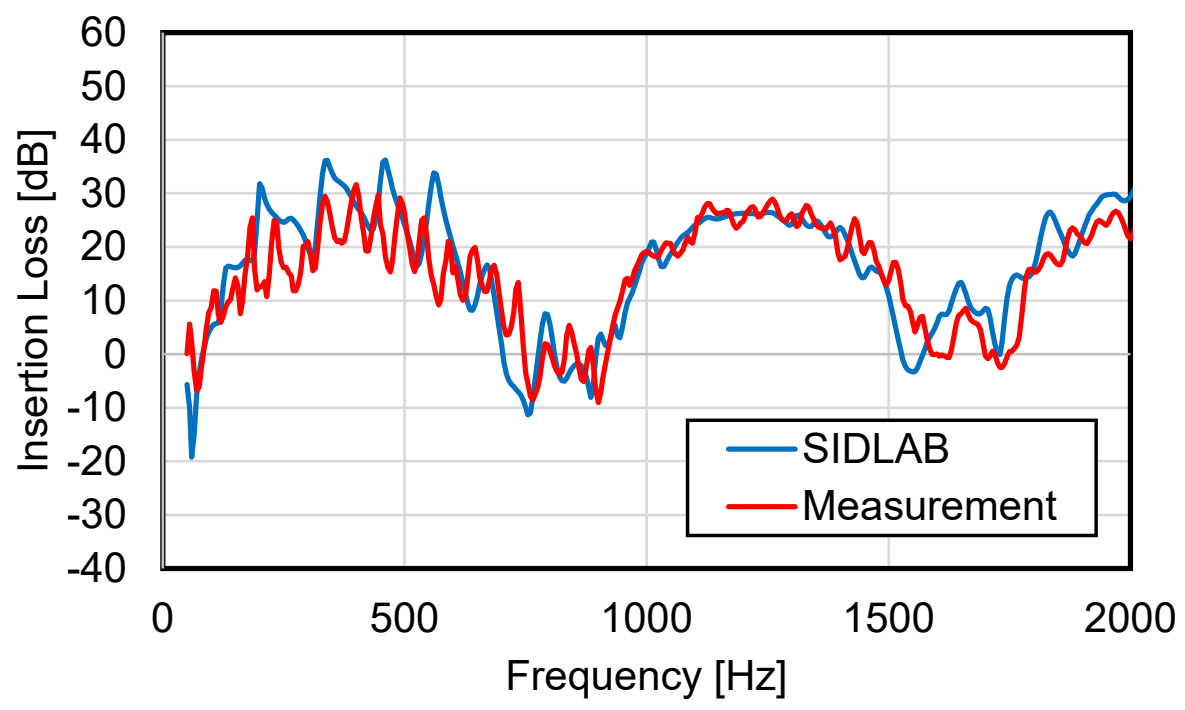

Figure 4.25 Insertion loss for an expansion chamber with $0.1 \mathrm{Ma}$ flow

The second case, a $3.3 \%$ perforated expansion chamber muffler, was tested. The muffler was selected since flow generated noise is low. The predicted and experimental insertion loss are compared without flow and showed acceptable 
agreement. There are some deviations at higher frequencies with flow rates of 0.15 and $0.2 \mathrm{Ma}$ correlation is still acceptable. The behavior follows the trend expressed by Bies et. al [5] where troughs are smoothed with increasing flow.

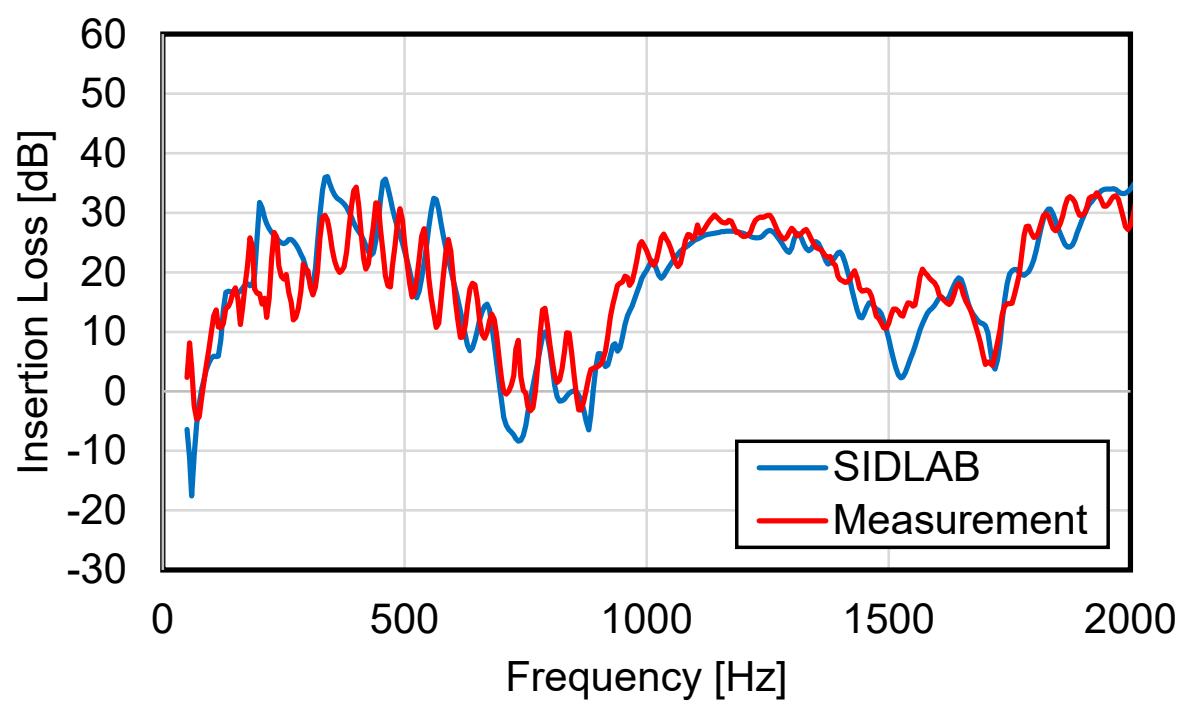

Figure $4.26\{3.3 \%\}$ Expansion chamber insertion loss

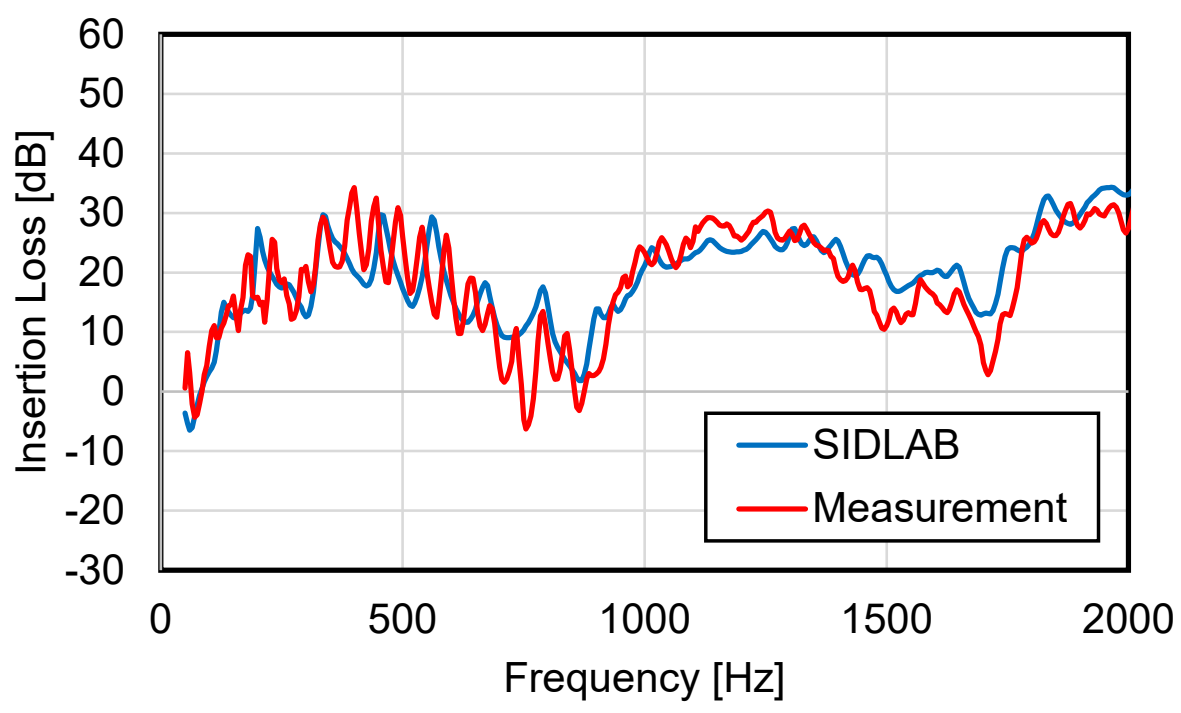

Figure 4.27 \{3.3\%\} Expansion chamber insertion loss with 0.1 Ma mean flow 


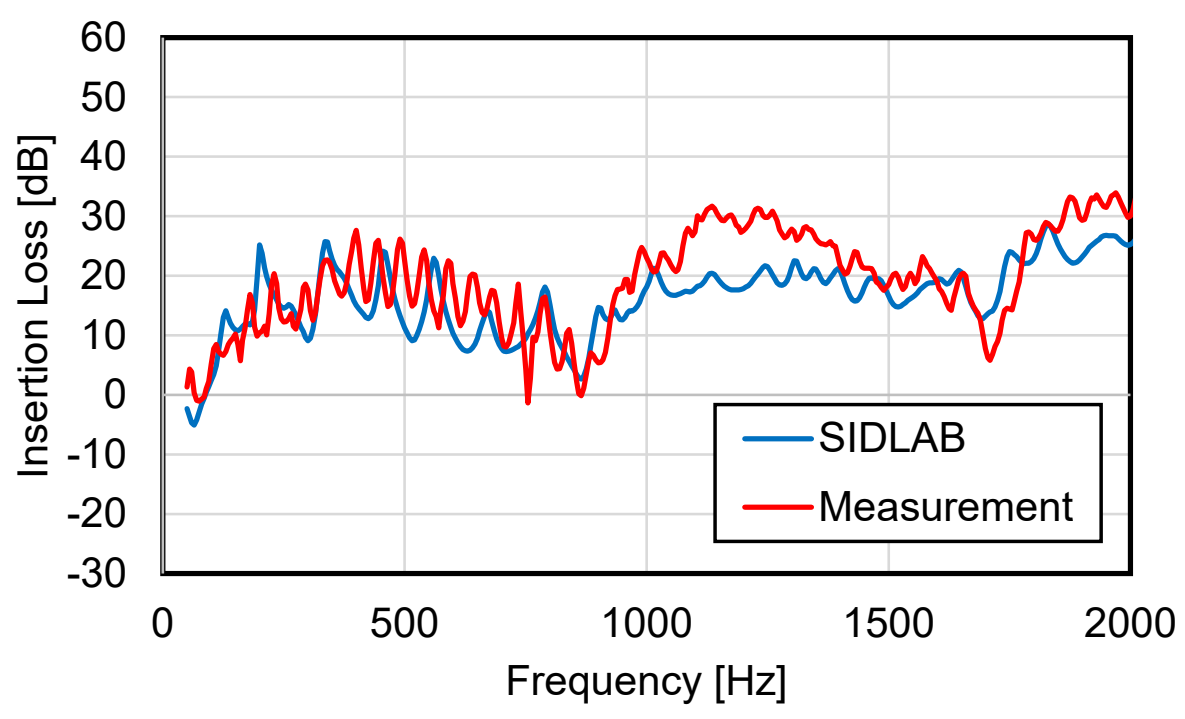

Figure $4.28\{3.3 \%\}$ Expansion chamber insertion loss with 0.15 Ma mean flow

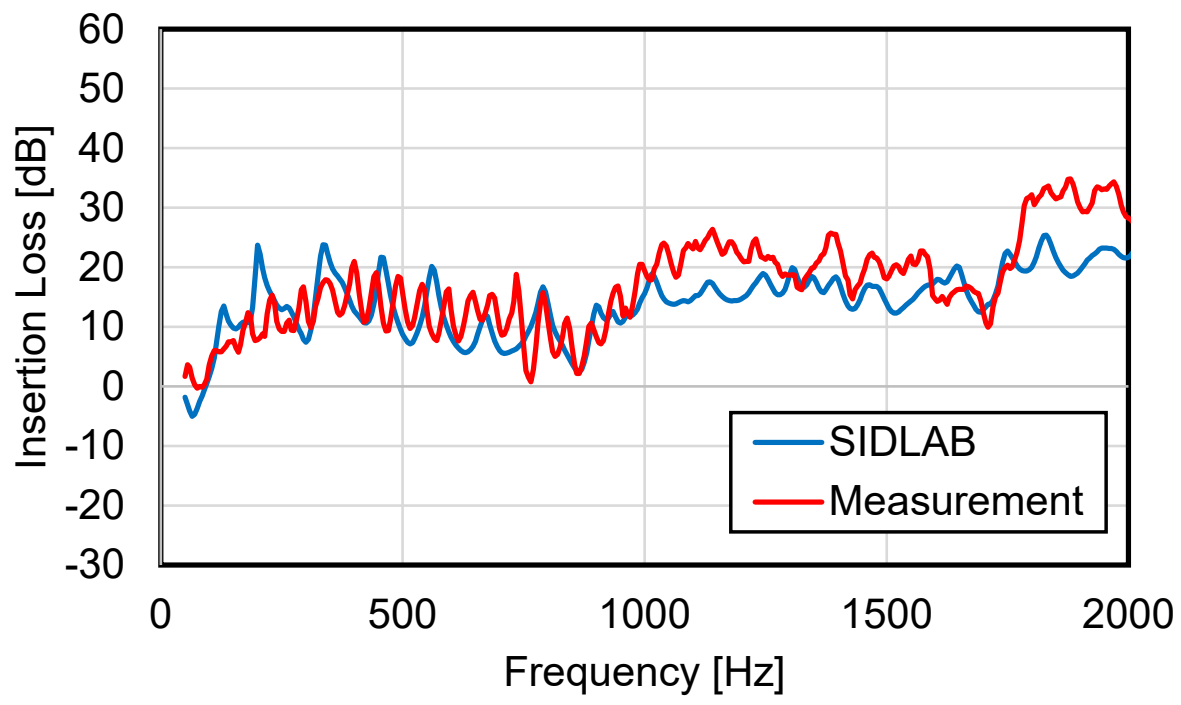

Figure $4.29\{3.3 \%\}$ Expansion chamber insertion loss with 0.2 Ma mean flow

The third case considered is an expansion chamber with a microperforated tube traversing the length from inlet to outlet as shown in Figure 4.23. The panel porosity is $2 \%$ and the perforation diameter is $1 \mathrm{~mm}$. The muffler was first tested under no flow conditions followed by testing with mean flows of $0.1 \mathrm{Ma}, 0.15 \mathrm{Ma}$, and 0.2 Ma. Insertion loss comparisons are shown in Figures 4.30 to 4.33. The agreement is considered acceptable and follows general trends seen with grazing 
flow over microperforated panels. It is well known that grazing flow compromises microperforated panel performance [52].

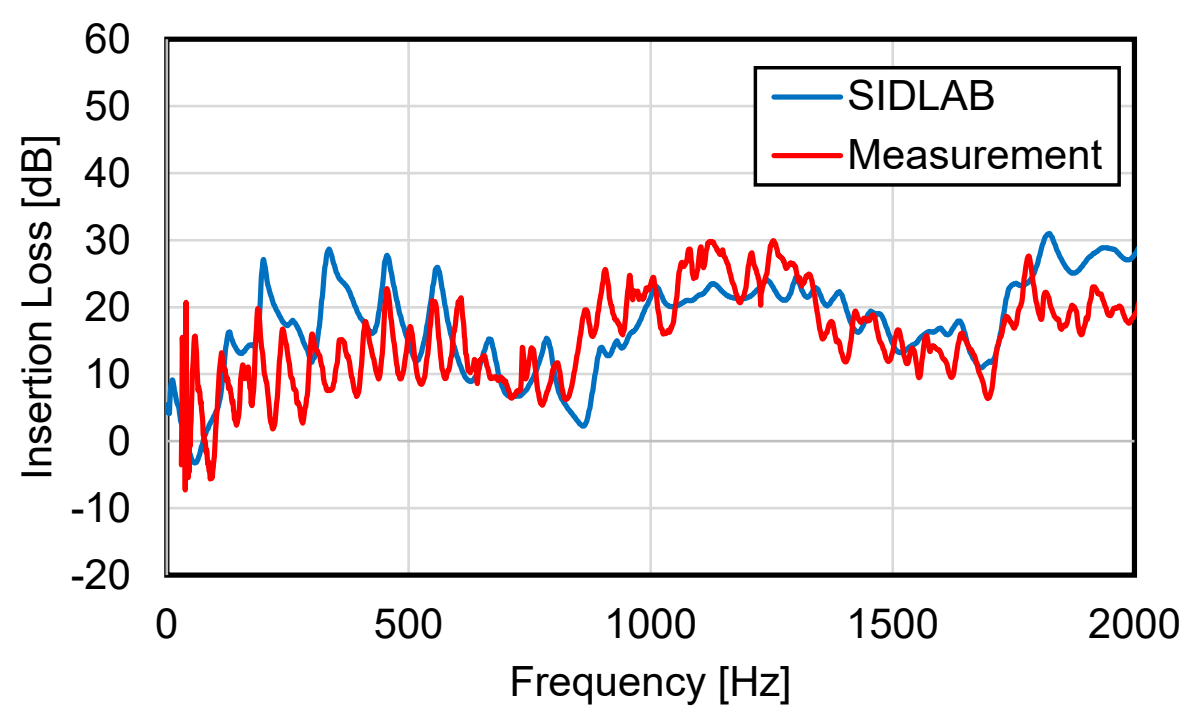

Figure $4.30\{2 \%\}$ Expansion chamber insertion loss

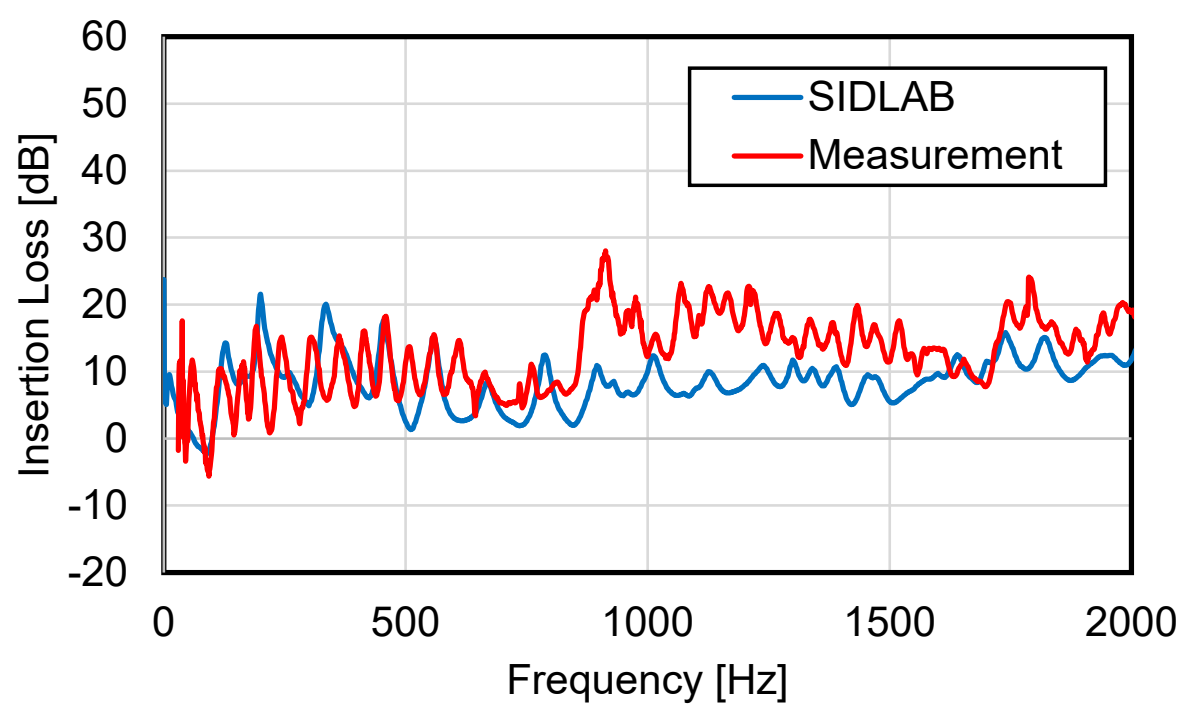

Figure $4.31\{2 \%\}$ Expansion chamber insertion loss with 0.1 Ma mean flow 


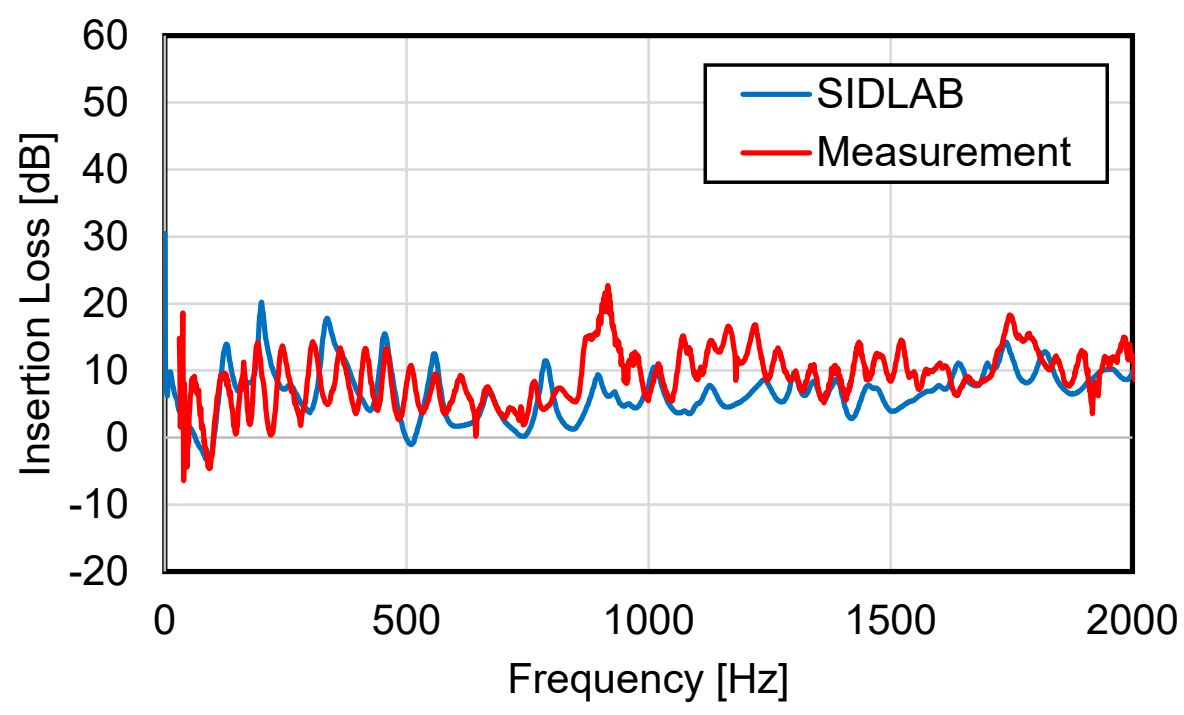

Figure $4.32\{2 \%\}$ Expansion chamber insertion loss with 0.15 Ma mean flow

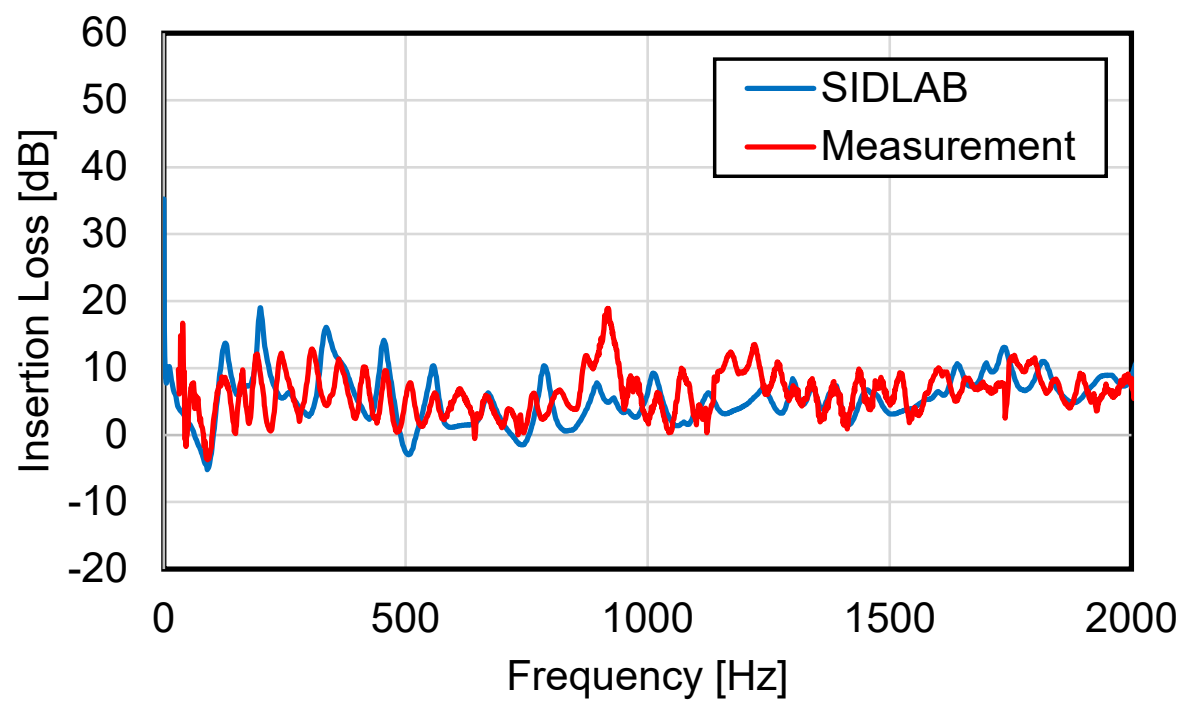

Figure $4.33\{2 \%\}$ Expansion chamber with 0.2 Ma mean flow

The final expansion chamber case is a $45.3 \%$ perforated muffler. This case was chosen since higher flow noise generation is anticipated. Measured and predicted acoustic insertion loss showed good agreement for no flow and fair agreement for $0.1 \mathrm{Ma}$. When flow increases to 0.15 and $0.2 \mathrm{Ma}$, correlation between measurement and simulation is poor. This is anticipated because the simulation does not include flow generated noise. 


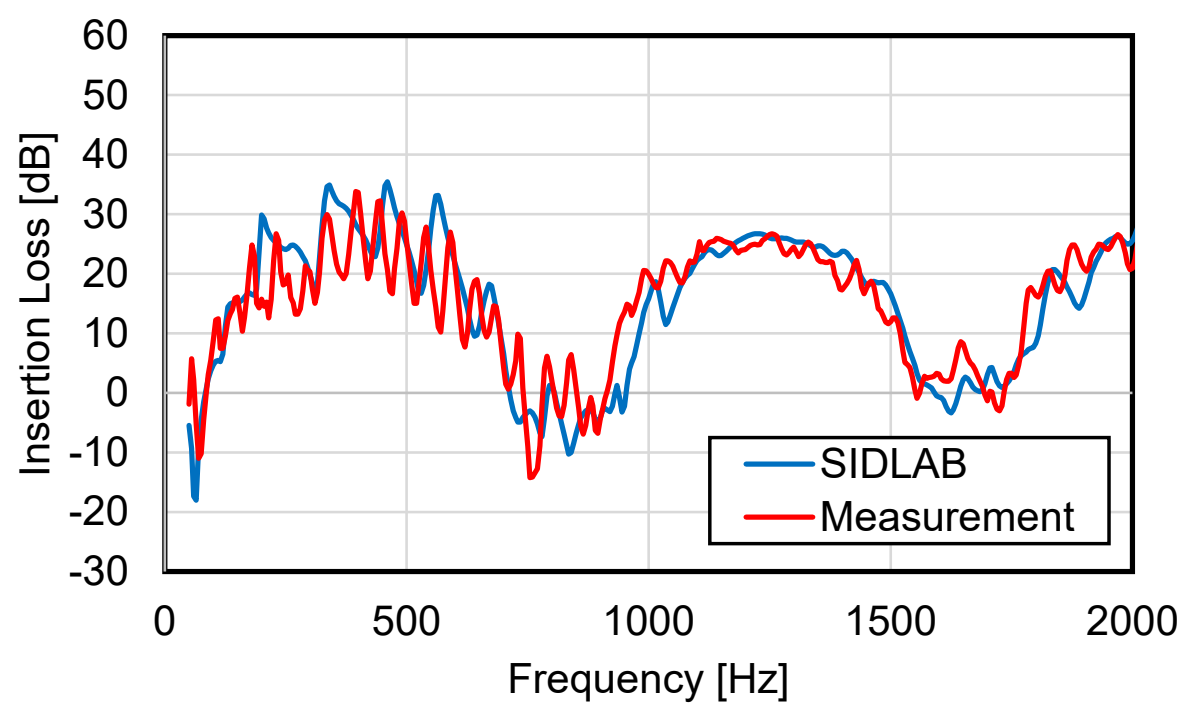

Figure $4.34\{45.3 \%\}$ Expansion chamber insertion loss

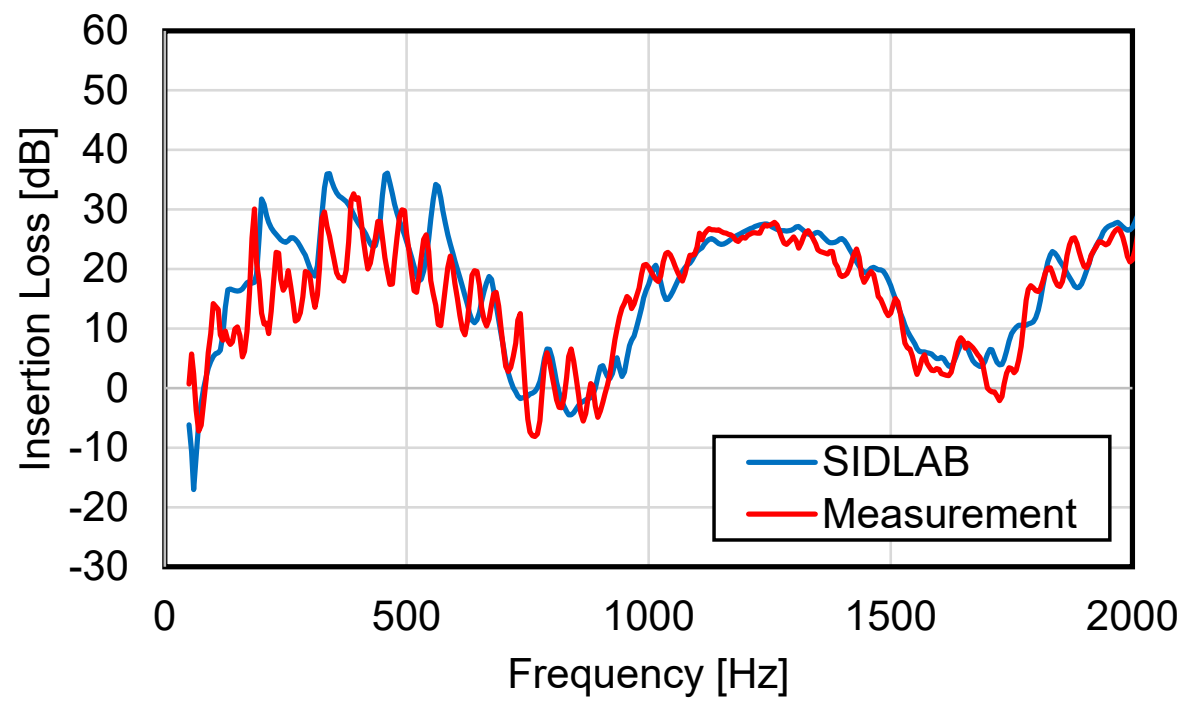

Figure $4.35\{45.3 \%\}$ Expansion chamber insertion loss with 0.1 Ma mean flow 


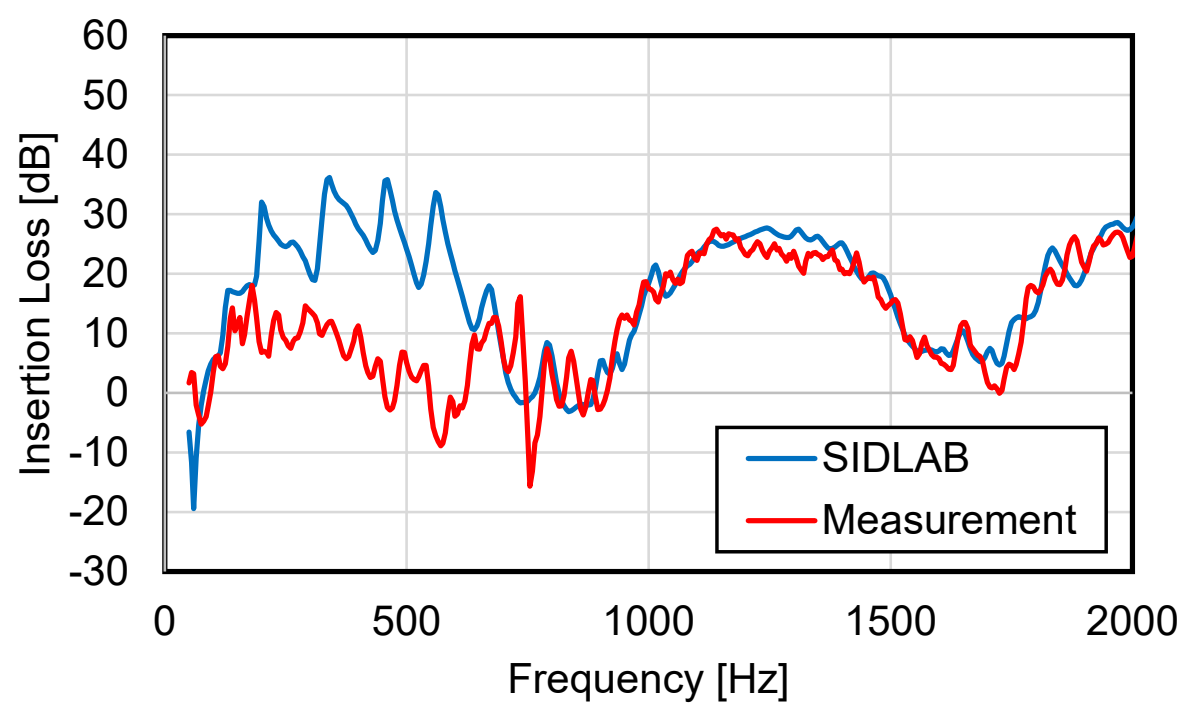

Figure $4.36\{45.3 \%\}$ Expansion chamber insertion loss with 0.15 Ma mean flow

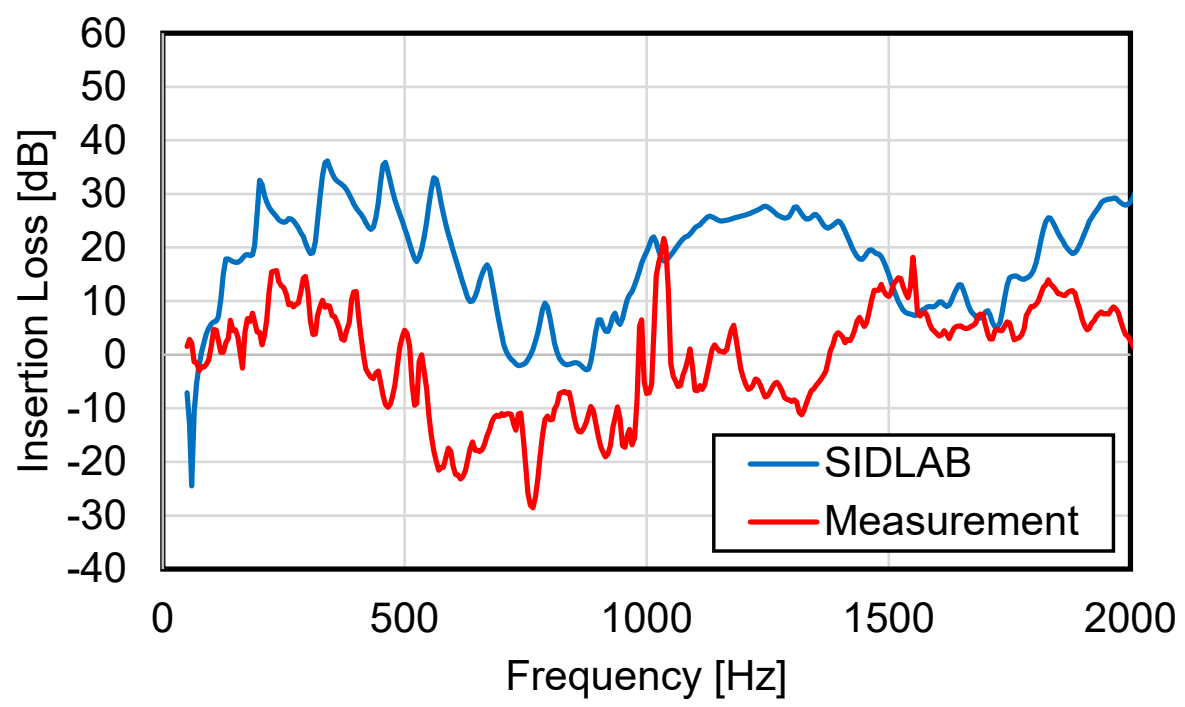

Figure $4.37\{45.3 \%\}$ Expansion chamber insertion loss with 0.2 Ma mean flow

To validate that flow generated noise was indeed the reason for the disagreement, the sound pressure level was measured with no flow and with 0.15 and $0.2 \mathrm{Ma}$ number flow as shown in Figure 4.38. It can be seen that the flow-induced noise exceeds or is close to the level of the source at a number of frequencies below $1000 \mathrm{~Hz}$. 


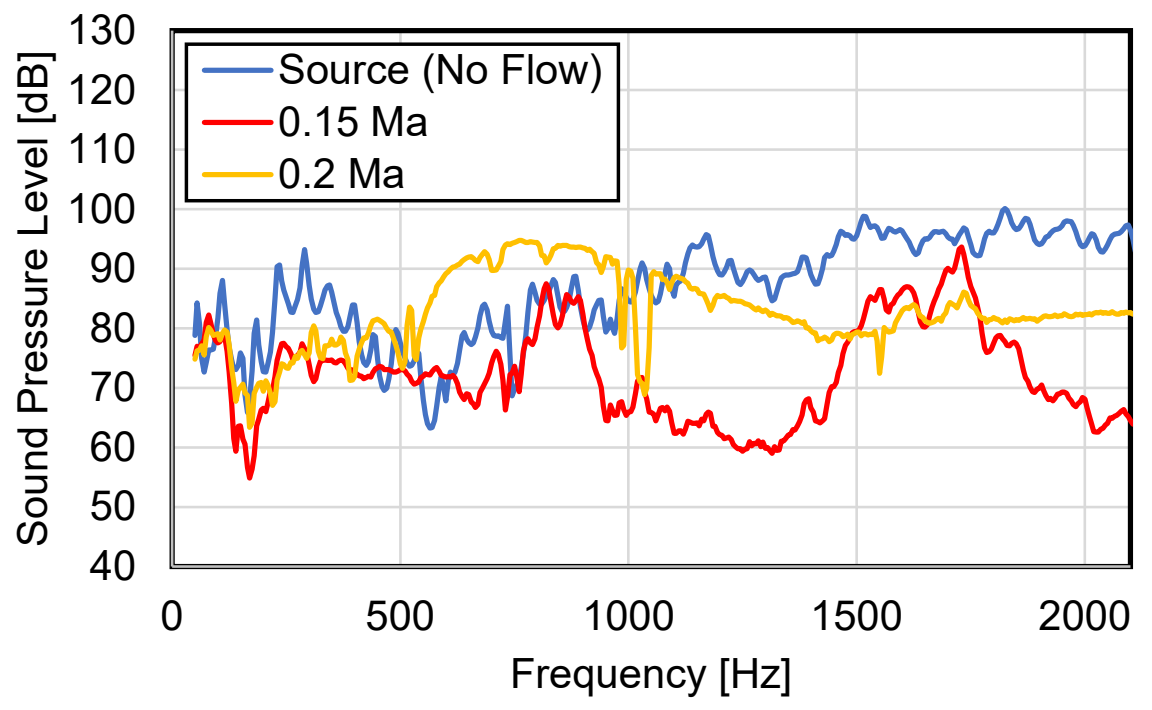

Figure 4.38 Test rig with no flow and tailpipe radiated sound with 0.15 and 0.2 Ma mean flow

\subsection{Summary}

After completing the four stages of qualification, the test rig has been validated. Pressure drop measurements were qualified against 1D Bernoulli's equation and SIDLAB. Acoustic validation between transmission loss, noise reduction, and insertion loss showed a satisfactory agreement between theoretical prediction and measurement. Correlation between predicted and measured values only failed when an element produced significant aeroacoustics noise. Better correlation is anticipated in these cases if the source level is substantially increased. Insertion loss correlation may be improved if the source impedance measurement is improved. 


\section{CHAPTER 5 CONCLUSIONS}

Muffler and silencer performance has been defined by three common metrics, insertion and transmission loss, and noise reduction. Measurement methods for each metric are detailed in chapter two of this thesis work. Each method requires different methodologies and instrumentation. Furthermore, the application of each metric has its place. An argument can be made that insertion loss is a closer representation to field performance. Transmission loss serves as an excellent tool for engineers in choosing muffler designs to implement.

A specialized test rig is necessary to introduce flow safely into the system. Detailing the design of the apparatus is the subject of chapter three. The flow source is an electric blower that provides an upwards range of 0.17 Ma with a 1.87" $(4.75 \mathrm{~cm})$ diameter. Flow velocities may be lower or higher if a different inlet and outlet diameter is used. Linear acoustic theory can be used for flow rates under $0.3 \mathrm{Ma}$ because the flow is still considered incompressible. Flow noise was suppressed by an outlet silencer incorporating microperforated panel and fiberglass. Downstream acoustic sources are separated into low and high frequency sources. The low frequency source is powered by a subwoofer and an inverted horn to reduce impedance changes from the speaker and the inlet to the flow path. The high frequency source is a compression driver flush mounted to the piping just downstream of the low frequency source. There are several methods for measuring insertion loss either inline or in free-field where the difference before and after the muffler is attached. Inline measurements are performed by measuring sound power, or pressure with flush mounted microphones. Sound power can be measured from the radiated sound waves from the pipe outlet by a microphone hemisphere or intensity scan.

Qualification of the rig is performed in chapter four, first for static pressure drop and then for each of the three acoustic muffler metrics. The qualification performed in a systematic manner. First, the test fixture was validated for pressure drop where theoretical and measured results correlated well. The second qualification 
correlated predicted and measured transmission loss for a pipe opening and open expansion chamber without flow. Acceptance between the predicted and measured results was reasonable.

The third qualification consisted of measuring a load or termination dependent metric, noise reduction. An expansion chamber is measured with a microphone upstream and downstream for the difference in sound pressure level without flow. The load impedance is measured using the two-microphone method and used to predict noise reduction. Correlation between predictions and measurement was acceptable.

The final qualification compared predicted and measured insertion loss. Insertion loss was predicted using the plane wave simulation. The source impedance was measured in input into the model along with the theoretical termination impedance. Validation cases included a straight duct and expansion chamber. Several variations of the expansion chamber were also predicted and measured by inserting perforated pipes between the entrance and outlet of the chamber having different porosities. Results compared well between simulation and experiment.

Thus, the test rig has passed several preliminary qualification tests. Some important limitations should be noted. First, flow pulsations seen in engines are not present. Second, the rig operates close to room temperature with slightly elevated temperatures occurring with the increased load on the blower. Finally, the source impedance of the rig will differ from other sources. Even with limitations, the rig is important for noise control engineers in assessing flow-induced noise. Measured results may be compared with simulation since the source impedance is known.

\subsection{Future Work and Direction}

The test rig can be enhanced in a number of ways. First, the speaker amplitude can be increased to allow for improved signal to noise ratio if microphones are placed inside the pipe. Flow noise can be filtered out of the measurement by recording pressure fluctuations versus time and then using the pressure fluctuation 
data as a filter to remove flow noise from the spectrum [53]. Secondly, additional loudspeakers can be added, and nonlinear effects can be considered.

The rig should also be modified to permit transmission loss measurements with flow. If the 3-point method is used, an anechoic termination should be developed. An acoustic horn with sound absorbing surfaces could be used at the termination. Alternatively, the two-load method can be implemented with flow. Initial work has already demonstrated the approach without flow and flow can likely be included without too much additional work.

Measurement of grazing flow impedance might also be of interest. Side branch elements can be fitted with perforates or other sound absorption and the impedance of the samples can be measured with flow. This may be of special interest with 3D printed materials which are currently in development.

This is by no means an exhaustive list. It is anticipated that the test rig will be improved by future students and that the rig will be utilized for practical studies. Also, the rig should be a valuable resource for industry moving forward. 


\section{REFERENCES}

1. S. Allam and H. Bodén, "Methods for Accurate Determination of Acoustic Two-Port Data in Flow Ducts," Twelfth International Congress on Sound and Vibration Conference Proceedings, (2005).

2. T. Elnady, "A Platform to Measure Transmission Loss of Mufflers with Flow," INTER-NOISE Conference Proceedings, (2007).

3. R. Singh and T. Katra, "Development of an Impulse Technique for Measurement of Muffler Characteristics," Journal of Sound and Vibration 56(2), 279-298, (1978).

4. H. Kim, "Transmission loss of silencers with flow from a flow-impedance tube using burst signals," The Ohio State University, ProQuest Dissertations Publishing, (2011).

5. D. A. Bies, C. H. Hansen, C. Q. Howard, "Engineering Noise Control," CRC Press, Taylor and Francis Group, (2018).

6. D. W. Herrin, Y. Zhang, P. Wang, T.W. Wu and T. Elnady, "Notes on the Muffler Design Process," INTER-NOISE and NOISE-CON Congress and Conference Proceedings, (2014).

7. ASHRAE, 2017 ASHRAE Handbook-Fundamentals, Chapter 8, Atlanta: ASHRAE. (2017).

8. I. Vér and Beranek, "Noise and Vibration Control Engineering," John Wiley and Sons, Inc., (2006).

9. ASTM E1050, "Standard Test Method for Impedance and Absorption of Acoustical Materials Using a Tube, Two Microphones and a Digital Frequency Analysis System," American Society for Testing and Materials, (2008).

10. H. Boden and M. Åbom, "Modelling of Fluid Machines as Sources of Sound in Duct and Pipe Systems", Acta Acoustica 3(1995) 549-560.

11. J. Liu, and D.W. Herrin, "A Simplified Two-Load Method for Measuring Source Impedance," INTER-NOISE and NOISE-CON Congress and Conference Proceedings, (2008).

12. Y. Zhang, "Studies to Improve Exhaust System Acoustic Performance by Determination and Assessment of the Source Characteristics and Impedance Optimization," (2016). Theses and Dissertations--Mechanical Engineering.

13. M. L. Munjal, "Acoustics of Ducts and Mufflers," Wiley, (2014).

14. M. G. Prasad and M. J. Crocker, "Acoustical Source Characterization Studies on a Multi-cylinder Engine Exhaust System," Journal of Sound and Vibration, 90(4), 479-490, (1983). 
15. M.G. Prasad, "A Four Load Method for Evaluation of Acoustical Source Impedance in a Duct," Journal of Sound and Vibration, 114 (2), 347-356. (1987).

16. H. P. Wallin, U. Carlsson, M. Åbom, H. Boden and R. Glav, "Sound and Vibration," KTH, Stockholm, (1999).

17. ASTM E2611, "Standard Test Method for Measurement of Normal Incidence Sound Transmission of Acoustical Materials Based on the Transfer Matrix Method," American Society for Testing and Materials, (2009).

18. Z. Tao and A. Seybert, "A Review of Current Techniques for Measuring Muffler Transmission Loss," SAE Technical Paper 2003-01-1653, (2003).

19. M. L. Munjal and A.G. Doige, "Theory of a two source-location method for direct experimental evaluation of the four-pole parameters of an aeroacoustic element," Journal of Sound and Vibration 141, 323-333 (1990).

20. G. C. Wan, "Prediction and Measurement of the Acoustic Performance of Mufflers," INTER-NOISE Conference Proceedings, (1995).

21. S. Bilawchuk and K.R. Fyfe, "Measuring Acoustic Transmission Loss using the 3-Point Method," From Acoustics Week in Canada, (2002).

22. M. Åbom, "Measurement of the scattering-matrix of acoustical two-ports," Mechanical Systems and Signal Processing, 5(2), 89-104. (1991).

23. U. Ingard, "Notes on Acoustics," Infinity Science Press, (2008).

24. R. J. Alfredson and P. O. A. L. Davies, "The radiation of sound from an engine exhaust," Journal of Sound and Vibration. 13(4), 389-408 (1971).

25. W. DeRoeck and W. Desmet, "Experimental acoustic identification of flow noise sources in expansion chambers," Proceedings of ISMA, 455-470, (2008).

26. I. Kim, "Acoustic Characteristics of Perforated Dissipative and Hybrid Silencers," The Ohio State University, ProQuest Dissertations Publishing, (2005).

27. H. Howell, Personal Correspondance, (2016-2019).

28. J. Chen, D. W. Herrin, "Development of a muffler insertion loss flow rig," SAE International Noise and Vibration Conference \& Exhibition, Grand Rapids, MI, June 10-13, 2019.

29. B. Kaplan, "The Design, Fabrication, and Evaluation of a Low-Speed, LowTurbulence, Anechoic Wind Tunnel," Embry-Riddle Aeronautical University, Theses and Dissertations-Aerospace Engineering, (1996). 
30. R. Loehrke,. And H. Nagib, "Control of Free-Stream Turbulence by Means of Honeycombs: A Balance Between Suppression and Generation," Journal of Fluids Engineering, 342-353, (1978).

31. Y. A. Çengel, and J. M. Cimbala. "Fluid Mechanics: Fundamentals and Applications," McGraw-Hill Higher Education, (2006).

32. M. Karlsson and M. Åbom, "Aeroacoustics of T-junctions-An experimental investigation," Journal of Sound and Vibration 329 1793-1808, (2010).

33. ISO 9614-2, "Acoustics - Determination of sound power levels of noise sources using sound intensity - Part 2: Measurement by scanning," International Organization for Standardization, (1996).

34. J. Li, "Analytical Simulation of Circular Lined Ducts with a Perforated Cover," Vibro-Acoustic Consortium

35. W. Liu, "Ultra-Thin Microperforated Panel Absorbers with Application to Mufflers," Vibro-Acoustic Consortium

36. A. Cummings, "Acoustic Noise Transmission Through the Walls of Air Conditioning Ducts (TRP-318)," ASHRAE Report (TRP-318), (1983).

37. K. Ruan and D.W. Herrin, "Using Simulation to Determine Elbow and Side Branch Attenuation and Duct Breakout Transmission Loss (RP-1529)," ASHRAE Transactions, 122(1), 12-21, (2016b).

38. L. L. Beranek, "Noise Reduction,” McGraw-Hill, (1960).

39. X. Hua, and D. W. Herrin, "Practical Considerations when using the Two-Load Method to Determine the Transmission Loss of Mufflers and Silencers," SAE Int. J. Passeng. Cars - Mech. Syst. 6(2), (2013).

40. SIDLAB 4.2.1, Acoustics User Manual and Online Help, (2018).

41. Siemens, LMS Virtual.Lab Online Help (2018).

42. ISO 3744, "Acoustics - Determination of sound power levelsand sound energy levels of noise sources using sound pressure -Engineering methods for an essentially free field over a reflecting plane," International Organization for Standardization, (2010).

43. L. L. Beranek, "Acoustics," American Inst. of Physics, (1996).

44. A. Holmberg, M. Åbom, and H. Bodén, "Accurate experimental two-port analysis of flow generated sound," Journal of Sound and Vibration 330 63366354, (2011).

45. V. Mason, "Some experiments on the propagation of sound along a cylindrical duct containing flowing air," Jornal of Sound and Vibration 10(2), 208-226, (1969). 
46. ISO 5136, "Acoustics - Determination of sound power radiated into a duct by fans and other air-moving devices - In-duct method," International Organization for Standardization, (2003).

47. J. Chen, D. W. Herrin, "Description and validation of a muffler insertion loss flow rig," Inter-Noise 2019 Conference, Madrid, Spain, June 16-19, 2019.

48. L. E. Kinsler, A. R. Frey, A. B. Coppens, J. V. Sanders, "Fundamentals of Acoustics," Wiley, (2000).

49. H. Levine and J. Schwinger, "On the radiation of sound from an unflanged circular pipe," Physics Review Journal, 73(4), 383-406, (1948).

50. G . F. Carrier, "Sound Transmission from a Tube with Flow," Quarterly of Applied Mathematics 13(4) 457-461, (1956).

51. V. B. Panicker, and M. L. Munjal, "Radiation Impedance of an Unflanged Pipe with Mean Flow," Noise Control Engineering 18(2), (1982).

52. S. Allam and M. Åbom, "A New Type of Muffler Based on Microperforated Tubes," ASME. J. Vib. Acoust. 133(3):031005-031005-8, (2011).

53. S. Allam, "Acoustic Modelling and Testing of Advanced Exhaust System Components for Automotive Engines," (2004). 
VITA

JONATHAN CHEN

\section{PLACE OF BIRTH}

Louisville, KY, USA

\section{EDUCATION}

University of Kentucky

Lexington, $\mathrm{KY}$

Bachelor of Science in Mechanical Engineering

May 2016

\section{PROFESSIONAL POSITIONS HELD}

University of Kentucky College of Engineering, Lexington, KY

Graduate Research Assistant

Graduate Teaching Assistant

Jan 2018 - June 2019

Aug 2016 - Dec 2017

Thermo King Corporation (Ingersoll Rand), Minneapolis, MN/Remote

Noise and Vibration Engineering Intern May - Nov 2018

Blachford Acoustics Group, West Chicago, IL

Acoustic Engineering Intern

May - Aug 2017

Institute of Research for Technology Development (IR4TD), Lexington, KY

Undergraduate Researcher (Unpaid) Jan - Dec 2015

LINAK U.S. Inc., Louisville, KY

Research and Development Engineering Intern May - Aug 2015

Hitachi Automotive Systems Americas, Harrodsburg, KY (Contracted by Nesco)

Quality Assurance Engineering Intern June - Aug 2014

\section{CONFERENCE PROCEEDINGS}

J. Chen, D. W. Herrin, "Description and validation of a muffler insertion loss flow rig," Inter-Noise 2019 Conference, Madrid, Spain, June 16-19, 2019.

J. Chen, D. W. Herrin, "Development of a muffler insertion loss flow rig," SAE International Noise and Vibration Conference and Exhibition, Grand Rapids, MI, June 10-13, 2019.

J. Chen, D. W. Herrin, C. Moritz, and J. Shaw, "Characterization of low frequency reverberation room behavior using simulation," Inter-Noise 2018 Conference, Chicago, IL, August 26-29, 2018. 